\title{
Effect of Au Content on Microstructural Evolution of SnAgCu Solder Joints that Undergo Isothermal Aging and Reliability Testing
}

\author{
A Thesis \\ presented to \\ the Faculty of California Polytechnic State University, \\ San Luis Obispo \\ In Partial Fulfillment \\ of the Requirements for the Degree \\ Master of Science in Engineering, With a Specialization in Materials Engineering \\ By \\ Patrick Hyland \\ June, 2011
}


(C)2011

Patrick J. Hyland

ALL RIGHTS RESERVED 


\section{COMMITTEE MEMBERSHIP}

TITLE:

AUTHOR:

DATE SUBMITTED:

COMMITTEE CHAIR:

COMMITTEE MEMBER:

COMMITTEE MEMBER:
Effect of Au Content on Microstructural Evolution of $\mathrm{SnAgCu}$ Solder Joints that Undergo Isothermal Aging and Reliability Testing

Patrick J. Hyland

August 2011

Dr. Linda Vanasupa, Associate Professor,

Cal Poly Materials Engineering Department

Dr. Jianbiao Pan, Associate Professor, Cal Poly Industrial and Manufacturing Engineering Department

Dr. Richard Savage, Associate Professor, Cal Poly Materials Engineering Department 


\begin{abstract}
Effect of Au Content on Microstructural Evolution of SnAgCu Solder Joints that Undergo Isothermal Aging and Reliability Testing

Patrick J. Hyland
\end{abstract}

Electronics, especially, printed circuit boards (PCBs) are a widespread technology. Metal coatings or "surface finishes" are often added to PCB board pads and component leads during manufacturing to improve their performance. Electroplated nickel/gold over copper is a popular surface finish for printed circuit boards and component leads. The presence of gold in solder joints, however, is known to have detrimental effects referred to as gold embrittlement. It is generally understood that tin-lead solder joints with less than 3 weight percent (wt\%) of gold will not experience reliability issues. The acceptable level of gold in lead-free solder joints, however, is less well understood, as the technology is younger. The purpose of this study was to investigate the effect of gold content on the microstructural evolution of SnAgCu solder joints. Three integrated circuit packages with various thicknesses of gold coatings were assembled on boards that were made with thin (flash) or thick gold over nickel coatings. The boards were divided into three groups based on the isothermal aging they underwent: 0 days, 30 days, or 56 days of aging at $125{ }^{\circ} \mathrm{C}$. Thirty four of the forty boards then underwent mechanical reliability testing. Components were cross-sectioned and polished. Scanning electron microscopy (SEM) and energy dispersive spectroscopy (EDS/EDX) were used to characterize the morphology and elemental composition of the solder joints and any intermetallic compounds (IMCs) that formed. The growth of bulk and interfacial layer IMCs in each package/board system was studied. In thick gold boards, $\mathrm{AuSn}_{4}$ particles observed in the bulk solder grew larger over time, absorbed $\mathrm{Ni}$, and migrated to the component and board interfaces. $\left(\mathrm{Cu}_{1-\mathrm{p}-\mathrm{q}} \mathrm{Au}_{\mathrm{p}} \mathrm{Ni}_{q}\right)_{6} \mathrm{Sn}_{5}$ and $\left(\mathrm{Au}_{1-\mathrm{x}} \mathrm{Ni}_{\mathrm{x}}\right) \mathrm{Sn}_{4} \mathrm{IMCs}$ were found at most board and component interfaces after aging. It was observed that most fractures occurred in or along the $\left(\mathrm{Au}_{1-x} \mathrm{Ni}_{x}\right) \mathrm{Sn}_{4}$ IMCs. Cracks were observed within IMC particles in the bulk solder, along the boardside and component side interfaces, and in the bulk solder traveling toward voids. Components with joint Au contents higher than $10 \mathrm{wt} \%$ had unacceptably poor reliability. The conclusion of this work is that gold content of SAC305 solder joints on boards 
with Au over Ni surface finishes should be kept below 3 wt\% to conservatively minimize the risk of creating a microstructure that has poor reliability.

Keywords: $\quad$ solder, intermetallic, isothermal aging, SAC, SnAgCu, SAC305, $\mathrm{AuSn}_{4}, \mathrm{SEM}$, EDS 


\section{ACKNOWLEDGEMENTS}

There have been many people who have made my time and studies at Cal Poly rich experiences that have made me wiser. I will name a few of them here as I cannot remember them all or fit them onto a page.

My thesis advisor and stern project manager, Dr. Pan, gave me so much guidance and direction. He pushed me through difficult tasks so that I could grow as an engineer.

My other thesis advisor, Dr. Savage, has awed and inspired me so much through his teaching about the worlds of microtechnology, MEMS, and corporate engineering, I hope someday I can have half as much perspective as he does that I might achieve such great poise.

I cannot thank my other other thesis advisor, Dr. Vanasupa, enough for the time and energy she has spent in putting up with me as her thesis student. In my periods of greatest stress, your words were enormously calming. My thesis experience has been a curious one, but excellent nonetheless.

Mike Powers and Julie Silk of Agilent Technologies for their vision, support, facilities, and mentoring.

My thanks to Sundar Sethuraman, Quyen Chu, Noel Hancock, and Michael Santos of Jabil for performing the assembly of our boards and their generous instruction in PCB metallographic technique.

I am thankful to the Surface Mount Technology Association - Silicon Valley Chapter for supporting my studies and providing me with an opportunity to develop my professional presentation skills.

Michael Santos, David Gibbs, and Christine Ghent for their help and expertise in metallographic sample preparation. Big thanks to Ladd Caine for helping me repair that grimy, corroded belt grinder that was so critical to this project.

John Alexander and Tank showed me what experience really means and how that can shape a person.

Thank you to all the MATE students, professors, and dear friends who have been with me through my years at Cal Poly and this project. I hope we will meet again.

Thanks everyone. 


\section{Table of Contents}

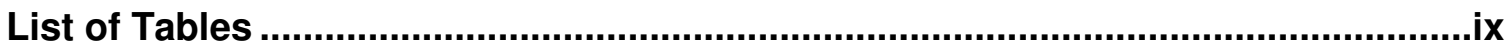

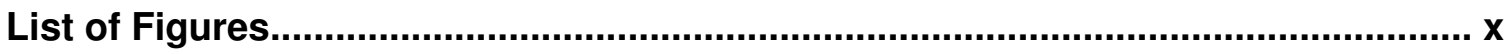

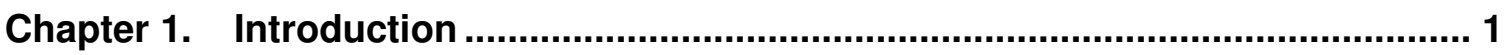

Chapter 2. Literature Review .......................................................................... 3

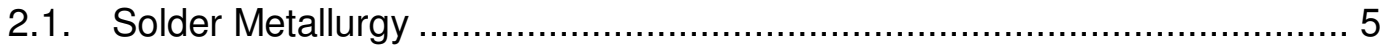

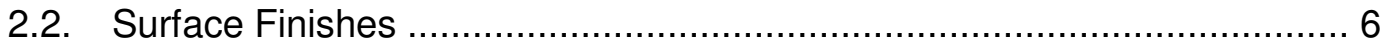

2.3. Intermetallic compounds.............................................................. 7

2.4. Isothermal Aging Samples................................................................. 8

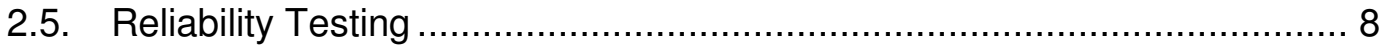

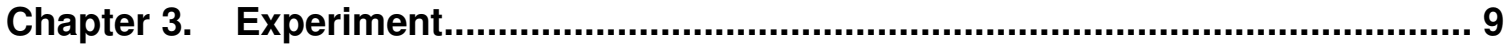

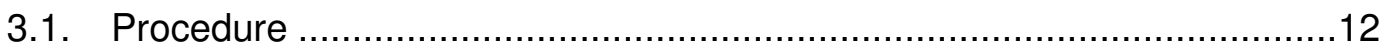

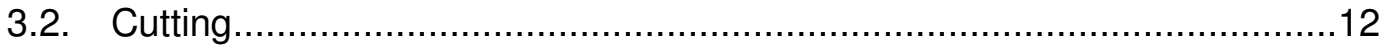

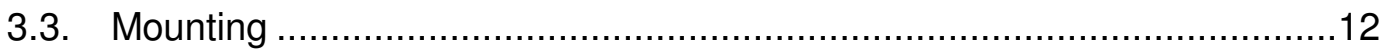

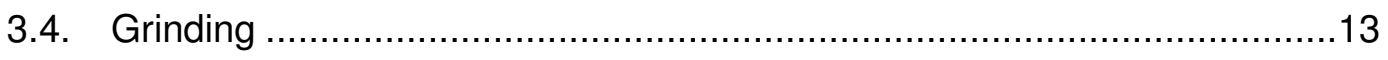

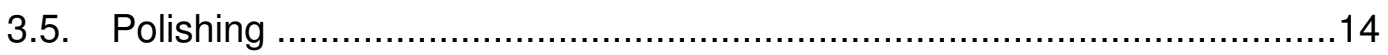

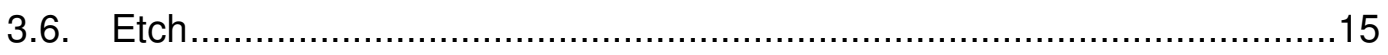

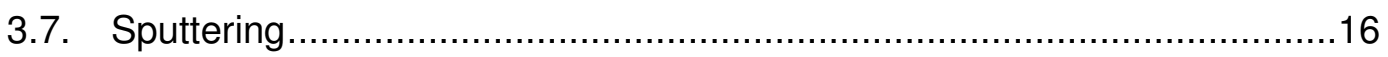

3.8. Effect of Au film on X-ray absorption ................................................16

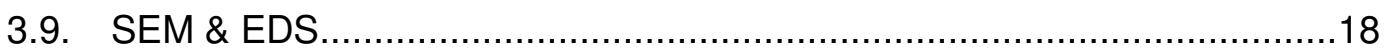

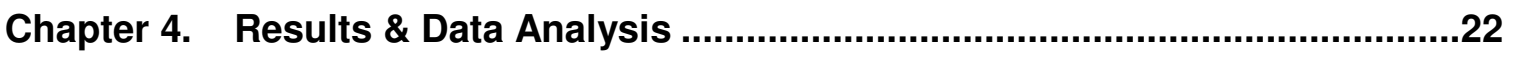

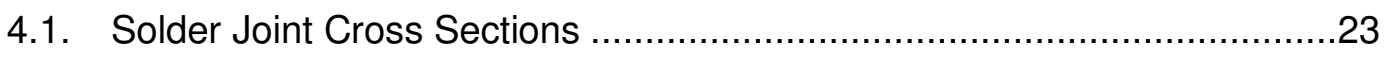

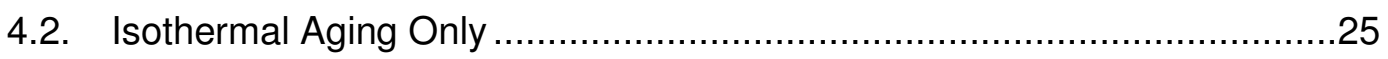

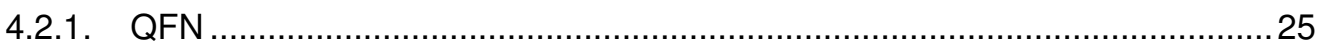

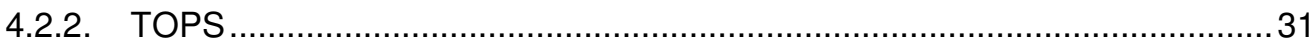

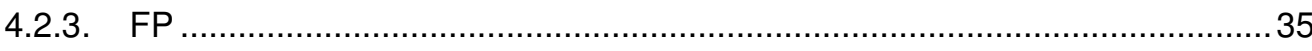

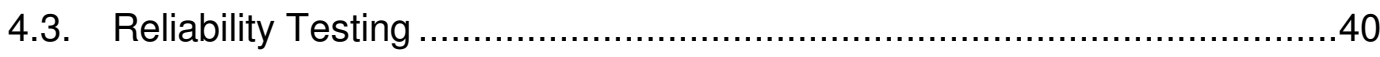

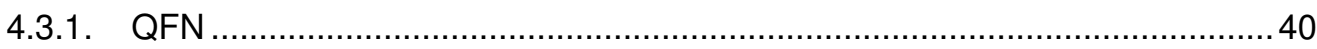

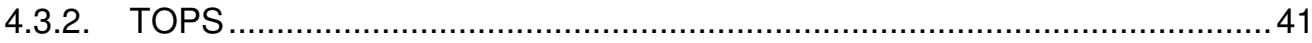

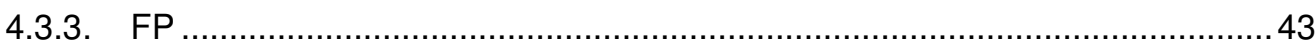

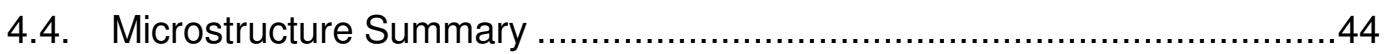

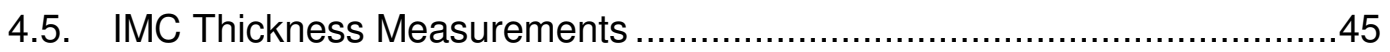

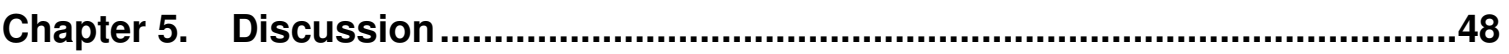

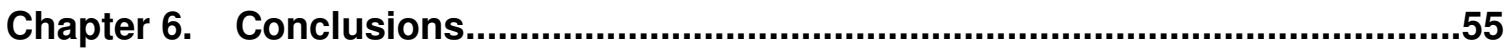

Chapter 7. Future Work ................................................................................... 


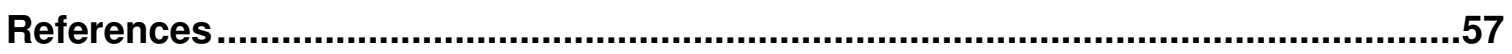




\section{List of Tables}

Table I - Abrasive grit designations and average particle sizes of SiC pads used to prepare samples (Federation of European Producers of Abrasives n.d., Allied High Tech 2011)

Table II - Vickers Hardness values from CES level 3 and abrasive particle sizes used (CES n.d.).............................................................. 15

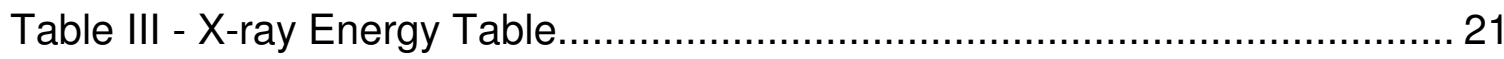

Table IV - Summary of IMC microstructure and reliability data.......................... 44

Table V - Metals and IMCs found in this experiment with crystal structure information (Bangert n.d., Zou, et al. 2009, Ho, Shiau and Kao 2002, Baker 2002) 


\section{List of Figures}

Figure 1 - Cu-Sn binary phase diagram with highlighted intermetallic compounds (National Institute of Standards and Technology n.d.) .. 7

Figure 2 - Underside leads and ground pad of TOPS package $(10 \times 10 \mathrm{~mm}$ outline) ............................................................................ 10

Figure 3 - Underside leads and ground pad of QFN5 package (5 $55 \mathrm{~mm}$

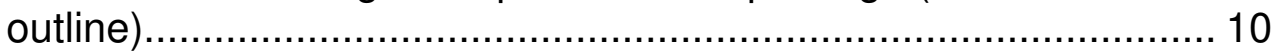

Figure 4 - Underside leads and ground pad of QFN6 package (6 $66 \mathrm{~mm}$

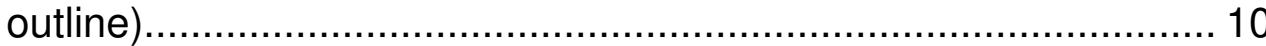

Figure 5 - Underside leads and ground pad of FPI package $(6.4 \times 6.4 \mathrm{~mm}$ outline)

Figure 6 - Underside leads and ground pad of FPII package $(10.2 \times 9.7 \mathrm{~mm}$ outline) 10

Figure 7 - Cured epoxy puck containing a sectioned QFN component. 13

Figure 8 - Schematic of grinding of components mounted in cured epoxy resin. The dashed red lines indicate planes remove material up to with the initial rough grind once the joints on both sides and the leads are exposed.

Figure 9 - Examples of region selection using the EDS software 19

Figure 10 - Electron penetration depth as a function of primary electron accelerating voltage

Figure 11 -The combination of interaction volume and IMC arrangements may have caused the variations in elemental measurements.

Figure 12 - Schematic representation of solder joint before reflow and after aging.

Figure 13 - Examples of IMC morphologies in image of a 30 day aged TOPS joint on a flash Au board........................................................... 24

Figure 14 - QFN5 (left) and QFN 6 (right) package undersides........................ 25

Figure $15-0$ days aged QFN5 on a flash Au board (0.9 wt\% Au) .................. 26

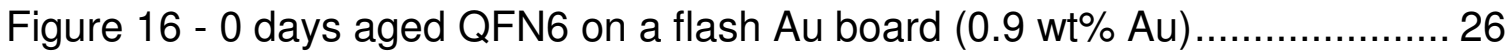

Figure $17-\mathrm{AuSn}_{4}, \mathrm{Ag}-\mathrm{Sn}$, and $\left(\mathrm{C}_{\mathrm{u1}-\mathrm{p}-q} \mathrm{Au}_{\mathrm{p}} \mathrm{Ni}_{\mathrm{q}) 6} \mathrm{Sn}_{5}\right.$ IMCs in the joint of a 0 days aged QFN on thick Au board $(6.3 \mathrm{wt} \% \mathrm{Au})$........................... 27

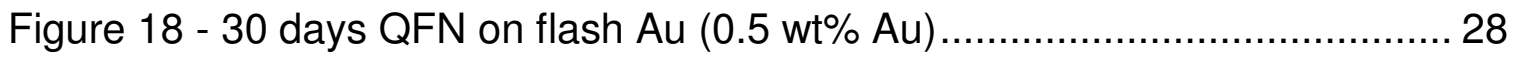

Figure 19 - 30 day aged QFN on Thick Au board (5.6 wt\% Au) ...................... 29

Figure 20 - 56 day aged QFN on Flash Au board (0.6 wt\% Au) ...................... 30 
Figure 21 - 56 day aged QFN joint on Thick Au board (5.6 wt\% Au) ................ 30

Figure $22-0$ days aged TOPS on a flash Au board (3.0 wt \% Au) .................. 31

Figure 23 - TOPS on Thick Au board with lots of voids $(8.0 \mathrm{wt} \% \mathrm{Au}) \ldots \ldots \ldots \ldots . . . . . . .32$

Figure 24 - This joint of a 30 day aged TOPS package on a flash Au board has $\left(\mathrm{Au}_{1-x} \mathrm{Ni}_{\mathrm{x}}\right) \mathrm{Sn}_{4}$ in the bulk and as interfacial layers on top of $(\mathrm{Ni}, \mathrm{Cu}) \mathrm{Sn}$ interfacial layers that sit on the Ni layers on both sides of the joint $(2.4 \mathrm{wt} \% \mathrm{Au})$

Figure $25-\left(\mathrm{Au}_{1-x} \mathrm{Ni}_{\mathrm{x}}\right) \mathrm{Sn}_{4}$ can be seen in the bulk and as interfacial layers in the joints of 30 day aged TOPS packages on thick Au boards (7.1 wt\% Au)

Figure 26 - The $\left(\mathrm{Au}_{1-\mathrm{x}} \mathrm{Ni}_{\mathrm{x}}\right) \mathrm{Sn}_{4} \mathrm{IMC}$ sits mostly along the interfacesin this joint from a TOPS package on a flash Au board aged for 56 days (2.5 $w t \% A u)$

Figure $27-\left(\mathrm{Au}_{1-x} \mathrm{Ni}_{\mathrm{x}}\right) \mathrm{Sn}_{4}$ boulders and pillars can be seen in the bulk and along the interfaces of this joint in a TOPS package on a thick board that was aged for 56 days (6.5 wt\% Au)

Figure 28 - Joint from an FP package on a flash Au board consumed in the as-built condition with Au IMCs (15.9 wt\% Au)

Figure 29 - FPI joint on thick Au board with crack initiated along center (14.4 $w t \% A u)$.....

Figure 30 - FPII with large crack (14.4 wt\% Au)

Figure 31 - Joint of 30 days aged FPI package on a flash Au board; many $\left(\mathrm{Au}_{1-\mathrm{x}} \mathrm{Ni}_{\mathrm{x}}\right) \mathrm{Sn}_{4}$ pillars visible $(13.1 \mathrm{wt} \% \mathrm{Au})$

Figure $32-\left(\mathrm{Au}_{1-\mathrm{x}} \mathrm{Ni}_{\mathrm{x}}\right) \mathrm{Sn}_{4}$ pillars are distinctly visible in this joint, as are the $\mathrm{Ni}$ and Kovar layers on the lead and the Ag3Sn in the bulk of the solder (11.3 wt\% Au)

Figure 33 - A large space passes through this joint on a 30 day aged FP package on a thick $\mathrm{Au}$ board; $\left(\mathrm{Au}_{1-\mathrm{x}} \mathrm{Ni}_{\mathrm{x}}\right) \mathrm{Sn}_{4}$ consumes almost all of the bulk solder (15.8 wt\% Au).....

Figure 34 - Component side half of fractured joint from an FP package on a thick Au board after 56 days of aging; most of solder consumed by $\left(\mathrm{Au}_{1-\mathrm{x}} \mathrm{Ni}_{\mathrm{x}}\right) \mathrm{Sn}_{4}(\sim 15 \mathrm{wt} \% \mathrm{Au})$....

Figure 35 - Board side half of a fractured joint from an FP package on a thick Au board after 56 days of aging; most of the solder is taken up by $\left(\mathrm{Au}_{1-\mathrm{x}} \mathrm{Ni}_{\mathrm{x}}\right) \mathrm{Sn}_{4}(\sim 15 \mathrm{wt} \% \mathrm{Au})$.

Figure 36 - Crack initiated in corner of QFN joint on 30 days aged flash $A u$ board.

Figure 37 - Cracks initiating at high stress points and propagating into joint on 56 day aged QFN on flash Au board 
Figure 38 - Cracks along IMCs in a joint from a 30 days aged TOPS package on a thick Au board

Figure 39 - Crack traveling along the board side interfacial IMC and bulk IMC particles in this 30 day aged TOPS joint

Figure 40 - Cracks travel from IMCs across the bulk to voids in this joint from a 30 day aged TOPS on a thick Au board

Figure 41 - Images of a joint that had a crack propagate along most of the length of the board side interface in a 30 days aged TOPS sample

Figure 42 - IMC thickness measurements from the component/solder interface on QFN components (error bars are $\pm 1 \sigma$ ).

Figure 43 - IMC thickness measurements from the board pad/solder interface on QFN components (error bars are $\pm 1 \sigma$ ).

Figure 44 - IMC thickness measurements from the component/solder and board pad/solder interface on TOPS components (error bars are $\pm 1 \sigma)$

Figure 45 - Graph demonstrates that IMC growth data follows a time $e^{0.5}$

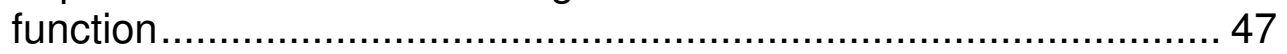

Figure 46 - Au-Sn Binary phase diagram (Selvaduray n.d.) …........................ 48 


\section{Chapter 1. Introduction}

Electronics have infiltrated many aspects of modern life and are an accepted part of our culture. Printed circuit boards are used in electronic devices from personal computers to computer-numeric-control (CNC) machine controls, medical equipment for cardiographs or magnetic resonance imagin (MRI), and microwave ovens for cooking food. Components are connected to the wiring in the circuit board by solder joints. It is estimated that ten trillion solder interconnects are produced per year and the industry associated with producing those amounts to $\$ 1.3$ trillion (Braithwaite 2005). Given such volume, it would be best if many of those connections were reliable, so that they could function for years without needing replacement, and made of non-toxic materials, so that they would not cause harm to organisms they interact with. Heavy metals such as lead are toxic to humans, animals, plants (Occupational Safety \& Health Administration n.d.).

Although electronics can be used to make scientific discoveries and help keep people healthy, their manufacture and disassembly can be hazardous and roughly 40 million tons of electronic waste or e-waste is produced worldwide every year (Schluep, et al. 2009). The European Union created the Restriction of Hazardous Substances (ROHS) directive in February of 2003 and made effective as of July 1, 2006 (Directive 2002/95/EC of the European Parliament and of the Council of 27 January 2003 on the restriction of the use of certain hazardous substances in electrical and electronic equipment 2003). The ROHS directive prohibits the use of heavy metals such as mercury, cadmium, lead, and chromium VI in electronic products. The electronics industry responded by developing lead-free solders, most of which have tin as a majority component. One of the main lead-free solders currently in use is SAC305, a solder standard that the Japan Electronics and Information Technology Industries Association (JEITA) recommended. SAC305 is composed of $96.5 \mathrm{wt} \% \mathrm{Sn}, 3 \mathrm{wt} \% \mathrm{Ag}$ and $0.5 \mathrm{wt} \% \mathrm{Cu}$. SAC305 was chosen for its blend of mechanical properties, melting temperature, reliability, and costs.

Microelectronic packaging and solder joints are used to mechanically and electrically connect integrated circuits or packaged components to printed circuit boards. Microelectronic packages (also "components" or "packages") are devices that house semiconductor chips or 
integrated circuits and provide electrical connection from the chips to printed circuit boards. They protect chips from environmental and mechanical damage in addition to helping dissipate heat. Chips are connected to metal leads, usually by wire bonds (on the order of $25 \mu \mathrm{m}$ ), encased in a plastic, metal, or ceramic housing to protect them from mechanical damage, moisture, and radiation (Railkar and Warren 2006).

This work focuses on printed circuit board level interconnections. This level of interconnection is the interface between packaged microelectronic devices and the pad within the circuit board. These interconnections are formed through the use of solder joints. Solder joints are formed melting and solidifying solder in-between leads on the components and pads on the boards. When solder melts, it can dissolve coatings (usually metals) placed on pads on the boards and on component leads. The mechanical behavior of these connections, as it relates to the various metallic and intermetallic phases and layers that form, was the focus of this work.

Tin-lead solder has been used in electronics for most of the twentieth century. Sn-Pb has been highly researched (Zheng 2003, Ho, Shiau and Kao 2002, Banerji 1993, Vianco 1998) and the effect that the gold content of a $\mathrm{Sn}-\mathrm{Pb}$ joint has on its reliability is well understood. Some researchers quote 5 wt\% as a safe limit (Banerji 1993) while others claim 4 wt\% (Bunis 1999). The study that marked $4 \mathrm{wt} \%$ as safe found that a joint gold content of greater than $4 \%$ translated to an up to $80 \%$ reduction in mechanical properties, a serious concern for reliability. Another researcher noted 3-4 wt\% Au as the critical limit (Vianco 1998). The purpose of this work was to understand the effect that gold content has on the reliability of components with matte Sn or $\mathrm{Au} / \mathrm{Ni}$ coatings on leads used with $\mathrm{SnAgCu}$ solder and boards with $\mathrm{Au} / \mathrm{Ni} / \mathrm{Cu}$ board surface finishes. Reliability problems in this case mean large cracks forming within interconnects that and can lead to components fracturing from boards (mechanical reliability). Changes in resistance were measured and used as indications that cracks had formed. The specific goal was to develop safe limits on gold content, below which minimal reliability problems arising from the presence of intermetallic compounds in the microstructure would arise. 


\section{Chapter 2. Literature Review}

It is necessary for intermetallic compounds to exist to form a metallurgical connection between multiple metal layers. Highly pure layers of copper and tin, for example, cannot immediately transition from the tetragonal crystal structure of tin to the face-centered cubic structure of copper. They need an intermediate layer or two, such as $\mathrm{Cu}_{6} \mathrm{Sn}_{5}$ and $\mathrm{Cu}_{3} \mathrm{Sn}$, in order to make a stable mechanical connection between the pure metals. The reliability of microelectronic packages is reduced by the presence of certain intermetallic compounds or thick intermetallic interfacial layers. Intermetallics tend to be brittle and the solid state diffusion processes that they form through can result in volumetric changes than can produce local residual stresses, (Chiu, et al. 2004). In short, intermetallics are necessary to form solder connections, but can cause problems if they form thick layers or have poor mechanical properties.

It has been demonstrated that the presence of Au IMCs can reduce the reliability of solder joints (Bunis 1999, Zheng 2003). It is also known that the mechanical reliability of joints decreases as IMC interfacial layers grow thicker over time (Limaye, et al. 2008, Pun, et al. 2008). The reason for this reduction, however, is not fully understood and is being debated. It has been proposed that the weak interface between the interfacial layers of $\left(\mathrm{Au}_{1-\mathrm{x}} \mathrm{Ni}_{\mathrm{x}}\right) \mathrm{Sn}_{4}$ and $\mathrm{Ni}_{3} \mathrm{Sn}_{4}$ is the reason for the poor reliability of these joints (Ho, Shiau and Kao 2002). It has also been noted by (Zhang, et al. 2009) that $\mathrm{AuSn}_{4}$ that forms in the bulk solder reduces the reliability of the joints. Others claim that the diffusion of surface finish elements ( $\mathrm{Au}, \mathrm{Ni}$ ) into the solder and the volumetric change associated with forming Au-Ni-Sn compounds creates local stresses and is the cause (Asrar 2009).

There are two techniques that have been shown to reduce or eliminate the formation of $\mathrm{AuSn}_{4}$ IMCs that are detrimental to joint reliability: 1) keeping the joint gold content below a certain weight percent and 2) hot solder dipping (also "wicking"). The gold content can be controlled by designing specific solder volumes and gold coating thickness on components and boards. In hot solder dipping, boards and components are washed separately in a bath of molten tin which removes coatings such as gold and replaces it with a solder finish (Vianco and Kilgo 
2000). This reduces the amount of gold that will dissolve into the joint when it is formed, lowering the gold content of the joint. 


\subsection{Solder Metallurgy}

Solder alloys are carefully designed and tested so that they perform well in the manufacturing process and throughout their service life (Vianco 1998). They have specific material properties (Abtew and Selvaduray 2000) such as:

low melting point

low electrical resistivity

high yield strength

high fracture toughness resistance to embrittlement \& creep good oxidation resistance wetting properties

reworkability

Lead-tin solder was the solder standard for many decades. $\mathrm{Sn}_{60} \mathrm{~Pb}_{40}$ and $\mathrm{Sn}_{63} \mathrm{~Pb}_{37}$ have both found wide use because of their low melting point $\left(\sim 183^{\circ} \mathrm{C}\right)$, good mechanical properties, and low cost. The added cost of lead-free solders and using slightly higher reflow temperatures is especially challenging to high volume manufacturing because of the amplification of factors such as raw material costs and process energy consumption. This is in addition to the massive cost of researching all the material properties of a new solder system.

The mechanical reliability of lead-free joints, however, is not as well understood as that of $\mathrm{PbSn}$ solders, which have been studied extensively for aerospace, military, biomedical, and now consumer electronics markets for almost a century. The higher the tin content of a solder, the better its mechanical properties such as yield strength and fatigue life (Prasad 1997). SAC305 is one of the most common high-Sn solders that is currently in use. 


\subsection{Surface Finishes}

Surface finishes are layers applied to the exposed pads on cured printed circuit boards (PCBs) to: 1) prevent the dissolution of the copper pads during soldering processes 2) to enhance the solderability (wetting properties) 3) prevent oxidation of pads if boards are to be stored for several months before being assembled (Vianco 1998). Similar coatings are sometimes applied to the leads of component packages for the same reasons.

$\mathrm{Cu} / \mathrm{Ni} / \mathrm{Au}$ metallizations are a common surface finish for higher performance applications. The Ni layer, on the order of $1.3-7.6 \mu \mathrm{m}$ thick, is used to prevent molten solder from dissolving the Cu pad layer during soldering and act as a diffusion barrier to prevent copper from diffusing into the joint over time (Vianco 1998). The outer Au layer, on the order of $0.2-1.0 \mu \mathrm{m}$ thick, is used to prevent oxidation (Ho, Shiau and Kao 2002). Gold does not oxidize below its melting temperature and so is commonly used as an oxidation barrier in electronics (Smith 2005). Its resistance to oxidation is the reason for its extensive use in space applications. Gold finishes allow boards to be stored for up to 6 months before losing solderability (Banerji 1993). One issue with gold coatings is that the gold dissolves into the molten solder during reflow, changing the metallurgical composition and often forms intermetallic compounds that have the potential to reduce the reliability of solder joints (Banerji 1993). Organic Solderability Preservative (OSP) finishes are polymeric finishes that also prevent oxidation, but less well than gold finishes (Vianco 1998). Problems stemming from high joint gold content can be lessened by using an OSP finish because it does not increase the gold content of a joint. OSP is much less effective than gold in terms of solderability, or how well solder can wet the surface.

Electrolytic Nickel and electrolytic gold are processes that use galvanic electroplating (Coombs 2008). The electrolytic techniques are a more specialized surface finish than standard methods such as hot air solder leveling (HASL). Electrolytic Au over Ni was developed in part to improve the wettability of difficult to solder to lead materials such as Kovar, which was used in one of the packages in this experiment. 


\subsection{Intermetallic compounds}

Intermetallic compounds (IMCs) are a group of materials that consist of multiple metal elements. They tend to have narrow composition ranges, unlike brass for example, and relatively simple stoichiometric proportions. Two Cu-Sn IMCs measured in this experiment are highlighted in the binary phase diagram in Figure 1. Note the narrow phase fields for the IMCs.

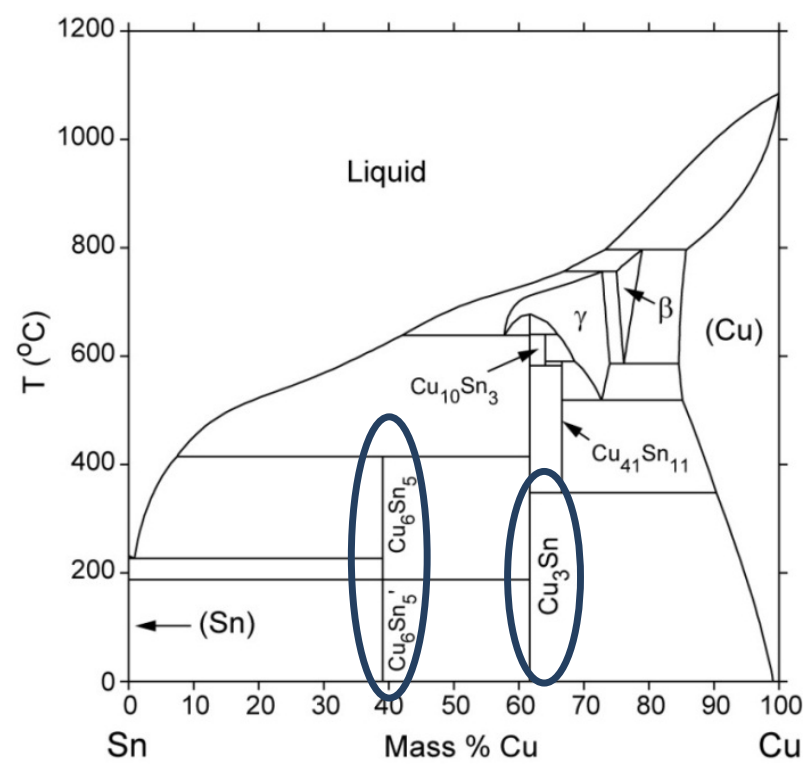

Figure 1 - Cu-Sn binary phase diagram with highlighted intermetallic compounds (National Institute of Standards and Technology n.d.)

They tend to be brittle and hard, which is partly why they serve as precipitation hardening agents such as $\mathrm{Al}_{2} \mathrm{Cu}$ or $\mathrm{Al}_{2} \mathrm{CuMg}$ in 2xxx aluminum alloys (van der Lingen, et al. 2005). IMCs form and grow as a result of one metal diffusing into the crystal vacancies of the other (NASA Electronic Parts and Packaging n.d.).

Intermetallics are most commonly found in alloys or at the interface between two metal layers. In solder joints, the interfacial layers of IMCs are hugely important because their size, chemical composition, and properties affect the mechanical reliability of the attachment between printed circuit boards and components such as microprocessors. If even one joint fails, an entire device or system may become unreliable or useless. 


\subsection{Isothermal Aging Samples}

It is commonly understood that intermetallic compounds and layers grow larger over time (Ho, Shiau and Kao 2002) because of the driving force to reduce the Gibbs free energy of the surrounding purer metals ( $\mathrm{Sn}$ in bulk solder, Cu layer, Ni layer) by mixing. Even if a layer with poor mechanical properties is present and grows thicker, a component might not fail until it has been used for several years. Isothermal aging can provide some insight as to how something will behave after years of service. In this study, the boards were divided into three groups that were aged at $125{ }^{\circ} \mathrm{C}$ for three different time periods: 0 days, 30 days, and 56 days. The thermal aging parameters of 0 days, 30 days, and 56 days at $125^{\circ} \mathrm{C}$ were used to simulate 0,7 , and 14 years of device operation at $60^{\circ} \mathrm{C}$ (Powers, et al. 2011).

\subsection{Reliability Testing}

Mechanical reliability tests were performed on one group of boards, after isothermal aging, to simulate the effect that manufacturing and shipping could have on the circuit boards. The hope was to match the reliability behavior to the microstructures of each particular component board system. The tests were fairly rigorous as each board underwent 500 total minutes of random vibration from 5 to $120 \mathrm{~Hz}$ and 100 total drops at $250 \mathrm{G}$. These tests were run in ten parts and resistance measurements were taken between each test cycle (50 minutes of vibration > measurement $>10$ drops $>$ measurement $>$ repeat 9 more times). The leads of the packages were daisy chained, which means that they were all connected in series so that changes in the resistance of a single joint would register as a particular package having a resistance increase. If a joint fractured it would register as an infinite resistance and the package may have fallen off of the board. If the joint fractured, but the package was still attached, however, individual joints had to be measured to check for an electrical open, indicating a fracture. 


\section{Chapter 3. Experiment}

Forty test vehicle PCBs were assembled for this study. The PCBs used were six-layer boards made of Nelco N4000-12, a common epoxy matrix for PCBs. The surface finish used on the pads of the boards was electrolytic Au over $\mathrm{Ni}(\mathrm{Au} / \mathrm{Ni} / \mathrm{Cu})$. Two thicknesses of $\mathrm{Au}$ were evaluated: 1) a flash Au finish (a $0.08 \sim 0.38 \mu \mathrm{m}$ thick Au layer over a $5 \mu \mathrm{m}$ thick Ni layer) and 2) a thick Au finish (a $2.0 \sim 2.54 \mu \mathrm{m}$ thick Au layer over a $5 \mu \mathrm{m}$ thick Ni layer). Six of those boardsthree with flash gold coatings and three with thick gold coatings-were assembled, inspected with $\mathrm{x}$-rays in case many voids formed, put through isothermal aging, and then cross-sectioned. The other thirty four were assembled, put through isothermal aging, and then put through mechanical reliability tests (Pan, Silk, et al. 2011). A few components from the boards that underwent the reliability tests were cross-sectioned to examine why they met the failure criteria of a resistance increase of 2 ohms during the tests.

Three types of components were used in this experiment. The QFN was a quad flat no lead (it has leads, but they are only on the package underside) plastic package. Two sizes of QFN were used: 1) $5 \times 5 \mathrm{~mm}$ and 2) $6 \times 6 \mathrm{~mm}$ outlines. The QFN packages had Cu leads coated with matte Sn. The TOPS was an RF laminate, open cavity, no lead package with a $10 \times 10 \mathrm{~mm}$ outline. The TOPS packages also had Cu leads, but were coated with a $0.28 \sim 0.46 \mu \mathrm{m}$ Au layer over a $3.8 \sim 8.5 \mu \mathrm{m}$ Ni layer. The FP were ceramic, open cavity, flat lead packages. Two sizes of FP package were also used: 1) 6.4 × $6.4 \mathrm{~mm}$ and 2) $10.2 \times 9.7 \mathrm{~mm}$ outlines. The FP packages had Kovar, a nickel-cobalt ferrous alloy (Fe-Ni-Co), leads with a $1 \sim 2 \mu \mathrm{m}$ Au over $1 \sim 5 \mu \mathrm{m} \mathrm{Ni}$ lead finish. All the components were daisy chained so that a single joint failure would register as a change in resistance during the tests. 


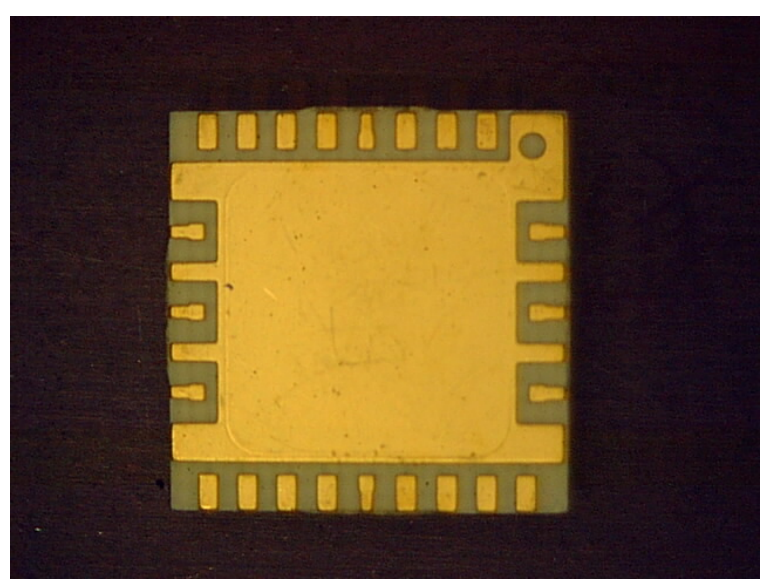

Figure 2 - Underside leads and ground pad of TOPS package (10 x $10 \mathrm{~mm}$ outline)

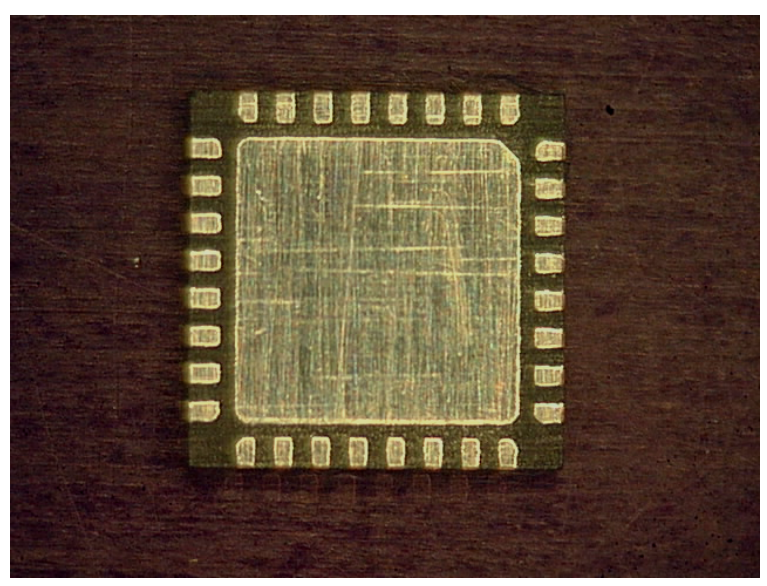

Figure 3 - Underside leads and ground pad of QFN5 package (5 x $5 \mathrm{~mm}$ outline)

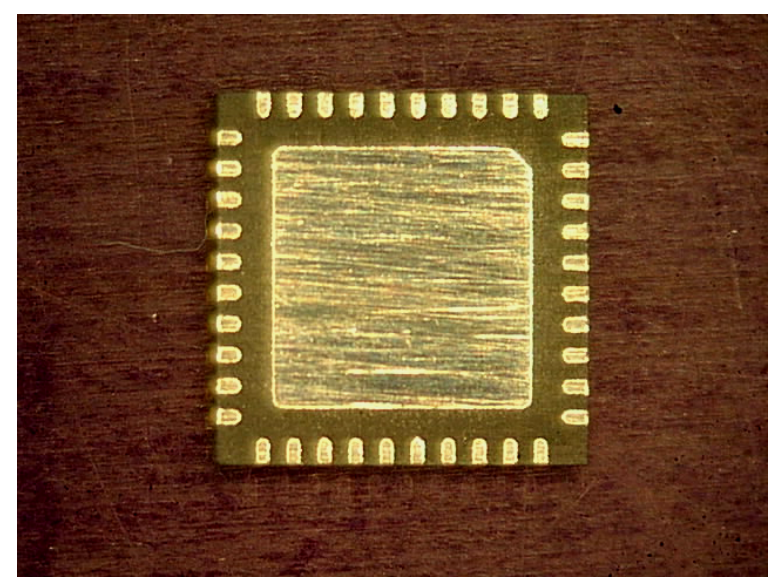

Figure 4 - Underside leads and ground pad of QFN6 package (6 $\times 6 \mathrm{~mm}$ outline)

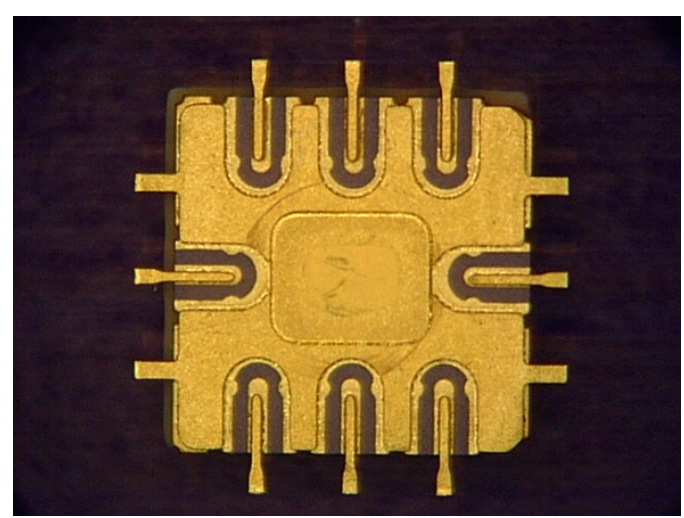

Figure 5 - Underside leads and ground pad of FPI package $(6.4 \times 6.4 \mathrm{~mm}$ outline $)$

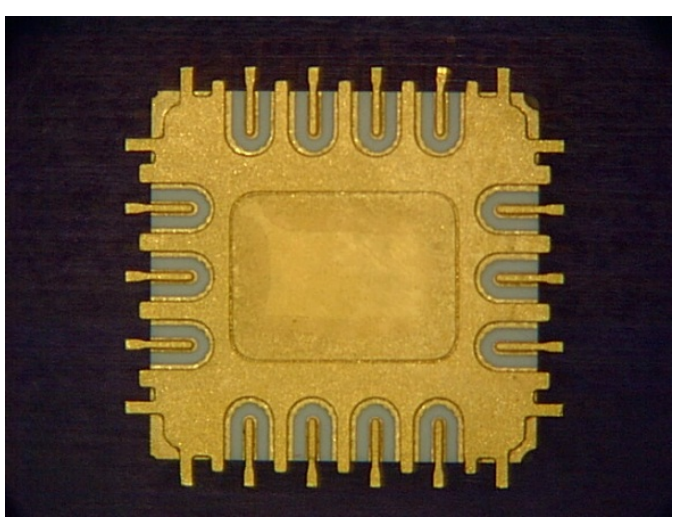

Figure 6 - Underside leads and ground pad of FPII package (10.2 x $9.7 \mathrm{~mm}$ outline)

After cross-sectioning and metallography (to be described in sections 3.2 and 3.3),

measurements were taken of which IMCs formed and where within the solder joints they formed. 
In the samples that underwent reliability tests, resistance measurements were taken between each cycle of vibration and drop testing. There are multiple standards that set criteria for failure that use resistance increases, but they differ and there is debate as to which method is the most effective (Powers, et al. 2011). An increase of $2 \Omega$ or more was used as the failure criterion for this project. As the packages were daisy chained, a fractured joint would register as the package failing, but individual joints had to be measured to check for an electrical open, implying a fracture. Samples were sectioned along specific joints that resistance measurements on specific joints indicated as open circuits. IMCs are 2 to 10 times less electrically conductive than the metals used in PCBs and solder connections (Fields and Low n.d.). Their presence of IMC in a planar layer at the component lead/bulk solder or board pad/bulk solder interface (interfacial IMC layer) could cause a measurable resistance change. More likely is if a joint completely fractured along an interfacial IMC layer, the measurements would indicate an open circuit because of the air gap, but if the reliability test caused the separated planes to reconnect, the measurement would no longer indicate an open circuit. X-ray images taken during the manufacturing were used to confirm the presence of voids that may have been more likely sites for fractures. After metallographic preparation and electron imaging, the locations and paths of cracks were noted, especially in relation to the IMCs present in the joint. 


\subsection{Procedure}

The components had to be prepared so that the cross sections of individual solder joints could be examined under a scanning electron microscope. This was accomplished using metallographic methods in the Materials Engineering labs at Cal Poly. Most of this technique was derived from conversations with Michael Santos (Santos 2010) and David Gibbs (Gibbs 2010) in addition to information from the ASM Handbooks (Voort 2002).

\subsection{Cutting}

Components were isolated from boards by cutting the board with a 4" metal bond $15 \mathrm{HC}$ (high concentration) diamond wafering saw, operated between 100 and $300 \mathrm{rpm}$. Blades of this type are effective at cutting hard materials, such as the glass fibers within printed circuit boards, and at precision cutting where kerf (cut width) needs to be minimized, which was helpful when the components were densely placed (only a few millimeters apart) on parts of the boards. A bath of deionized water was used as cutting fluid, mainly to remove debris that obstructed the view of the cut as it formed. Sectioned components were rinsed in deionized water to remove cutting debris.

\subsection{Mounting}

Allied High Tech EpoxySet resin was used to mount sectioned components because of its low curing temperature and low viscosity. The manufacturer claims a $54^{\circ} \mathrm{C}$ peak temperature (Allied High Tech: Mounting - Cold Mounting n.d.), which is less likely to cause components to crack from the rapid release of heat from the exothermic curing reaction that epoxy undergoes whereby cross links are formed (Mallick 2008). This epoxy took longer to cure than standard metallographic epoxy (8 hours as opposed to 2 hours), but samples were mounted in batches and cured overnight, increasing the overall efficiency of processing samples. The low viscosity helped the resin to achieve good fill, which means it wetted the spaces between the fine pitch leads of the packages. This was helpful because it prevents bubbles that form when resin cannot penetrate such small spaces which make polishing more difficult than a fully dense resin. 
Bubbles can trap particles from the abrasive compounds or from the sample surface and then release them, gouging large scratches in the surface (Santos 2010). Figure 7 is an image of a cured puck of epoxy with almost no bubbles.

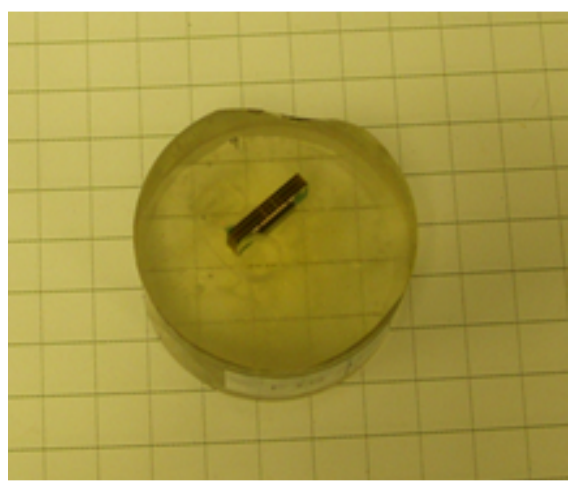

Figure 7 - Cured epoxy puck containing a sectioned QFN component

Some FP samples were attached to the boards when the epoxy was poured, but when cured samples were inspected, the FP components were at the bottom of the mount, indicating that they fractured from the board during the epoxy cure cycle before it fully solidified. This was yet another indication of reliability issues with these particular components.

\subsection{Grinding}

A belt sander was used to abrade the mounted component until the outer edge of the solder joints on both leads of the package and the ground pad were visible under an optical microscope at 50x or 100x. Figure 8 schematically illustrates this step.

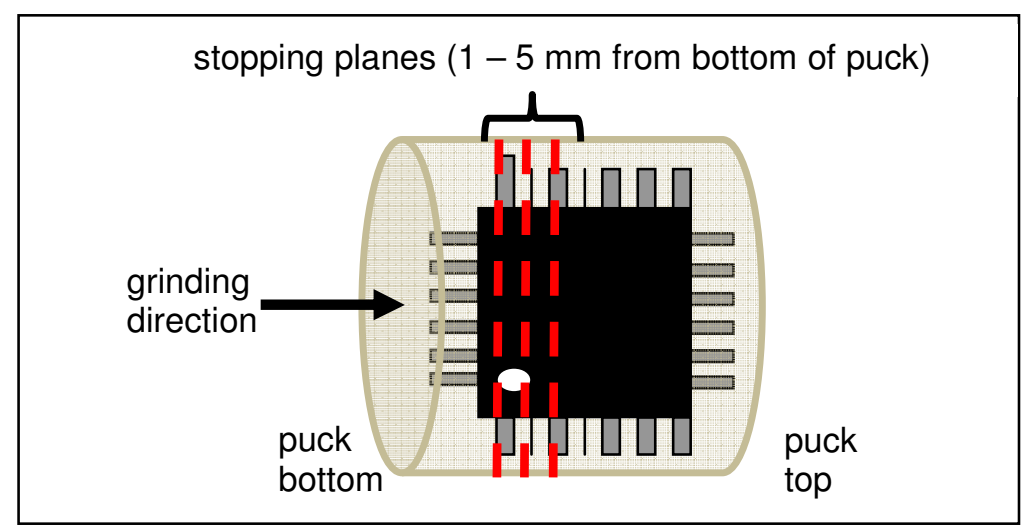

Figure 8 - Schematic of grinding of components mounted in cured epoxy resin. The dashed red lines indicate planes remove material up to with the initial rough grind once the joints on both sides and the leads are exposed. 
Once the outer part of the joints were exposed, a series of six progressively finer silicon carbide abrasive pads were used to remove material in a more controlled manner and leave a smoother surface roughness. The grits used and the corresponding average particle sizes are shown in Table I.

Table I - Abrasive grit designations and average particle sizes of SiC pads used to prepare samples (Federation of European Producers of Abrasives n.d., Allied High Tech 2011)

\begin{tabular}{|c|c|c|}
\hline $\begin{array}{c}\text { ISO/FEPA Grit } \\
\text { Designation }\end{array}$ & U.S. Grit Size & $\begin{array}{c}\text { Average Particle } \\
\text { Size }(\boldsymbol{\mu m})\end{array}$ \\
\hline$\sim$ P80-P100 & 80 & 190 \\
\hline$\sim$ P120-P150 & 120 & 192 \\
\hline$\sim$ P240-P280 & 240 & 53.5 \\
\hline$\sim$ P400 & 320 & 36 \\
\hline$\sim$ P800 & 400 & 23.6 \\
\hline$\sim$ P1200 & 600 & 16.0 \\
\hline P2400 & 800 & 12.2 \\
\hline P4000 & 1200 & 6.5 \\
\hline
\end{tabular}

The steps of grinding on the P2400 and P4000 pads were critical to obtaining a smooth surface because the larger particles from the lower grits can gouge deep scratches in the soft, low alloy, electrical grade metals which were only revealed and removed when the two finest grits were used. Standard metallographic practice is to grind using up to $600 \mathrm{US}$ grit (16.0 $\mu \mathrm{m}$ particle size) and then transfer to polishing suspensions. The 1200 U.S. grit pads were used in this experiment to make for a smaller difference in abrasive particle size in transferring from $\mathrm{SiC}$ paper to the alumina polish suspension because of the ultra-fine surface finish that was needed.

\subsection{Polishing}

Alumina polish suspensions of $0.3 \mu \mathrm{m}$ and $0.1 \mu \mathrm{m}$ particle size were used to further smooth the surfaces of the cross-sectioned joints, similar to what some researchers used (Chiang, Chang and Chuang 2004). A final polish of $0.02 \mu \mathrm{m}$ particle size silica was used because it produced relief or "surface-height variations between structural features of different hardnesses (Voort 2002) created great contrast between the various compounds present (IMCs, bulk solder, and surface finish layers) so that they could be distinguished on an optical 
microscope at 400x and in the scanning electron microscope at higher magnifications (Salam, Ekere and Durairaj 2006, Sun, et al. 2008).

The reason for the relief after the final polish, comes from the difference in the hardness of the phases in the joint and abrasives. Alumina, according to information from a database of specific materials and their properties (2010 CES level 3 database (CES n.d.)) has a Vickers hardness between 1,200 and 2,060 and silica has a Vickers hardness of 405 to 502 . CES also listed a Vickers hardness of 10 to 20 for a tin-silver alloy (3.5 wt\% $\mathrm{Ag}$ ) which is close in composition to the SAC 305 used in these experiments. Silicon carbide and alumina are much harder than silica and SAC solder, according to the data from CES. Silica is harder than SAC solder, but may be softer than the distinct copper, nickel, and intermetallic phases in the joint. If that were the case, the reason why this step generates such contrast is that the silica polish is abrading the bulk solder much more quickly than the other phases present.

Table II - Vickers Hardness values from CES level 3 and abrasive particle sizes used (CES n.d.)

\begin{tabular}{|c|c|c|}
\hline Material & Vickers Hardness & $\begin{array}{c}\text { Abrasive Particle } \\
\text { Size Used }\end{array}$ \\
\hline $\mathrm{SiC}$ & $1,900-3,500$ & $6.5-190 \mu \mathrm{m}$ \\
\hline $\mathrm{Al}_{2} \mathrm{O}_{3}$ & $1,200-2,060$ & $0.05-0.3 \mu \mathrm{m}$ \\
\hline $\mathrm{SiO}_{2}$ & $405-502$ & $0.02 \mu \mathrm{m}$ \\
\hline $\mathrm{Cu}$ & $10-20$ & $\mathrm{n} / \mathrm{a}$ \\
\hline $\mathrm{Ni}$ & $43-180$ & $\mathrm{n} / \mathrm{a}$ \\
\hline & $80-300$ & $\mathrm{n} / \mathrm{a}$ \\
\hline
\end{tabular}

\subsection{Etch}

In metallography, an etch is a method that uses acid solutions to preferentially remove material from the surface of a sample to enhance the visual contrast between regions. This can make it easier to distinguish multiple phases, grains, layers, or other features. An etch was not used in this experiment both because the final silica polish created great contrast between the various metals and IMCs present and because an etch would have changed the apparent chemistry of the joint. Etchants react at different rates with different elements and would alter the relative composition of compounds present in the joint. An etchant was not used because it 
would have altered the relative amount of the elements of interest in the joint, obscuring desired information about the morphology and molecular formulas of the IMCs present.

\subsection{Sputtering}

A conductive coating was necessary to prevent charging that occurred while imaging samples with an electron microscope (JEOL model JSM-6390). Copper tape was not a sufficient electrical ground by itself. Different SEM settings were used in an attempt to reduce charge buildup such as low $\mathrm{kV}$ and large spot size, but ultimately a thin film of gold, on the order of $5 \mathrm{~nm}$, was used as a conductive coating.

A Denton Desk IV sputtering machine was used with 50 mTorr of Ar gas to create a plasma for sputtering. The sputter process was run for 53.76 seconds at a $22 \%$ power setting which translates to a theoretical sputter rate (as claimed by sputter rate charts in the device manual from the manufacturer) of $0.93 \AA$ /second theoretically produced a coating $50 \AA$ thick coating of gold on the polished metallography samples. A thin film ellipsometer was not available to verify the thickness or uniformity of these coatings.

\subsection{Effect of Au film on X-ray absorption}

Gold is a heavy atom, atomic number 79 , which makes it an effective x-ray absorber. It was of concern that using a gold thin film as a conductive coating for electron microscope imaging might reduce the signal strength of the escaping $\mathrm{x}$-rays by absorption. To investigate this, Error! Reference source not found.Equation 1 and a value of $-207.8 \mathrm{~cm} / \mathrm{g} \cdot \mathrm{m}$ for the mass absorption coefficient for Au absorbing Cu-Ka x-rays were used (Cullity and Stock 2001). Values for Cr-Kaand Mo-Ka x-rays were also used and produced absorbance ratios within an order of magnitude of the Cu-Ka values at the theoretical film thicknesses. This basic equation for x-ray absorption was used to investigate the expected effect of the gold thin film on x-ray signal strength.

$$
I_{x}=I_{0} \cdot e^{\left(\frac{-\mu}{\rho}\right) \cdot \rho x}
$$


The results showed that the theoretically (thickness has not been verified) $5 \mathrm{~nm} \mathrm{Au}$ coating that was used would absorb $0.003(0.3 \%)$ of the escaping $x$-rays. If the film were $1 \mu \mathrm{m}$ thick, 200 times thicker than the films that were theoretically used, it would still only absorb 0.193 $(19.3 \%)$ of the escaping x-rays. Given these calculations, and that the EDS composition results matched closely to published IMC molecular formulas (Ho, Shiau and Kao 2002), it was decided that the conductive gold coating did not influence the results of this experiment significantly enough to require the use of a conductive carbon coating instead. 


\subsection{SEM \& EDS}

Scanning electron microscopes are devices that use electrons to generate images of physical features with a spatial resolution down to $10 \mathrm{~nm}$. A SEM was used in this project because the features of interest were finer than what an optical microscope could resolve and elemental information about the phases present in the microstructures were needed, which could be obtained from the EDS system attached to the SEM. A JEOL JSM-6390 was used for the analysis in this project. This system uses a thermal Tungsten electron source, which has a theoretical lateral resolution of roughly $10 \mathrm{~nm}$, but practically it was difficult to resolve features below $1 \mu \mathrm{m}$. Some researchers used secondary electron (SE) and back-scattered electron (BSE) images to examine solder joints. BSE images are used to produce phase contrast when two phases are otherwise indistinguishable, but the high contrast that the polishing process produced made this unnecessary.

EDS systems measure the number of $x$-rays that are emitted from samples point by point in a grid. An electron beam excites electrons in the sample to high energy states. Those electrons then decay to lower energy states and give off a characteristic $\mathrm{x}$-ray with a specific energy that is associated with the element. Table III shows the characteristic energies of the elements relevant to this project. A Thermo Scientific model 6733A-INUS-SN liquid nitrogen cooled EDS system was used in this study. The electron beam employed a $20 \mathrm{kV}$ accelerating voltage and a spot size setting of $75 \%$ were used on all samples to reduce variability in $x$-ray measurements due to changes in the electron interaction volume and x-ray generation region.

Area scans were used to analyze solder joint microstructures because they are more accurate than point scans since they measure x-rays from a region instead of a single pixel. Areas were either rectangles placed within regions of interest or contrast based maps of a distinct area that appeared to be a separate phase. The regions marked 6 and 14 in Figure 9 are examples of these selections. 


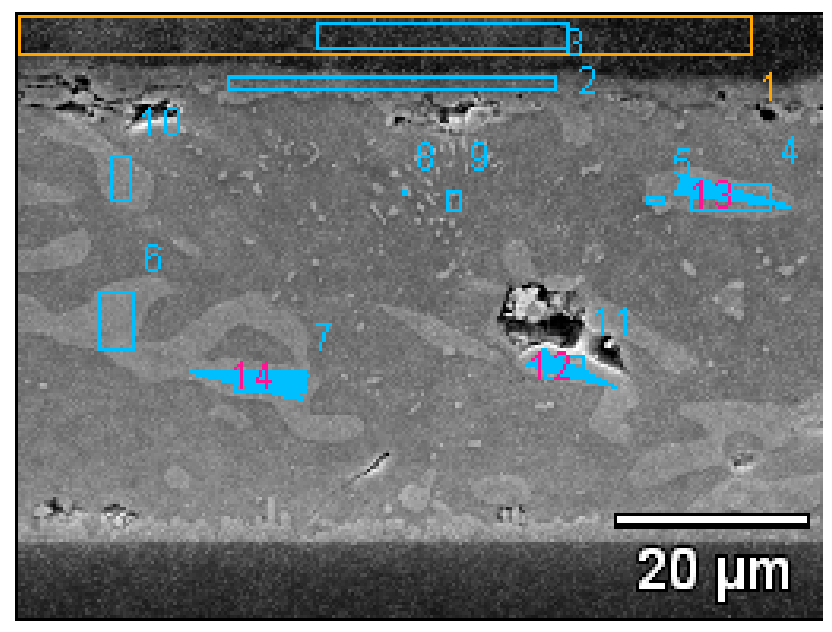

Figure 9 - Examples of region selection using the EDS software

In a SEM, an electron beam is generated which strikes the surface of a sample. Below the surface there is a teardrop shaped interaction volume which is usually $10 \AA-10 \mu \mathrm{m}$ deep (Figure 10). Within this volume different types of electrons and $\mathrm{x}$-rays are generated. X-rays are generated throughout the volume and can escape out of the material where they can be measured by an $\mathrm{x}$-ray detector in an EDS system.

In this work, many of the elemental measurements did not exactly match with published literature values for the stoichiometric ratios of intermetallic compounds. Some of the compounds are non-stoichiometric compounds, whose elemental composition cannot be represented by a ratio of well defined natural numbers (e.g. $\mathrm{H}_{2} \mathrm{~S}$ ) and so are instead represented by related variables (e.g. $\left.\mathrm{Au}_{1-x} \mathrm{Ni}_{x}\right) \mathrm{Sn}_{4}$. Some of the differences may have come from the $\mathrm{x}$-ray generation region existing outside of a particular intermetallic phase. The penetration depth of electrons is a function of their energy (accelerating voltage) and the atomic number of the sample atoms. Figure 10 illustrates how interaction volume changes as a function of acceleration voltage or atomic number. 


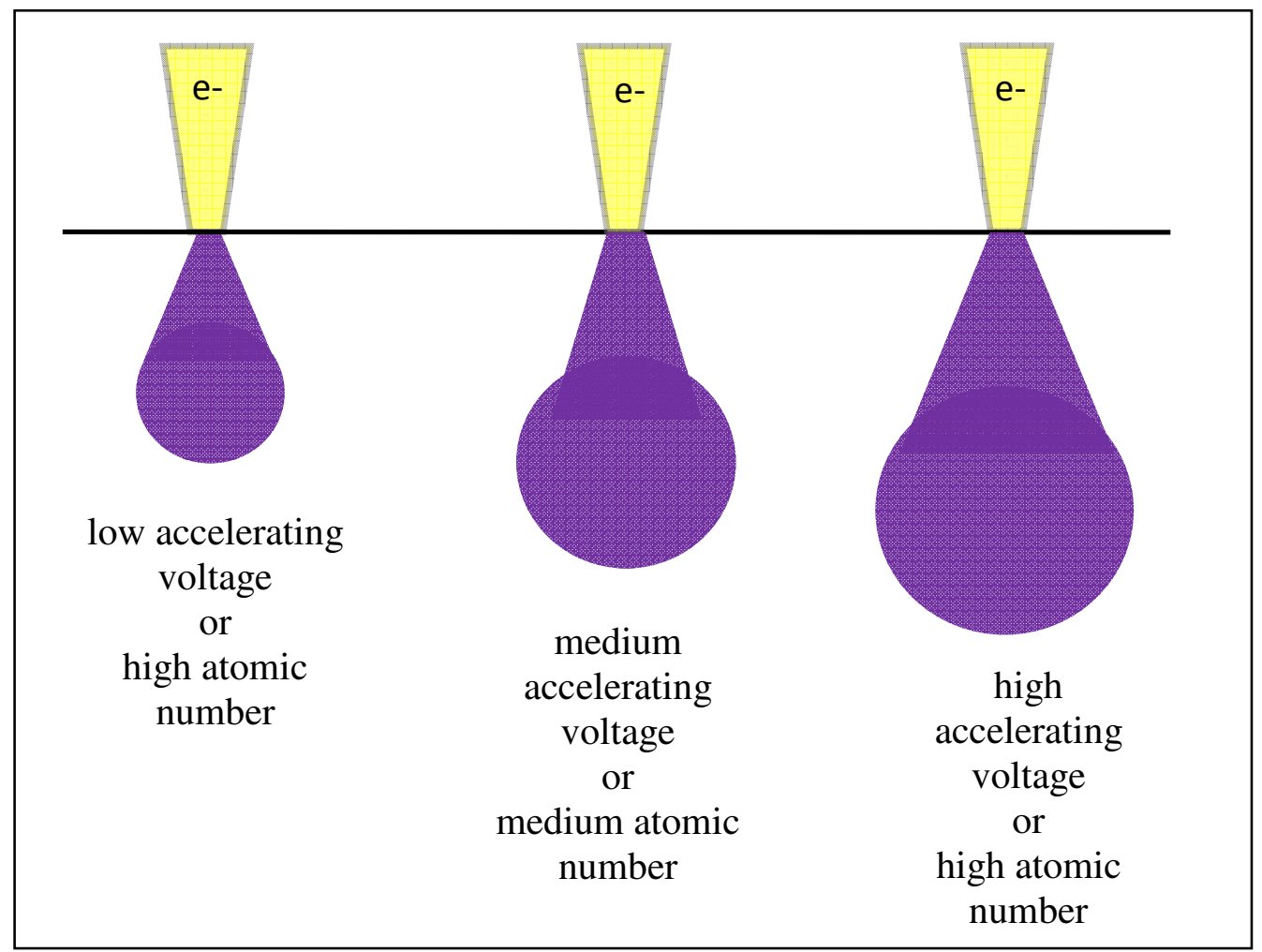

Figure 10 - Electron penetration depth as a function of primary electron accelerating voltage

Given that the size of the intermetallic phases was usually $1-10 \mu \mathrm{m}$, the interaction volume could have contained only one IMC phase, multiple IMC phases, or the bulk solder and an IMC phase. This is shown schematically in Figure 11. 


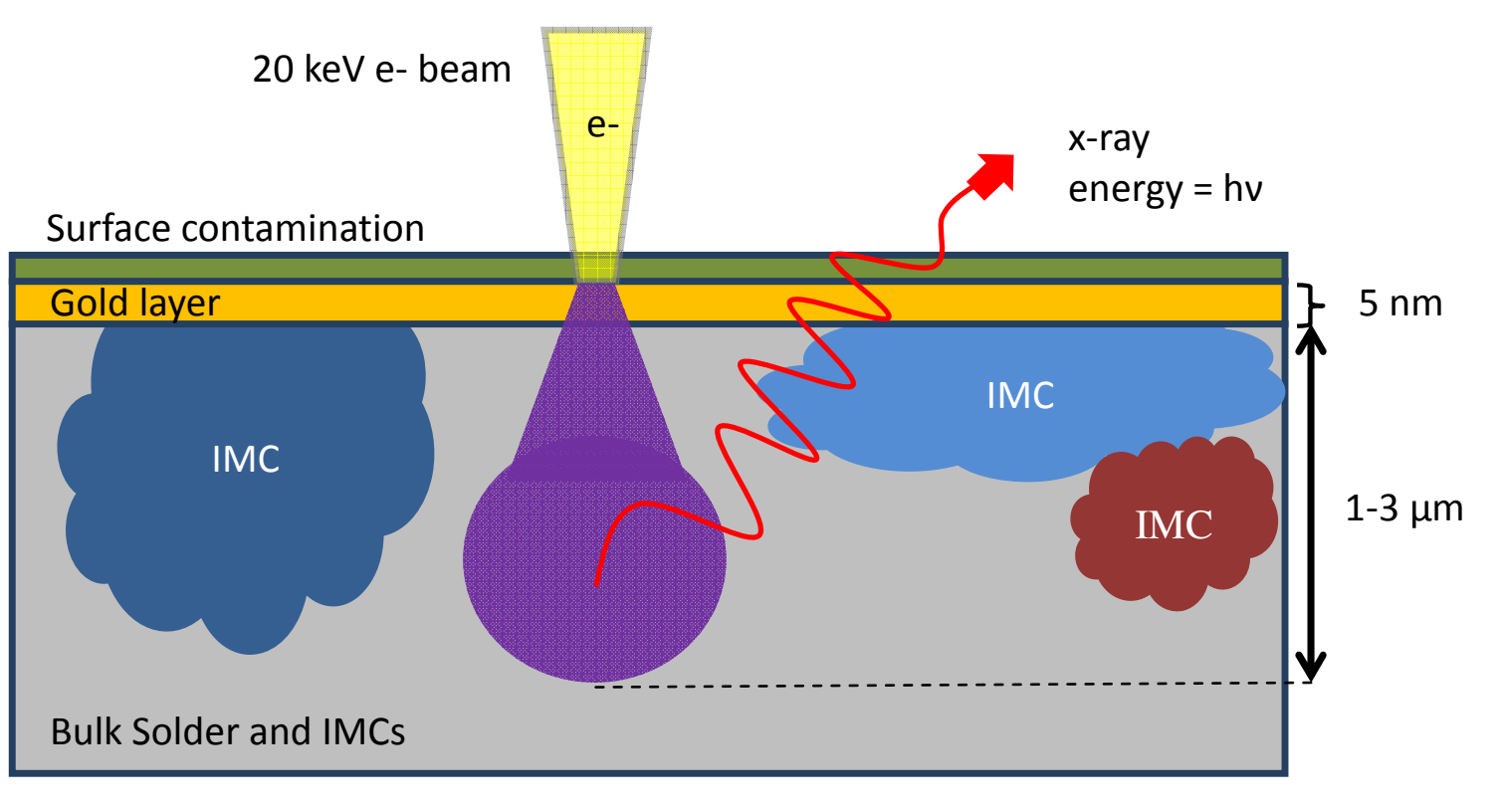

Figure 11 -The combination of interaction volume and IMC arrangements may have caused the variations in elemental measurements.

Any interaction volume that contained more than just one IMC phase would have generated an elemental profile that was mixed between two phases. The $\mathrm{x}$-rays listed in Table III are the primary x-rays that were used to identify specific elements of interest within EDS signals.

Table III - X-ray Energy Table

\begin{tabular}{|l|c|c|}
\hline Element & Molecular Weight $(\mathrm{g} / \mathrm{mol})$ & Primary Energy $(\mathrm{eV})$ \\
\hline $\mathrm{Au}$ & 196.97 & $\mathrm{~L} \alpha-9.712$ \\
\hline $\mathrm{Ag}$ & 107.87 & $\mathrm{~L} \alpha-2.984$ \\
\hline $\mathrm{Sn}$ & 118.710 & $\mathrm{~L} \alpha-3.443$ \\
\hline $\mathrm{Cu}$ & 63.546 & $\mathrm{~K} \alpha-8.040$ \\
\hline $\mathrm{Ni}$ & 58.6934 & $\mathrm{K \alpha}-7.471$ \\
\hline
\end{tabular}

The software compared the relative amounts of the signals to determine a composition for a particular region of interest. 


\section{Chapter 4. Results \& Data Analysis}

All raw elemental EDS data is presented as a weight percent (wt\%). Chemical and molecular formulas are given in numerical ratios which are measured by atomic percentage. For example, AuSn $n_{4}$ should be 20\% (atomic percent) gold and $80 \%$ tin. Formulas were converted using the 'atomic weight converter' tool from AMES laboratory. IMC thickness measurements were taken using the freehand area function of the ImageJ image analysis program. The outlines of IMC layers were traced along the width of the image, then the calculated area of the layer was divided by the width of the image of the joint, after adjusting for magnification ( $\mu \mathrm{m} /$ pixel). This is perhaps a more accurate method than that used by some researchers (Salam, Ekere and Durairaj 2006) where two lines are drawn at the edges of the intermetallic layer as close to an average as possible by visual inspection. 


\subsection{Solder Joint Cross Sections}

The results are organized in three main sections - images of the samples that were only isothermally aged, images of those that were isothermally aged and then put through reliability tests, and the IMC interfacial layer thickness measurements. Within the aging only group, the sections are further divided by package type: QFN, TOPS, FP and then by isothermal aging time: 0 days aged, 30 days aged, 56 days aged.

To familiarize the reader with the cross-section images shown in the next section, Figure 12 is presented as a schematic of what the electron images show.

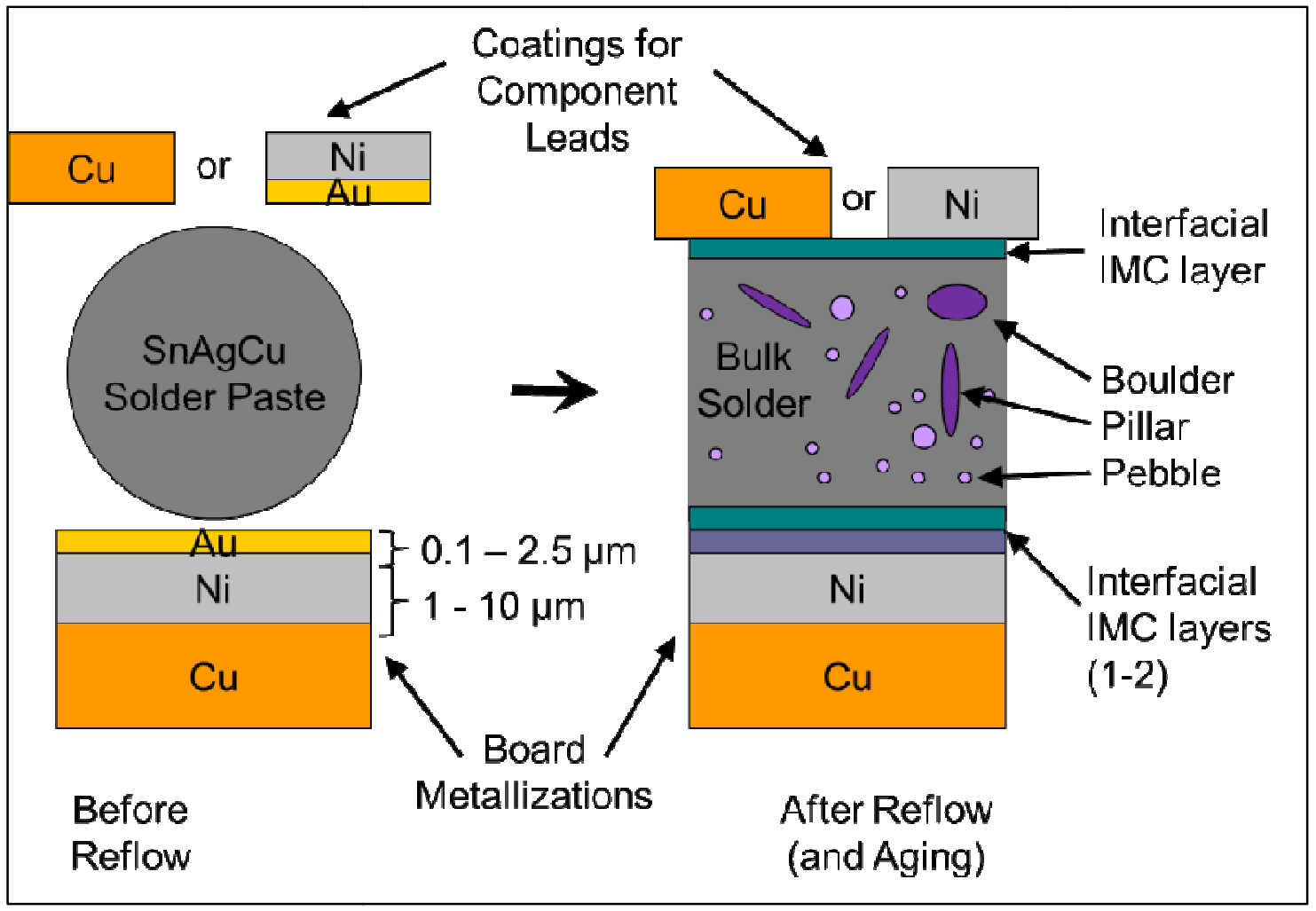

Figure 12 - Schematic representation of solder joint before reflow and after aging

The image on the right of Figure 12, the square shaped joint outlined by two teal layers is what most of the SEM images will resemble. 
The morphology of the IMCs seen in these samples is either an interfacial layer where the component lead or board pad (and metallizations, if present) meet the bulk solder or a mass in the bulk solder. The masses in the bulk solder had one of three morphologies as described here:

Boulder $-5 \sim 10 \mu \mathrm{m} ; \mathrm{AuSn}_{4},\left(\mathrm{Au}_{1-x} \mathrm{Ni}_{x}\right) \mathrm{Sn}_{4}$; vaguely round or rectangular shape

Pebble $-1 \sim 3 \mu \mathrm{m}$; seen mostly in 0 days aged samples; usually $\mathrm{Ag}_{3} \mathrm{Sn}$, but sometimes $\mathrm{Au}_{1-\mathrm{x}} \mathrm{Sn}_{\mathrm{x}}$ compounds

$\underline{\text { Pillar }}-\sim 5 \mu \mathrm{m}$ wide and $20 \sim 50 \mu \mathrm{m}$ long; $\mathrm{AuSn}_{4}$ or $\left(\mathrm{Au}_{1-\mathrm{x}} \mathrm{Ni}_{\mathrm{x}}\right) \mathrm{Sn}_{4}$; seen in QFN, and TOPS, and pillars filled the joints of almost every FP

It should be noted that, the 'boulder' morphology may be a cross section of pillars whose long axis is normal to the image or "into the page." The pillar shape may derive from preferential growth along one of the three orthorhombic crystal axis during solidification. Representative examples of all of these morphologies are labeled below in Figure 13. All subsequent joint images will have the same orientation: the component lead at the top of the image, the board pads at the bottom of the image, and the solder in between.

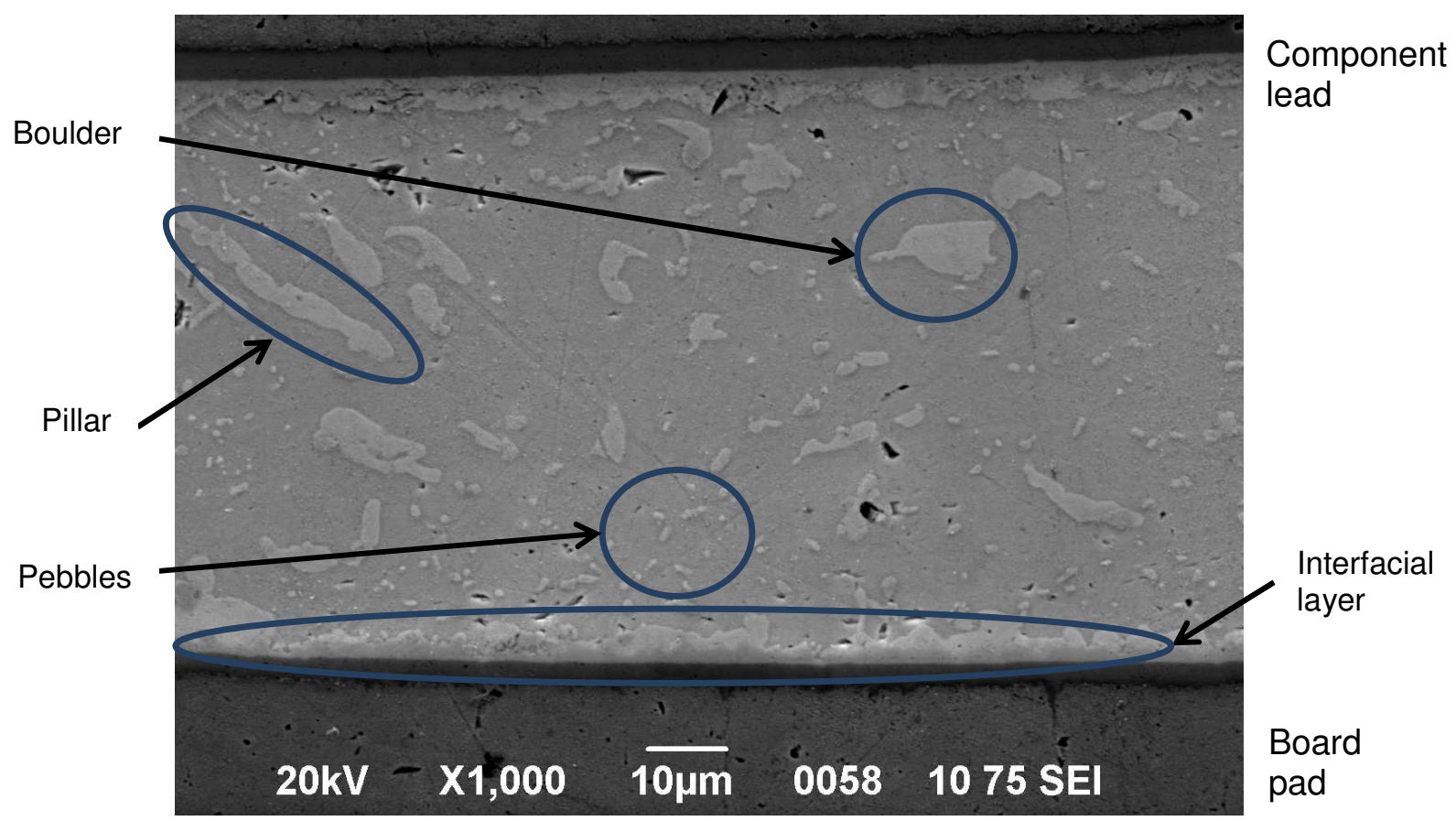

Figure 13 - Examples of IMC morphologies in image of a 30 day aged TOPS joint on a flash Au board 


\subsection{Isothermal Aging Only}

\subsubsection{QFN}

The QFN packages were expected to have few intermetallic compounds because their joint gold contents were $0.2-0.6 \mathrm{wt} \%$ on the flash Au boards and $2.4-6.8 \mathrm{wt} \%$ on the thick Au boards.

QFN 5

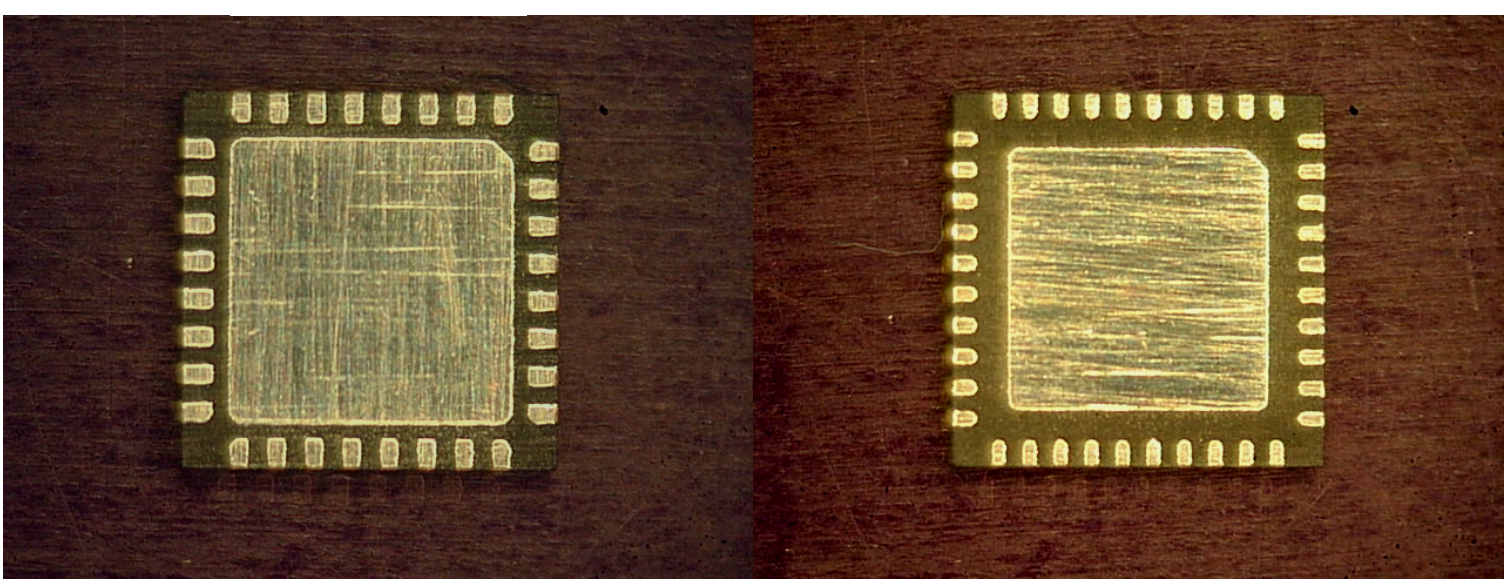

Figure 14 - QFN5 (left) and QFN 6 (right) package undersides

\section{0 days aged boards}

In the QFN samples, on the flash Au boards, the joints on the boards that were aged for 0 days had $\left(\mathrm{Cu}_{1-\mathrm{x}} \mathrm{Ni}_{\mathrm{x}}\right)_{6} \mathrm{Sn}_{5}$ intermetallic layers at the interfaces between the bulk solder and the component and the bulk solder and the board. The composition differed between the component lead/solder interface and the board pad/solder interface. The copper content was higher and the nickel content lower [35Cu-2Ni-63Sn] in the component side because there was no nickel layer on the component to inhibit copper dissolution and diffusion during reflow and aging, respectively. On the board side, however, there was a lower copper content and a higher nickel content [23Cu15Ni-2Ag-60Sn] because the nickel layer prevented copper dissolution, inhibited copper diffusion, and provided a source of nickel to diffuse into the layer. The bulk solder had pebbles of $\left(\mathrm{Cu}_{1-\mathrm{p}}\right.$ $\left.{ }_{q} A u_{p} A g_{q}\right)_{6} S_{5}$, but the reliability data did not indicate that the presence of pebble-shaped IMCs 
have any detrimental effect. Both the 0 days aged QFN5 and QFN6 had this microstructure, which is shown in Figure 15 and Figure 16.

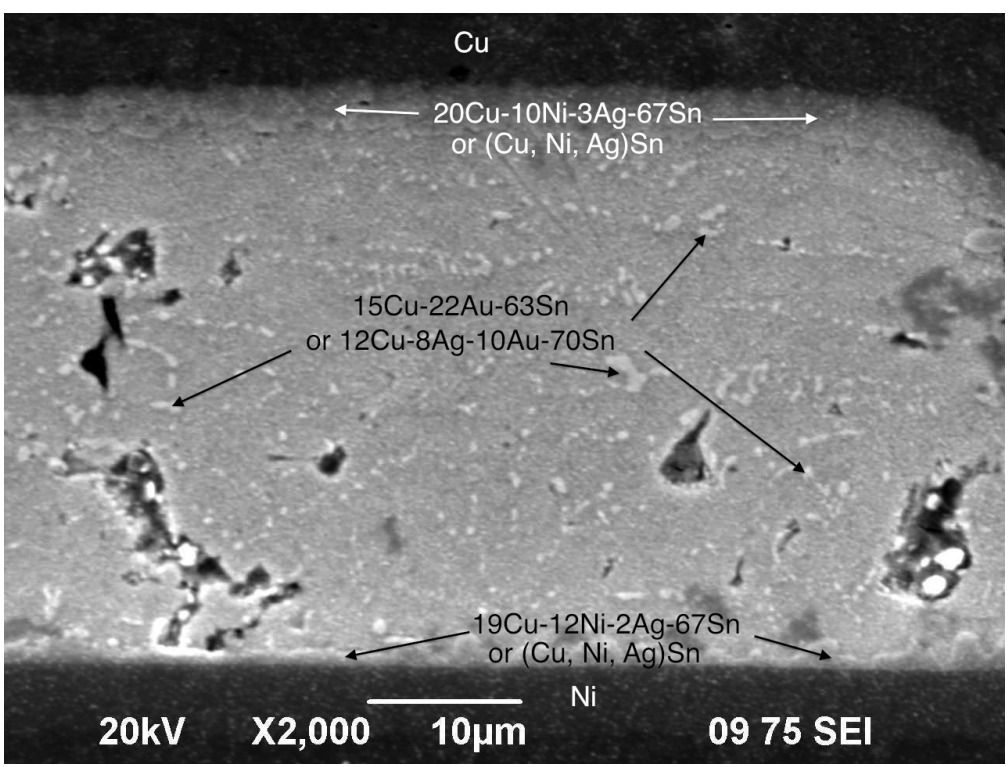

Figure 15 - 0 days aged QFN5 on a flash Au board (0.9 wt\% Au)

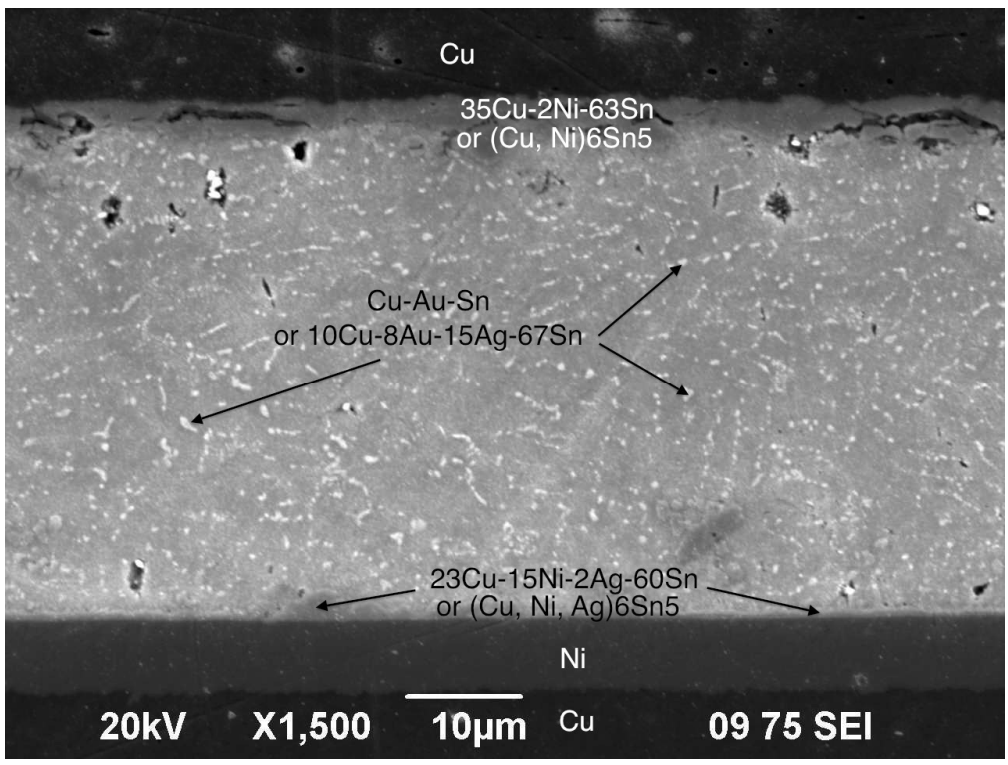

Figure 16 - 0 days aged QFN6 on a flash Au board (0.9 wt\% Au)

In the QFN samples, on the thick Au boards, the joints on the boards that were aged for 0 days had $\left(\mathrm{C}_{\mathrm{u1}-\mathrm{p}-\mathrm{q}} \mathrm{Au}_{\mathrm{p}} \mathrm{Ni}_{\mathrm{q}) 6} \mathrm{Sn}_{5}\right.$ and $\left(\mathrm{Cu}_{1-\mathrm{x}} \mathrm{Au}_{\mathrm{x}}\right)_{6} \mathrm{Sn}_{5}$ intermetallic layers at the interfaces between the bulk solder and the component and the bulk solder and the board as Figure 17 shows. The 
difference in $\mathrm{Cu}$ and $\mathrm{Ni}$ content between the board interfacial layer and component interfacial layer matched that seen in the flash Au boards. The bulk solder of the joints from the thick Au

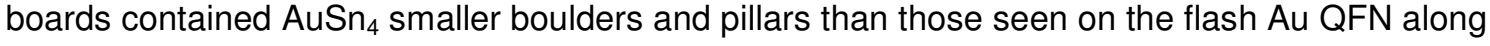
with a few $\mathrm{Ag}_{3} \mathrm{Sn}$ pebbles.

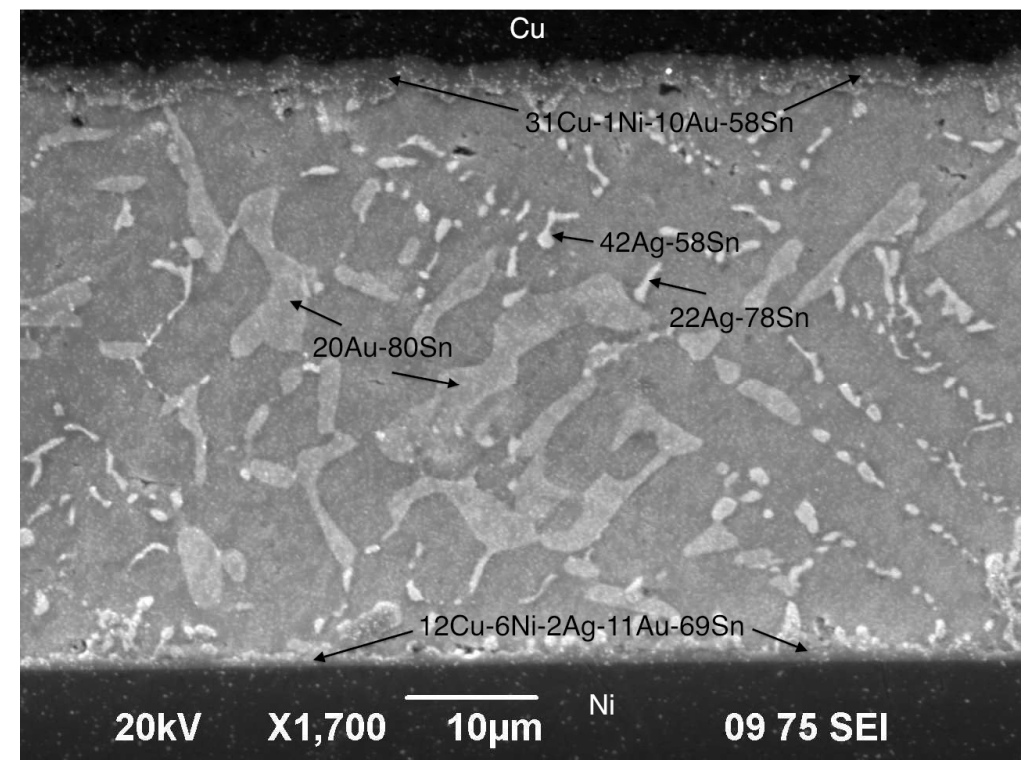

Figure $17-\mathrm{AuSn}_{4}, \mathrm{Ag}-\mathrm{Sn}$, and $\left(\mathrm{C}_{u 1-p-q} \mathrm{Au}_{\mathrm{p}} \mathrm{Ni}_{q) 6} \mathrm{Sn}_{5}\right.$ IMCs in the joint of a 0 days aged QFN on thick Au board $(6.3 \mathrm{wt} \% \mathrm{Au})$

\section{0 days aged boards}

In the solder joints on the flash Au boards that were aged for 30 days, the $\mathrm{Cu}-\mathrm{Au}-\mathrm{Sn}$ pebbles that were seen in the bulk of the 0 day samples are gone and the $\mathrm{Cu}-\mathrm{Ni}-\mathrm{Sn}$ interfacial layers on both sides now have about 2 wt\% gold in them and about the same amount of copper, as in Figure 18. In the board-side interfacial layer the nickel content rose from $\sim 7$ wt $\%$ to $\sim 15$ $w t \%$, indicating that some of the nickel from the adjacent Ni layer had diffused into the interfacial IMC layer. Ag-Sn pebbles were detected in the bulk. 


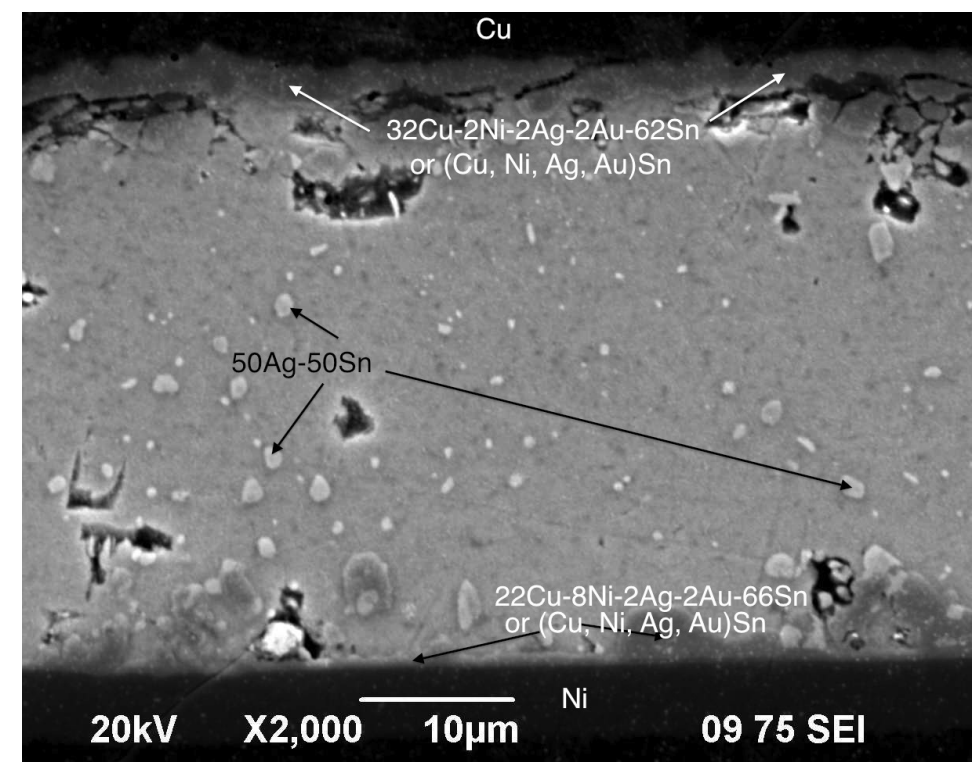

Figure 18 - 30 days QFN on flash Au (0.5 wt\% Au)

The joints on the flash boards had low gold contents (0.5 wt\%). Because of the low content, the joint had none of the gold-tin intermetallic microstructural features that the literature indicated as potential reliability problems.

The joints on the thick Au boards in the 30 day aged group had an Au content of 5.6 wt\% and had $\mathrm{AuSn}_{4}$ boulders throughout the bulk and near the interfacial layers, as well as Ag-Sn pebbles in the bulk, as Figure 19 shows. The larger amount of $\mathrm{AuSn}_{4} \mathrm{IMCs}_{\mathrm{I}}$ correlates with the larger Au content. 


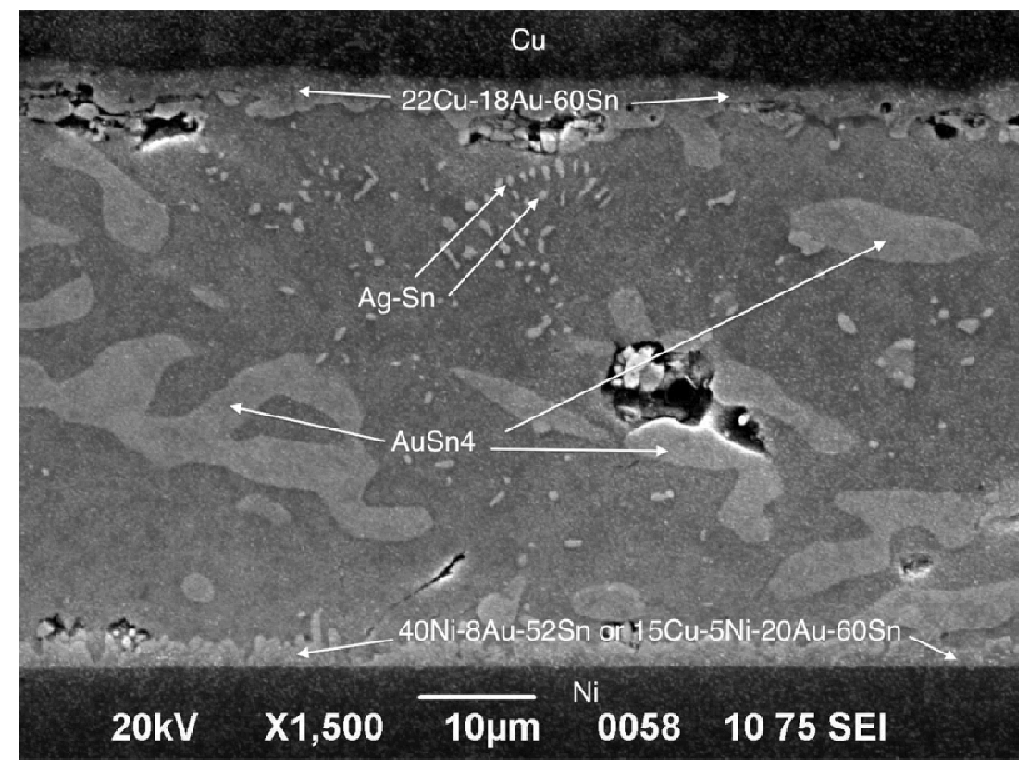

Figure 19 - 30 day aged QFN on Thick Au board (5.6 wt\% Au)

The composition of the component-side interfacial layer was measured as $22 \mathrm{Cu}-18 \mathrm{Au}-$ 60Sn which matches the $\left(\mathrm{Cu}_{1-x} \mathrm{Au}_{\mathrm{x}}\right)_{6} \mathrm{Sn}_{5} \mathrm{IMC}$ seen in literature. The board-side interfacial layer measurements indicate it was $\left(\mathrm{C}_{u 1-p-q} \mathrm{Au}_{\mathrm{p}} \mathrm{Ni}_{\mathrm{q}) 6} \mathrm{Sn}_{5}\right.$ or $\left(\mathrm{Au}_{1-x} \mathrm{Ni}_{\mathrm{x}}\right) \mathrm{Sn}_{4}$, depending on which part was measured. The composition of the Cu-Ni-Au-Sn on the thick 30 day QFN packages is similar to what was measured on the flash 30 day TOPS packages, but with $15 \mathrm{wt} \% \mathrm{Cu}$ and $5 \mathrm{wt} \% \mathrm{Ni}$ instead of $15 \mathrm{wt} \% \mathrm{Ni}$ only.

\section{6 day aged boards}

The 56 day aged QFN joints on the flash Au boards had a gold content of $0.6 \mathrm{wt} \%$ and were similar to the 30 day flash Au joints, as seen in Figure 20. They still have AgSn particles in the bulk, $\left(\mathrm{C}_{\mathrm{u} 1-\mathrm{p}-\mathrm{q}} \mathrm{Au}_{\mathrm{p}} \mathrm{Ni}_{\mathrm{q}) 6} \mathrm{Sn}_{5}\right.$ interfacial layers. 


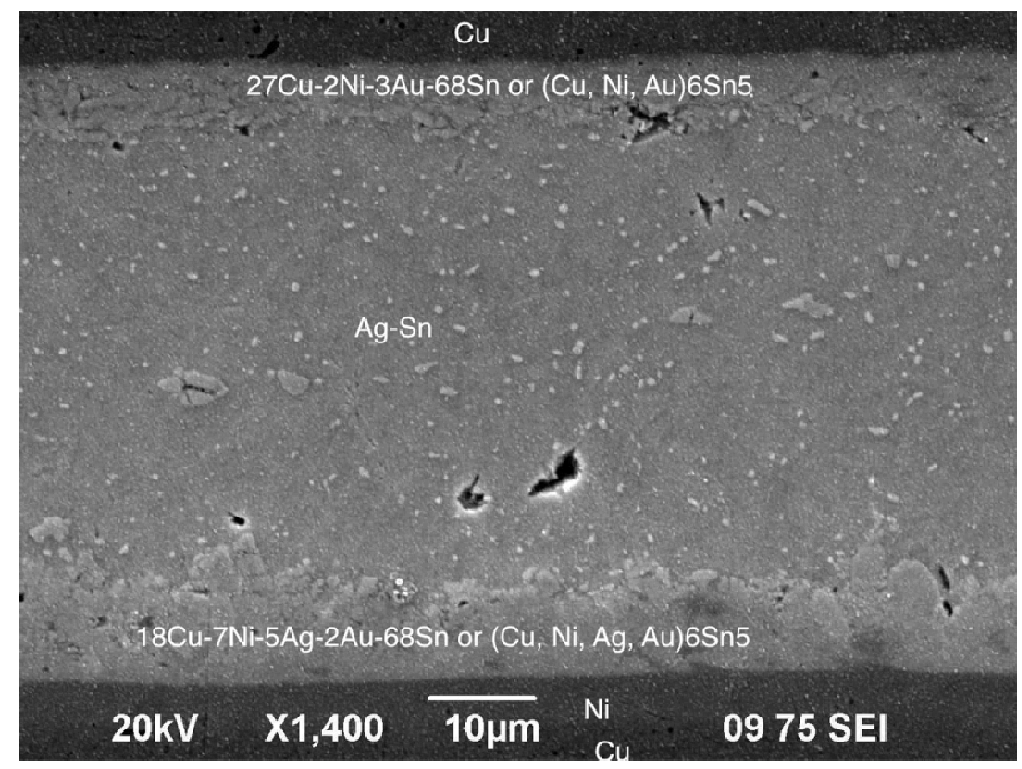

Figure 20 - 56 day aged QFN on Flash Au board (0.6 wt\% Au)

Thick $A u$ QFN joints had larger AuSn $n_{4}$ boulders in the bulk and $\left(\mathrm{Cu}_{1-x} A u_{x}\right) S n_{4}$ at the interfaces as in Figure 21. The component side IMC interfacial layer had a higher gold content than the board side, $14 \mathrm{wt} \%$ versus $4 \mathrm{wt} \%$. It is suspected that when copper is available, it can inhibit gold diffusion, as in the case on the QFN leads where the solder is in contact with copper, not a Ni barrier layer (Tian, et al. 2007).

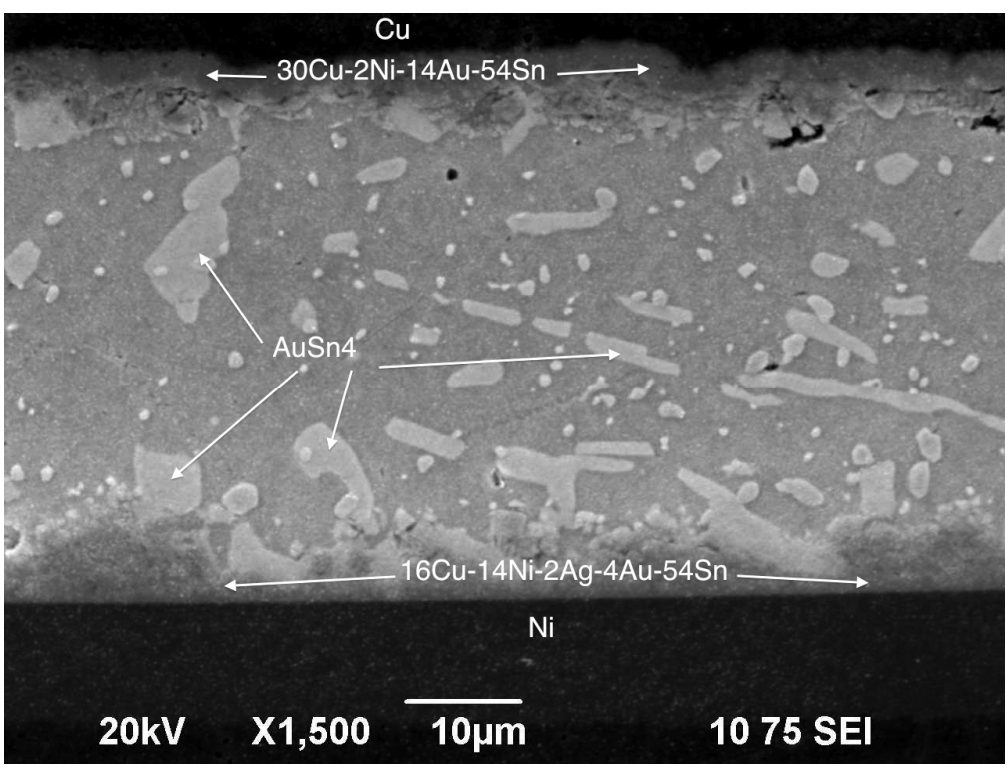

Figure 21 - 56 day aged QFN joint on Thick Au board (5.6 wt\% Au) 


\subsubsection{TOPS}

The TOPS joints were expected to have a larger volume fraction of IMCs based on the higher joint gold contents of $1.7-2.9$ wt\% on the flash Au boards and $3.6-8.1$ wt\% on the thick Au boards.

\section{0 days aged boards}

In the TOPS samples, on the Flash Au boards, the joints on the boards that were aged for 0 days had $\mathrm{AuSn}_{4}$ stones and Ag-Sn pebbles in the bulk and a $\left(\mathrm{Cu}_{1-\mathrm{p}-q} \mathrm{Au}_{\mathrm{p}} \mathrm{Ni}_{\mathrm{q}}\right)_{6} \mathrm{Sn}_{5}$ had already formed at both the board and component side interfaces with the bulk solder, although with

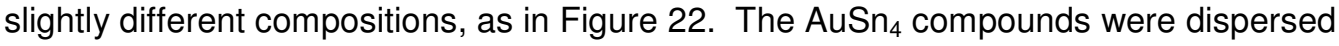
throughout the joint and had long thin geometries. The Ag-Sn pebbles were fine particles distributed between the $\mathrm{AuSn}_{4}$ stones in lines.

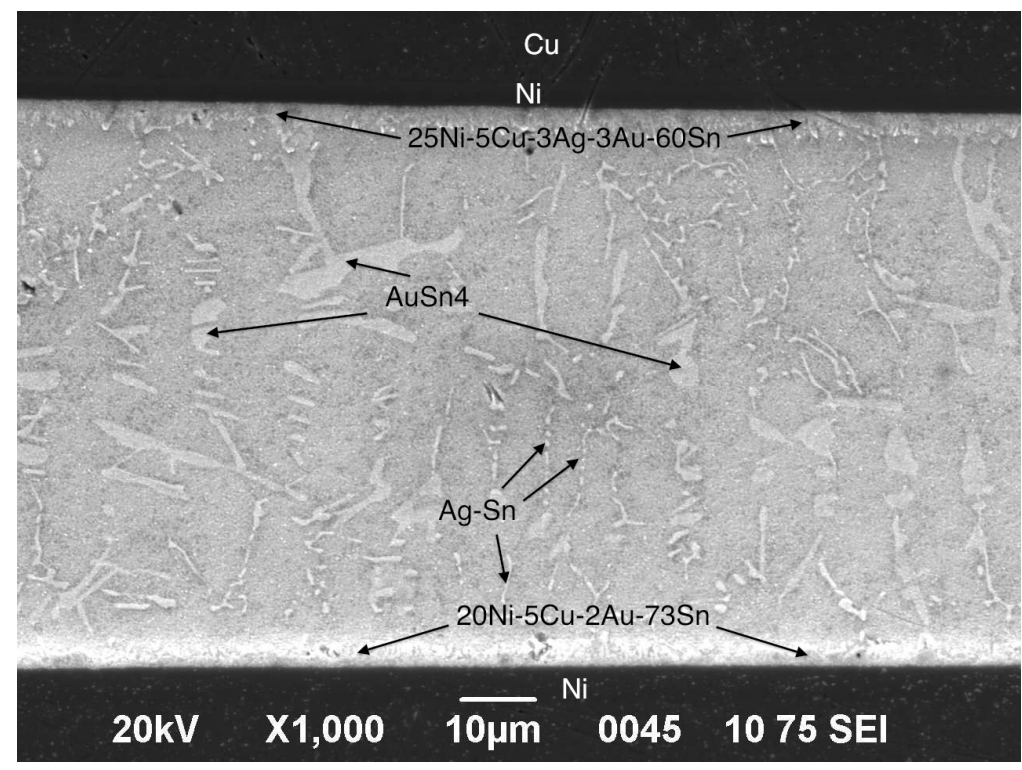

Figure 22 - 0 days aged TOPS on a flash Au board (3.0 wt \% Au)

The joints on the thick gold boards also had $\mathrm{AuSn}_{4}$ in the bulk with similarly long, thin or pillar-like morphologies. Lots of voids were visible in these joints which were later related to reliability issues in addition to gold. Figure 23 show an example of a typical TOPS thick Au joint with voids and thin $\mathrm{AuSn}_{4}$ pillars. 


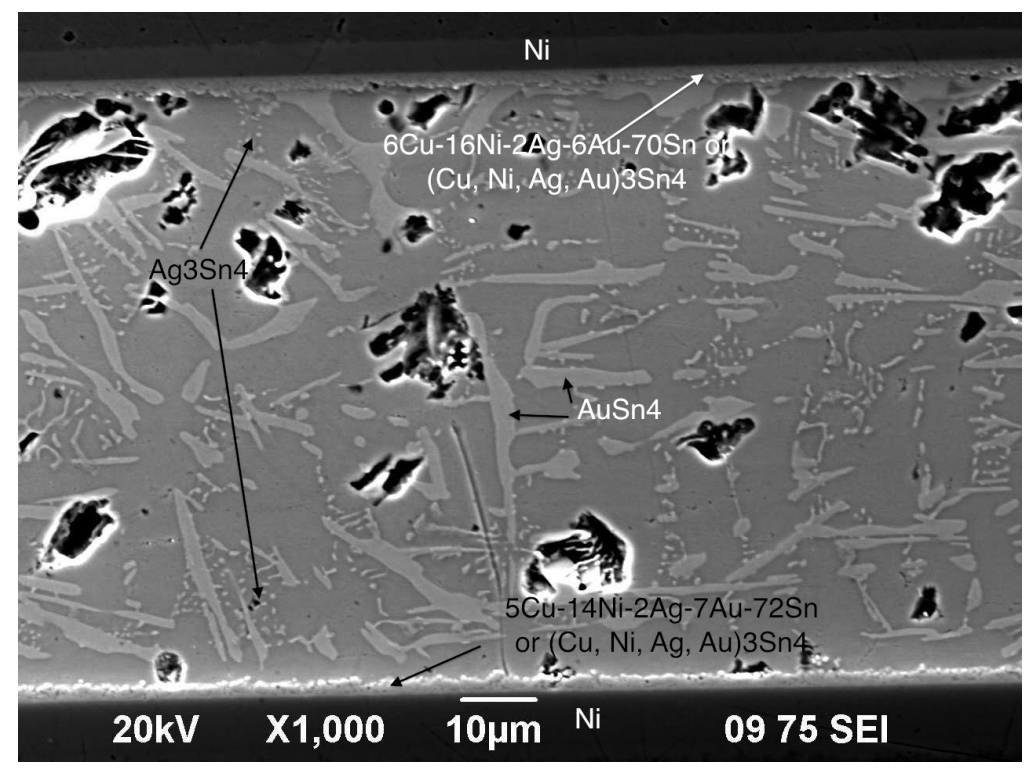

Figure 23 - TOPS on Thick Au board with lots of voids (8.0 wt\% Au)

\section{0 days aged boards}

This joints of a 30 day aged TOPS package on a flash Au board has $\left(\mathrm{Au}_{1-\mathrm{x}} \mathrm{Ni}_{\mathrm{x}}\right) \mathrm{Sn}_{4}$ in the bulk and as interfacial layers on top of $\left(\mathrm{Cu}_{1-\mathrm{p}-q} \mathrm{Au}_{\mathrm{p}} \mathrm{Ni}_{q}\right)_{6} \mathrm{Sn}_{5}$ interfacial layers which have absorbed some silver that sit on the Ni layers on both sides of the joint, as in Figure 24.

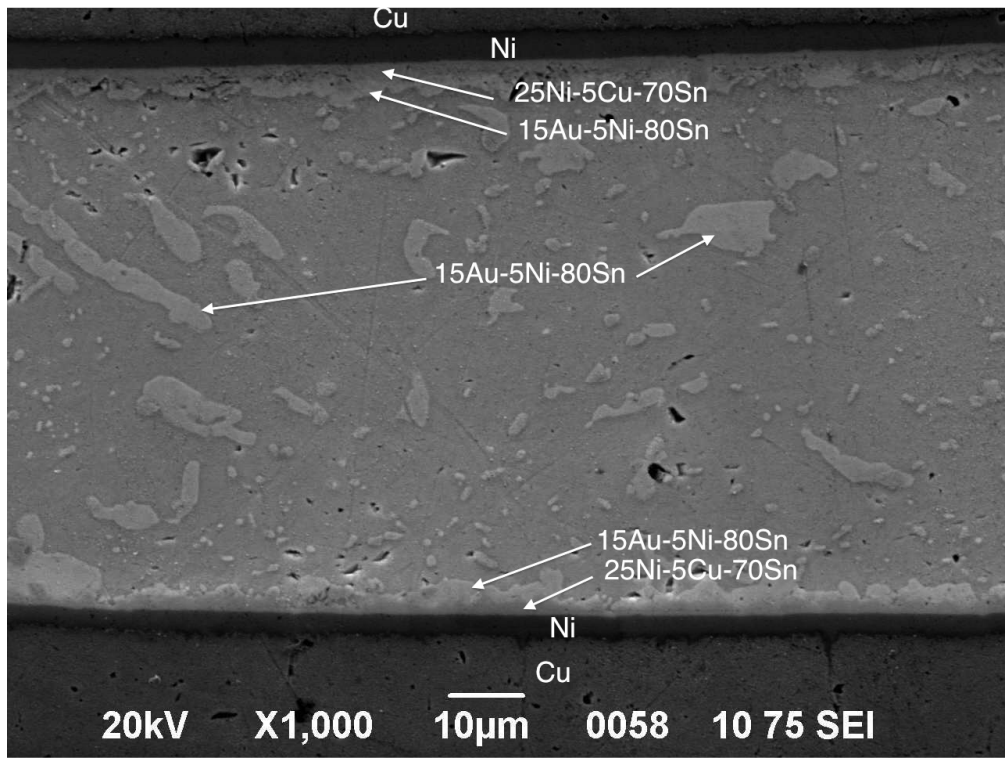

Figure 24 - This joint of a 30 day aged TOPS package on a flash Au board has $\left(\mathrm{Au}_{1-x} \mathrm{Ni}_{\times}\right) \mathrm{Sn}_{4}$ in the bulk and as interfacial layers on top of $(\mathrm{Ni}, \mathrm{Cu}) \mathrm{Sn}$ interfacial layers that sit on the Ni layers on both sides of the joint $(2.4 \mathrm{wt} \% \mathrm{Au})$ 
In the joints of 30 day aged TOPS packages on thick gold boards, $\left(\mathrm{Au}_{1-x} \mathrm{Ni}_{\mathrm{x}}\right) \mathrm{Sn}_{4}$ boulders and pillars can be seen in the bulk of the solder and as interfacial layers along the board and component side interfaces, as in Figure 25.

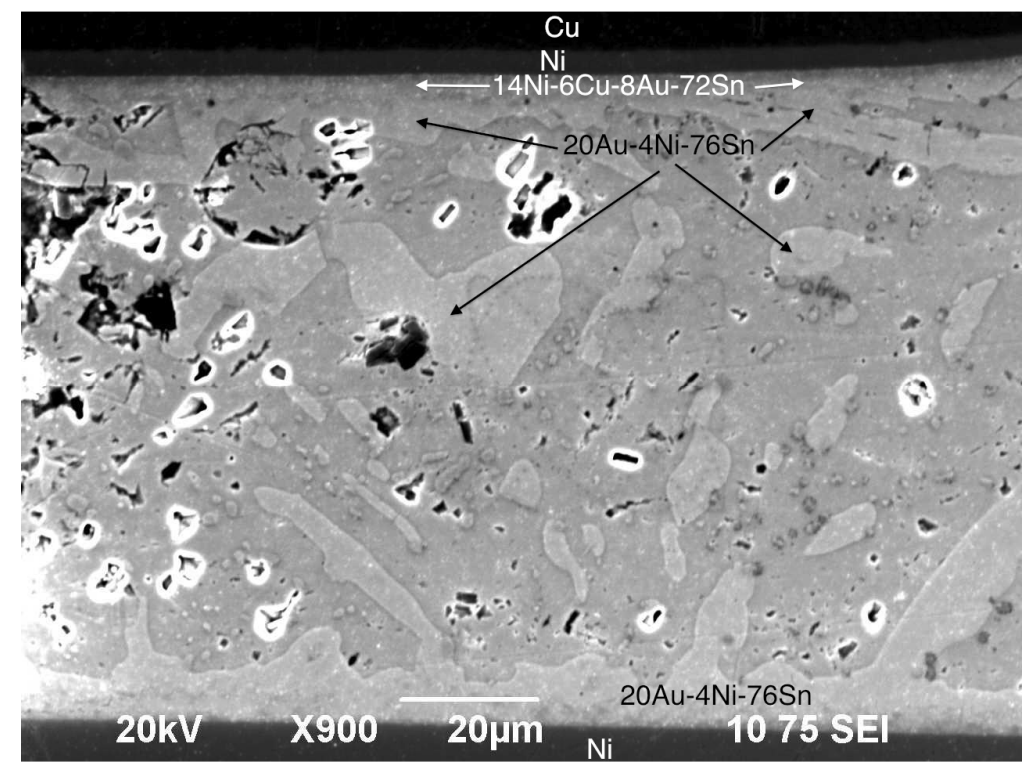

Figure $25-\left(\mathrm{Au}_{1-\mathrm{x}} \mathrm{Ni}_{x}\right) \mathrm{Sn}_{4}$ can be seen in the bulk and as interfacial layers in the joints of 30 day aged TOPS packages on thick Au boards $(7.1 \mathrm{wt} \% \mathrm{Au})$

\section{6 day aged boards}

The joint in figure 15 shows the $\left(\mathrm{Au}_{1-x} \mathrm{Ni}_{x}\right) \mathrm{Sn}_{4} \mathrm{IMC}$ layers that appear to have migrated to the component and boardside interfaces from the bulk solder. Some of the $\left(\mathrm{Au}_{1-\mathrm{x}} \mathrm{Ni}_{\mathrm{x}}\right) \mathrm{Sn}_{4}$ remains in the bulk, as in Figure 26. The $\left(\mathrm{Cu}_{1-x} \mathrm{Ni}_{x}\right)_{6} \mathrm{Sn}_{5}$ layers are still between the $\left(\mathrm{Au}_{1-x} \mathrm{Ni}_{\mathrm{x}}\right) \mathrm{Sn}_{4}$ and $\mathrm{Ni}$ layer on both sides of the joint. 


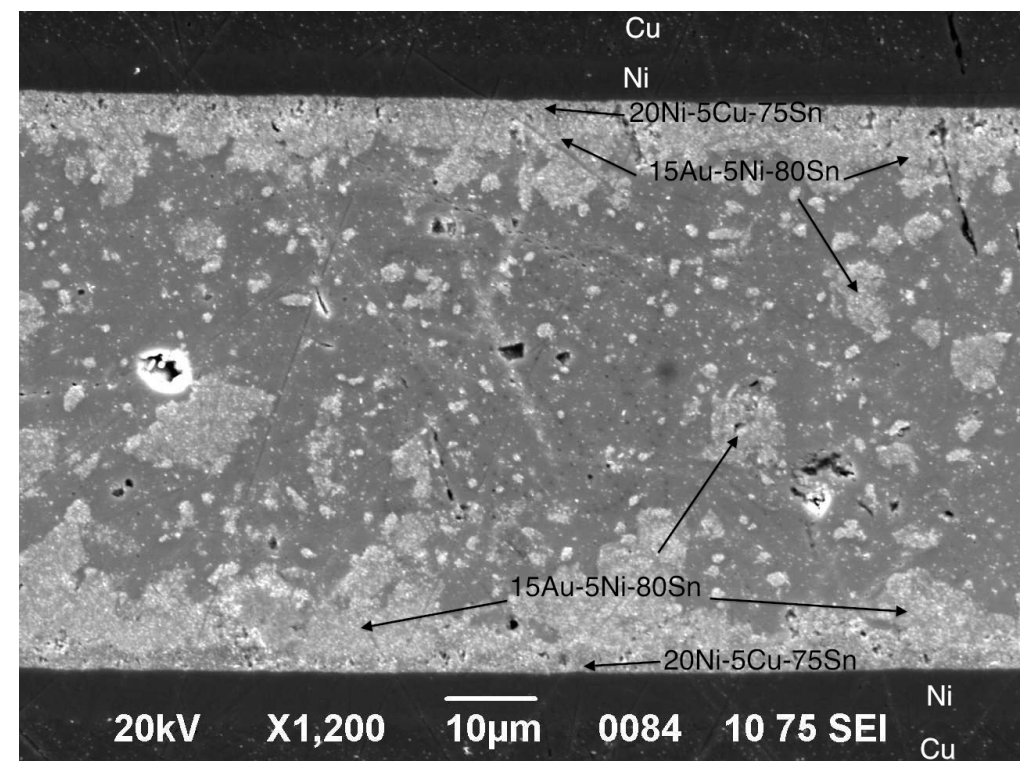

Figure 26 - The $\left(\mathrm{Au}_{1-x} \mathrm{Ni}_{\mathrm{x}}\right) \mathrm{Sn}_{4}$ IMC sits mostly along the interfacesin this joint from a TOPS package on a flash $\mathrm{Au}$ board aged for 56 days (2.5 wt\% Au)

$\left(\mathrm{Au}_{1-x} \mathrm{Ni}_{\mathrm{x}}\right) \mathrm{Sn}_{4}$ boulders and pillars can be seen in the bulk and along the interfaces of this joint in a TOPS package on a thick Au board that was aged for 56 days, as in Figure 27. It appears that there is a larger volume fraction of gold IMCs in the joint on the thick Au boards, as opposed to the flash Au boards, which corresponds to the higher joint gold content seen on the thick boards $6.5 \mathrm{wt} \%$ Au versus $2.5 \mathrm{wt} \% \mathrm{Au}$.

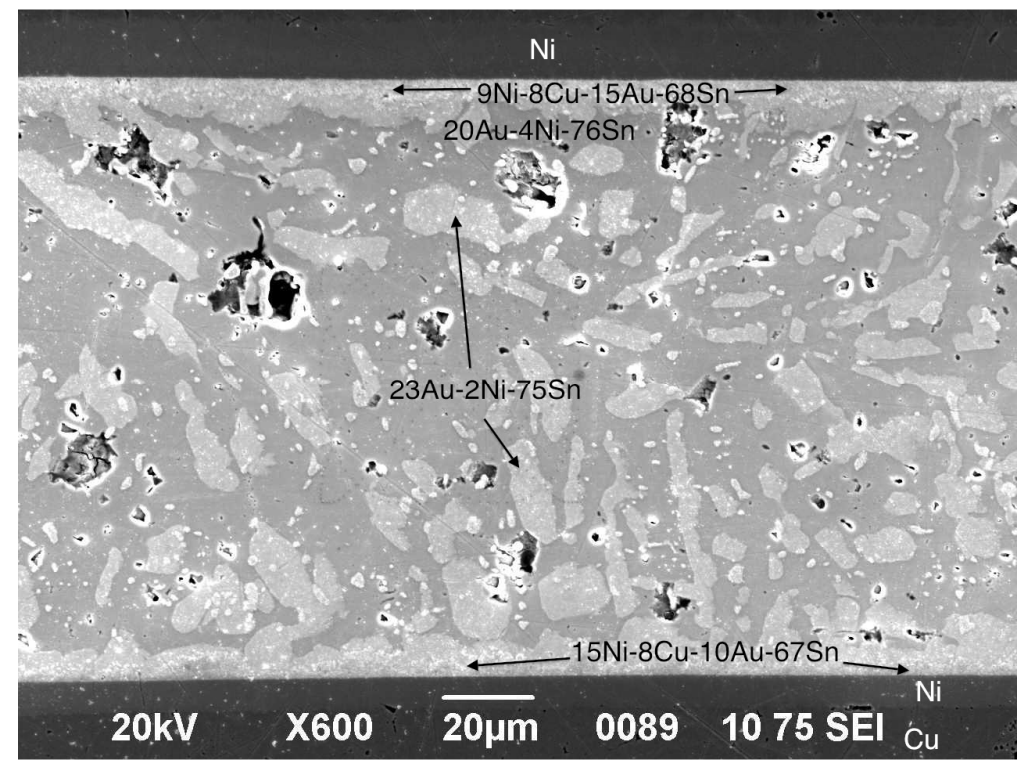

Figure 27 - $\left(\mathrm{Au}_{1-x} \mathrm{Ni}_{x}\right) \mathrm{Sn}_{4}$ boulders and pillars can be seen in the bulk and along the interfaces of this joint in a TOPS package on a thick board that was aged for 56 days $(6.5 \mathrm{wt} \% \mathrm{Au})$ 
The solder joints on the FP samples were expected to contain high volume fractions of gold IMCs because the joint gold content were $7.6-15.3 \mathrm{wt} \%$ on the flash Au board and $9.5-$ $19.5 \mathrm{wt} \%$ on the thick Au board. The cross-sections that were examined confirmed this expectation and showed that joints were almost entirely consumed by $A u S n_{4}$ and $\left(\mathrm{Au}_{1-\mathrm{x}} \mathrm{Ni}_{\mathrm{x}}\right) \mathrm{Sn}_{4}$ intermetallics with low $\mathrm{Ni}$ contents ( 1-10 wt\% Ni).

\section{0 days aged boards}

The solder joints on the Flash Au boards that were aged for 0 days were almost entirely filled with $\mathrm{AuSn}_{4}$ pillars. Some solder remained but constituted a minority of the joint, as Figure 28 shows.

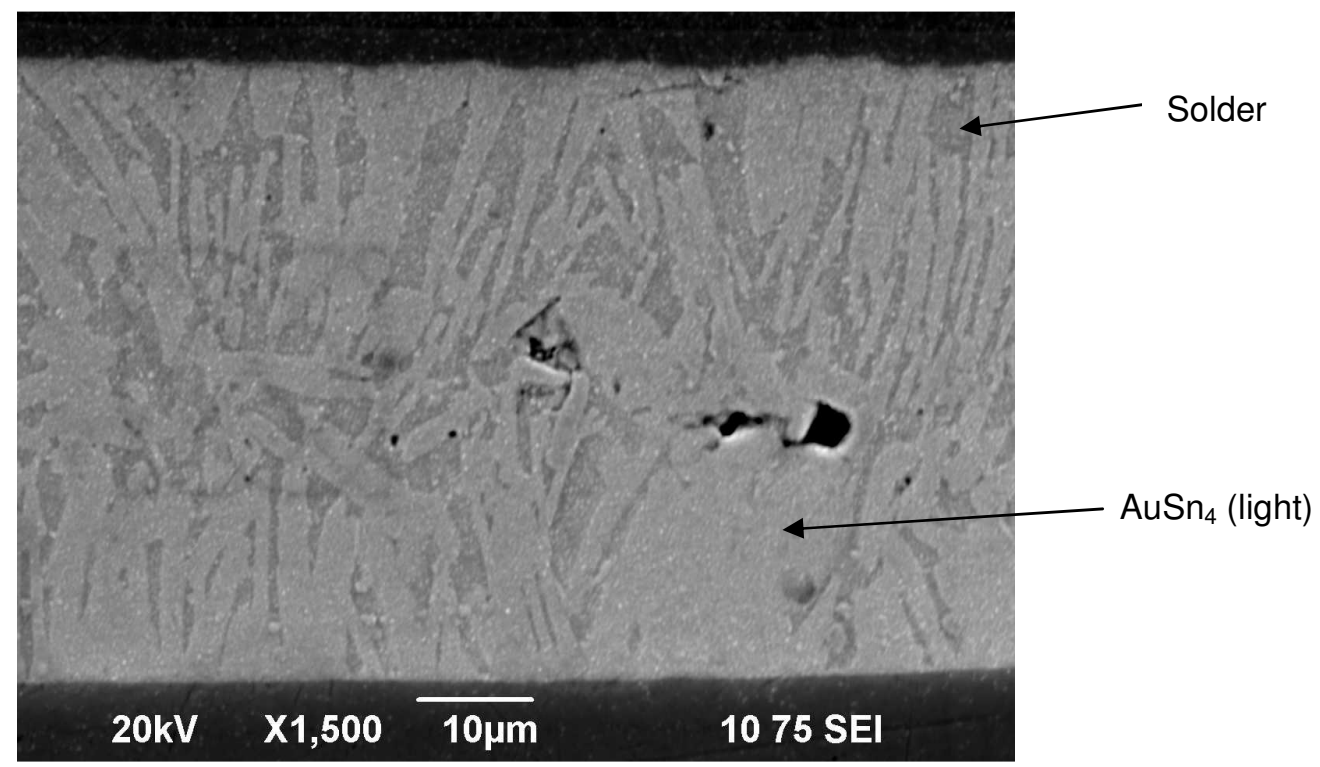

Figure 28 - Joint from an FP package on a flash Au board consumed in the as-built condition with Au IMCs (15.9 wt\% Au)

In unaged FPI packages, on thick gold boards, the joints had fractured and all the remaining parts of the solder joint were filled with $\mathrm{AuSn}_{4}$. The microstructure in Figure 29Figure 34 and Figure 30 is almost identical to that seen in fractured FP joints from 0 days and 30 days aged samples. 
The solder joints on the Thick Au boards that were aged for 0 days were also almost entirely filled with $\mathrm{AuSn}_{4}$ pillars, just as the joints on the flash gold boards were. Unlike the flash Au board joints, however, the joints on the thick Au boards had cracks in the 0-day (as-built) condition, as can be seen across the center of Figure 29. This explained why some of these components had broken off the boards even before board sectioning began. This clearly indicates reliability problems.

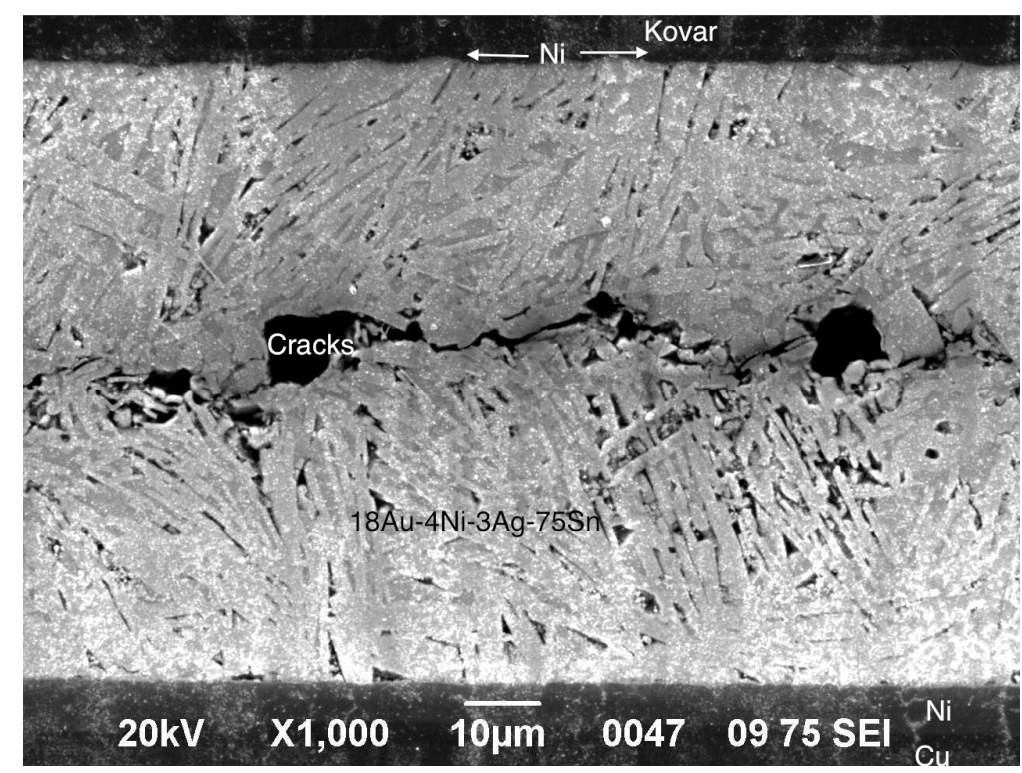

Figure 29 - FPI joint on thick Au board with crack initiated along center (14.4 wt\% Au)

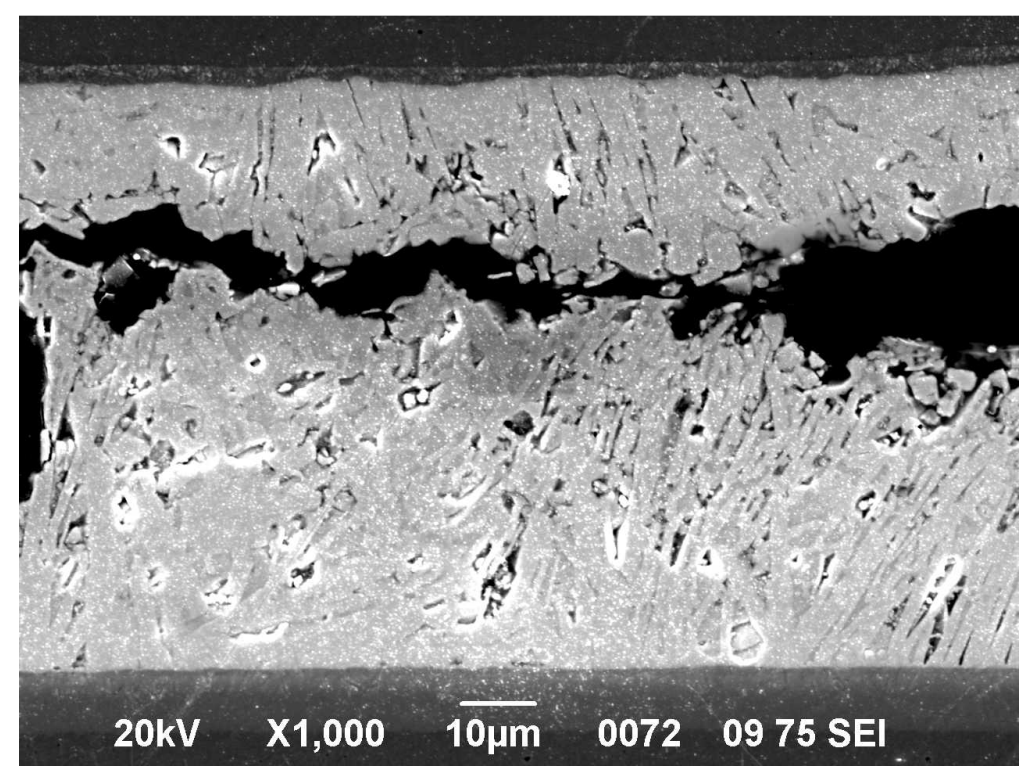

Figure 30 - FPII with large crack (14.4 wt\% Au) 
In the joints of FPI packages on flash Au boards, many $(\mathrm{Au}, \mathrm{Ni}) \mathrm{Sn}_{4}$ pillars are visible throughout the bulk and along both the component and board interfaces with the solder, as in Figure 31 and Figure 32.

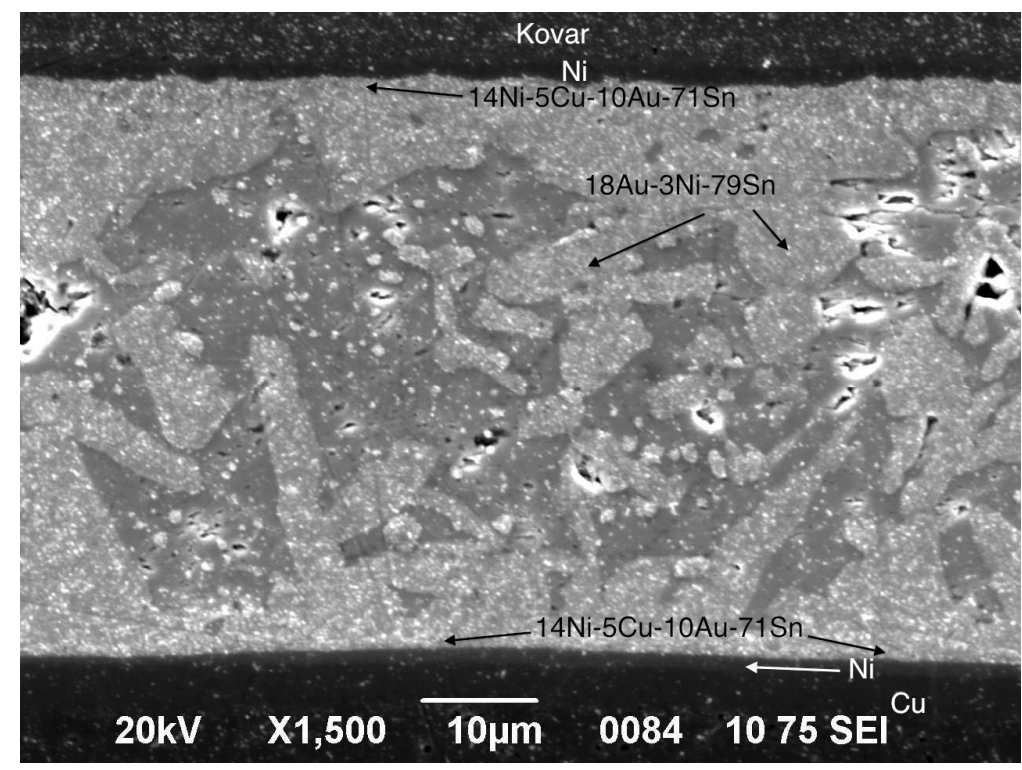

Figure 31 - Joint of 30 days aged FPI package on a flash Au board; many $\left(\mathrm{Au}_{1-x} \mathrm{Ni}_{x}\right) \mathrm{Sn}_{4}$ pillars visible (13.1 $\mathrm{wt} \% \mathrm{Au}$ )

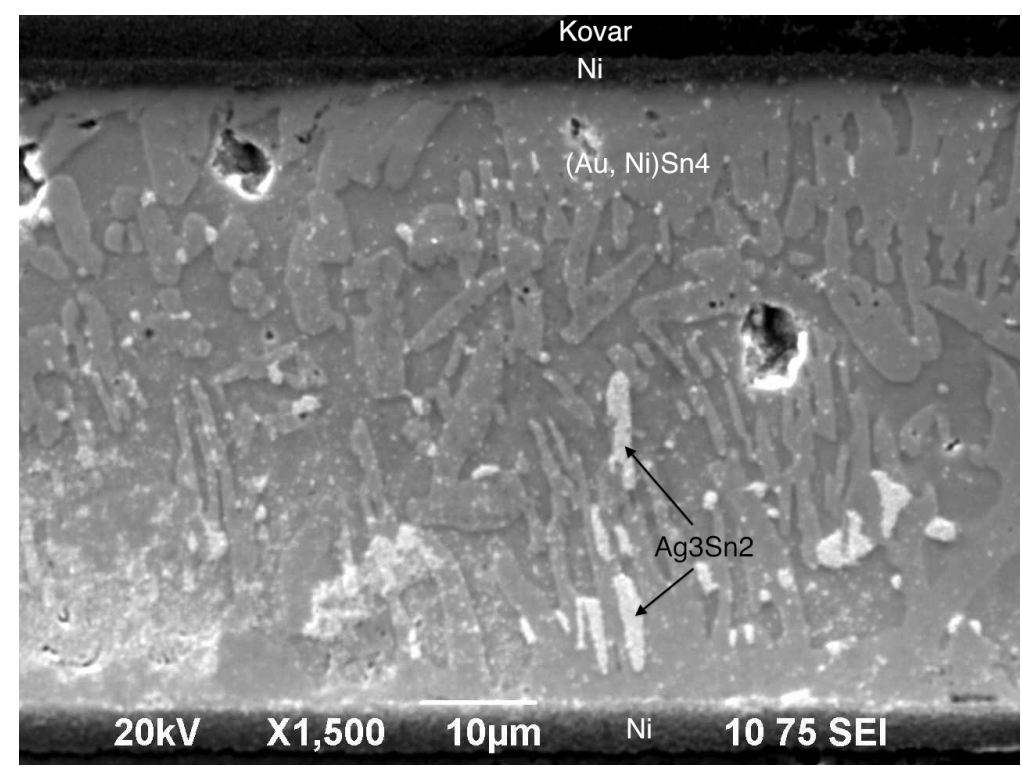

Figure $32-\left(\mathrm{Au}_{1-x} \mathrm{Ni}_{x}\right) \mathrm{Sn}_{4}$ pillars are distinctly visible in this joint, as are the $\mathrm{Ni}$ and Kovar layers on the lead and the Ag3Sn in the bulk of the solder (11.3 wt\% Au) 
In the joints of FP packages on thick Au boards that were aged for 30 days, $\left(\mathrm{Au}_{-\mathrm{x}} \mathrm{Ni}_{\mathrm{x}}\right) \mathrm{Sn}_{4}$ fills almost all of the joint, as in all other FP joints, as in Figure 33. The large space visible in Figure 33 may be a void that formed during the reflow process and not a crack.

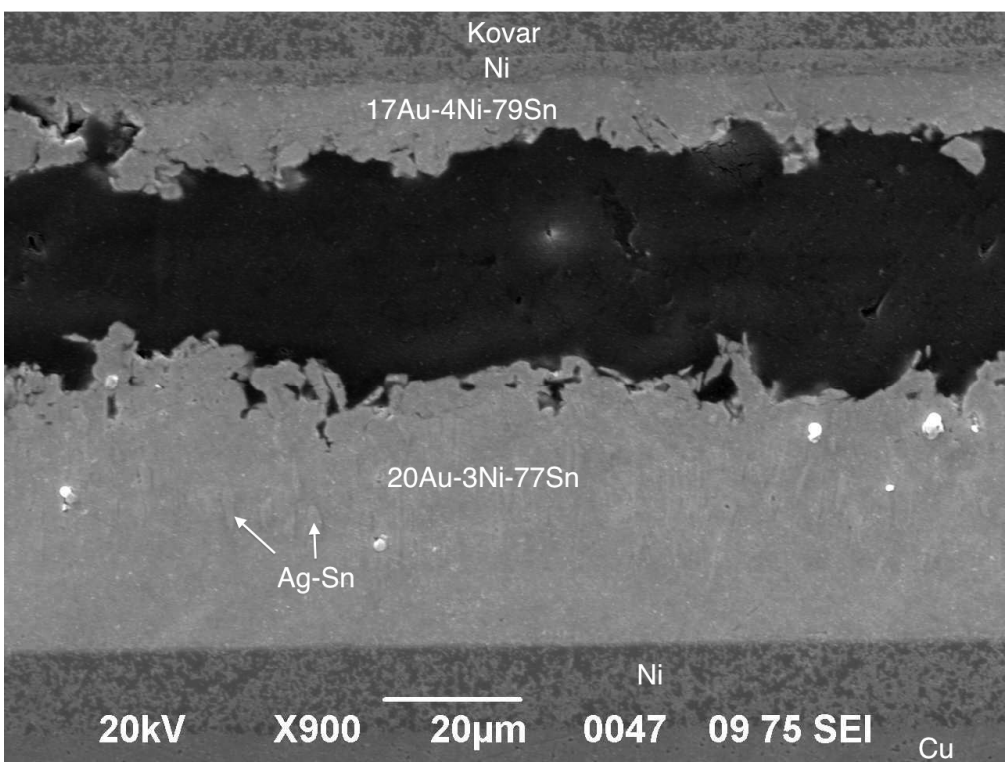

Figure 33 - A large space passes through this joint on a 30 day aged FP package on a thick Au board; $\left(\mathrm{Au}_{1-\mathrm{x}} \mathrm{Ni}_{\mathrm{x}}\right) \mathrm{Sn}_{4}$ consumes almost all of the bulk solder $(15.8 \mathrm{wt} \% \mathrm{Au})$

\section{6 days aged boards}

Many components in this group, on thick Au and flash Au boards, broke off from the boards before they were received or during handling and light loading in sample preparation. The few samples that were cross-sectioned from these groups had to be mounted and polished as two separate samples: component and matching board section. Intuitively, these components had reliability issues since they were literally falling off the boards. The joints that were crosssectioned and analyzed were almost completely consumed with $\left(\mathrm{Au}_{1-\mathrm{x}} \mathrm{Ni}_{\mathrm{x}}\right) \mathrm{Sn}_{4}$ as demonstrated by Figure 34 and Figure 35. This matches with the understanding that joints that contain Au-Sn IMCs and thick IMCs will have poor reliability. 


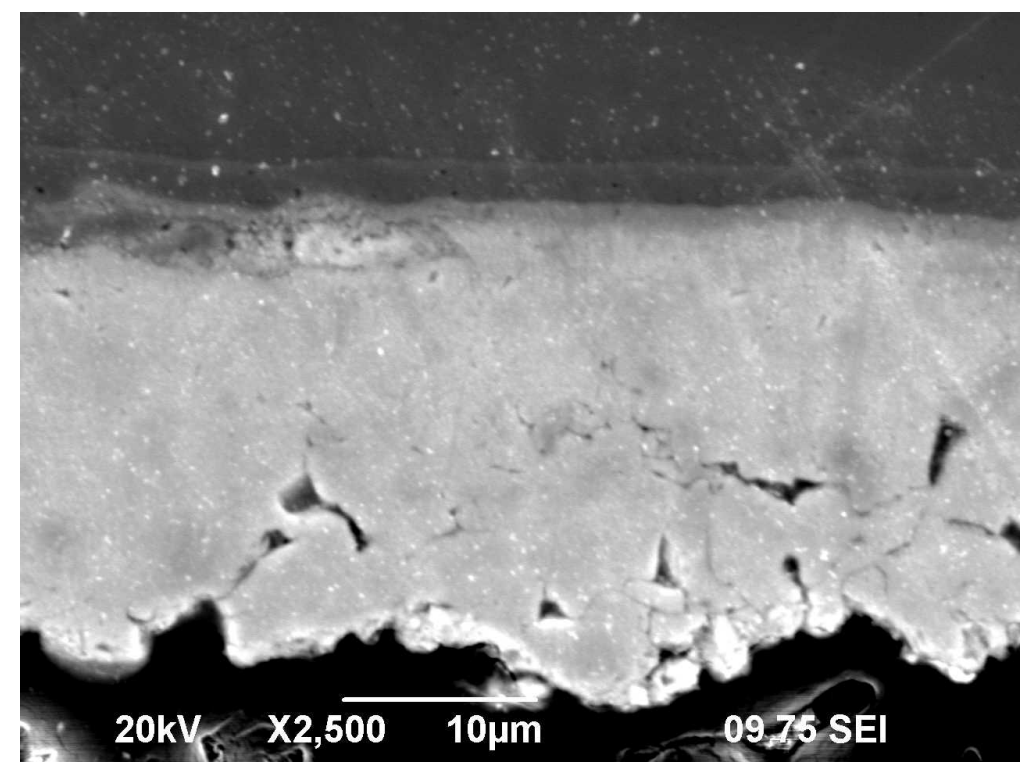

Figure 34 - Component side half of fractured joint from an FP package on a thick Au board after 56 days of aging; most of solder consumed by $\left(\mathrm{Au}_{1-\mathrm{x}} \mathrm{Ni}_{\mathrm{x}}\right) \mathrm{Sn}_{4}(\sim 15 \mathrm{wt} \% \mathrm{Au})$

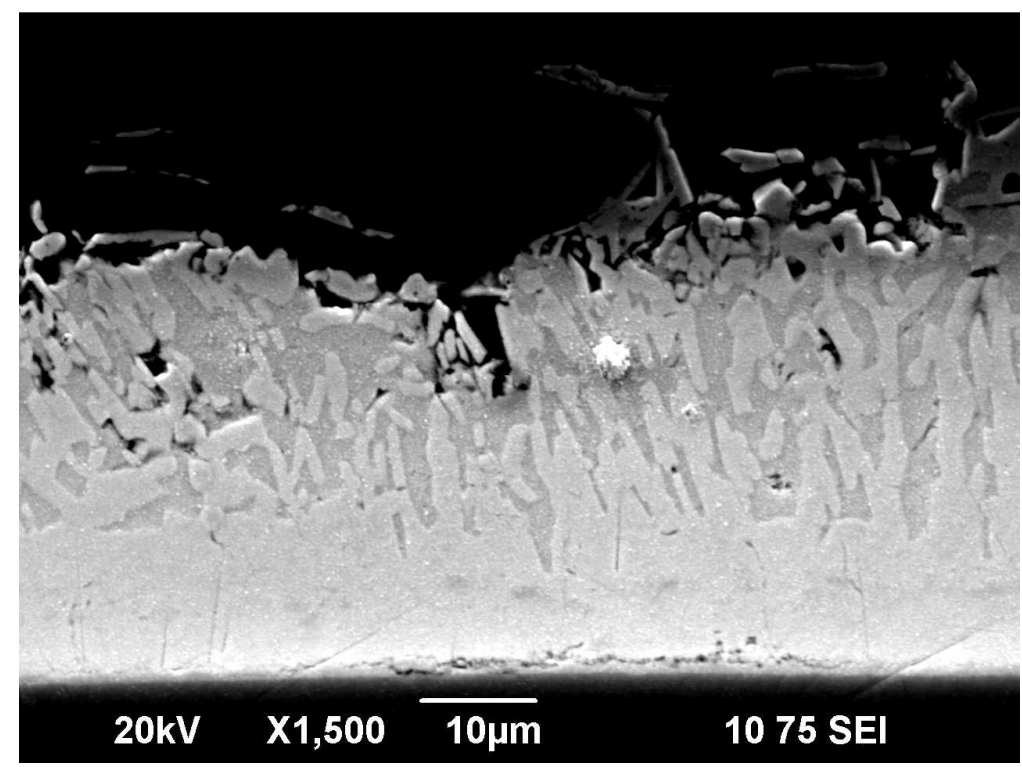

Figure 35 - Board side half of a fractured joint from an FP package on a thick Au board after 56 days of aging; most of the solder is taken up by $\left(\mathrm{Au}_{1-\mathrm{x}} \mathrm{Ni}_{\mathrm{x}}\right) \mathrm{Sn}_{4}(\sim 15 \mathrm{wt} \% \mathrm{Au})$ 


\subsection{Reliability Testing}

\subsubsection{QFN}

A few cracks were observed in QFN samples on flash Au boards that had initiated at the corner of the joints.

Crack initiation

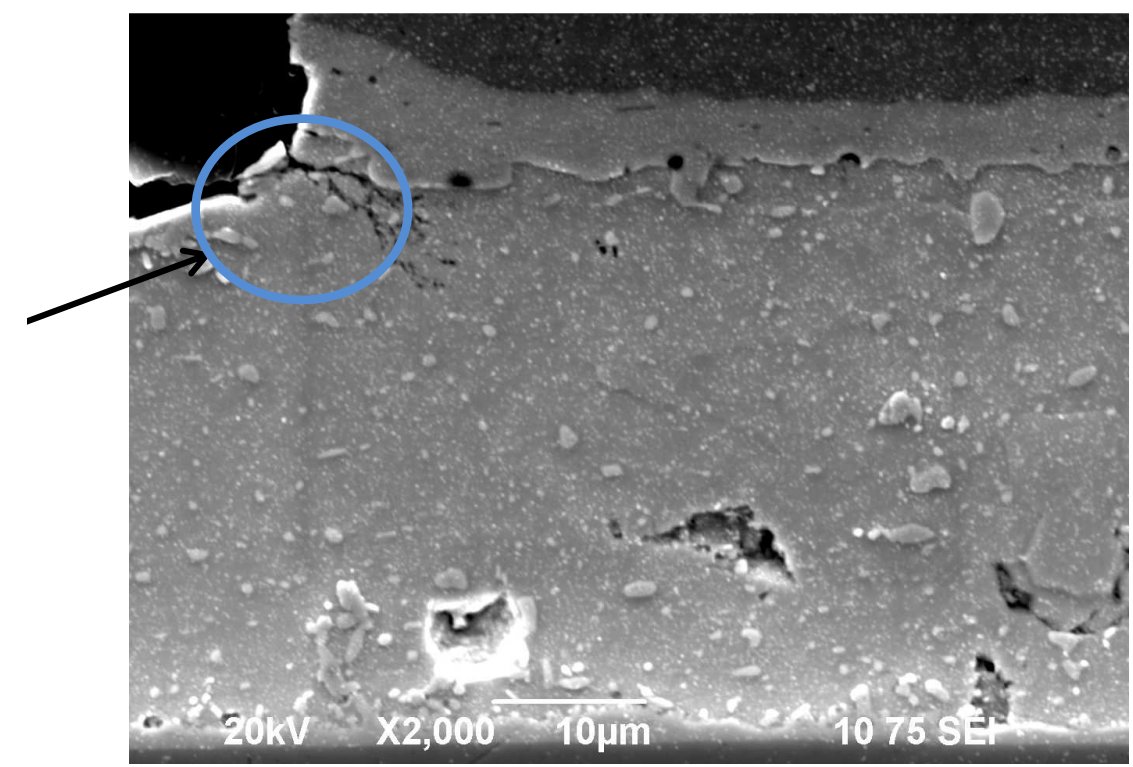

Figure 36 - Crack initiated in corner of QFN joint on 30 days aged flash Au board

On the flash and thick Au boards, most or all of two particular QFN packages that sit in two of the outermost corners of the board had cracks or failed. As very few of the other QFNs had such high failure rates, it is believed that the joints cracked from excessively high strain. This high strain was caused during the vibration and drop tests at the corners of the board, where the mounting holes are. 


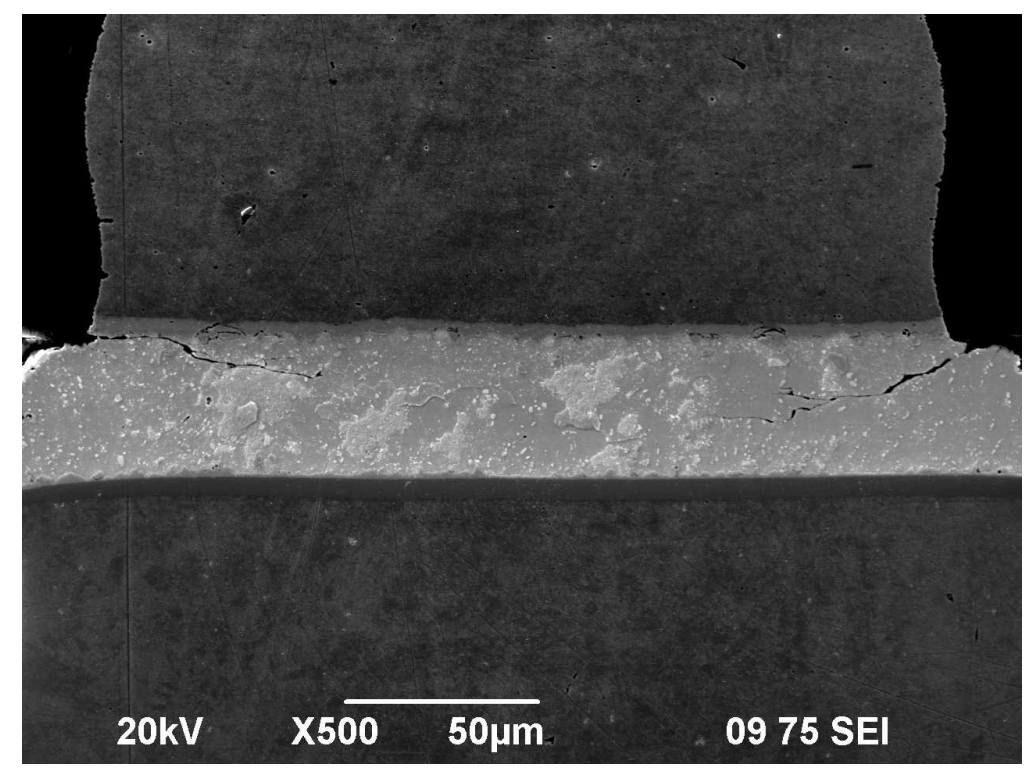

Figure 37 - Cracks initiating at high stress points and propagating into joint on 56 day aged QFN on flash Au board

\subsubsection{TOPS}

The images of joints from the TOPS packages (Figure 38, Figure 39, and Figure 40) clearly show cracks in and along intermetallic particles and layers.

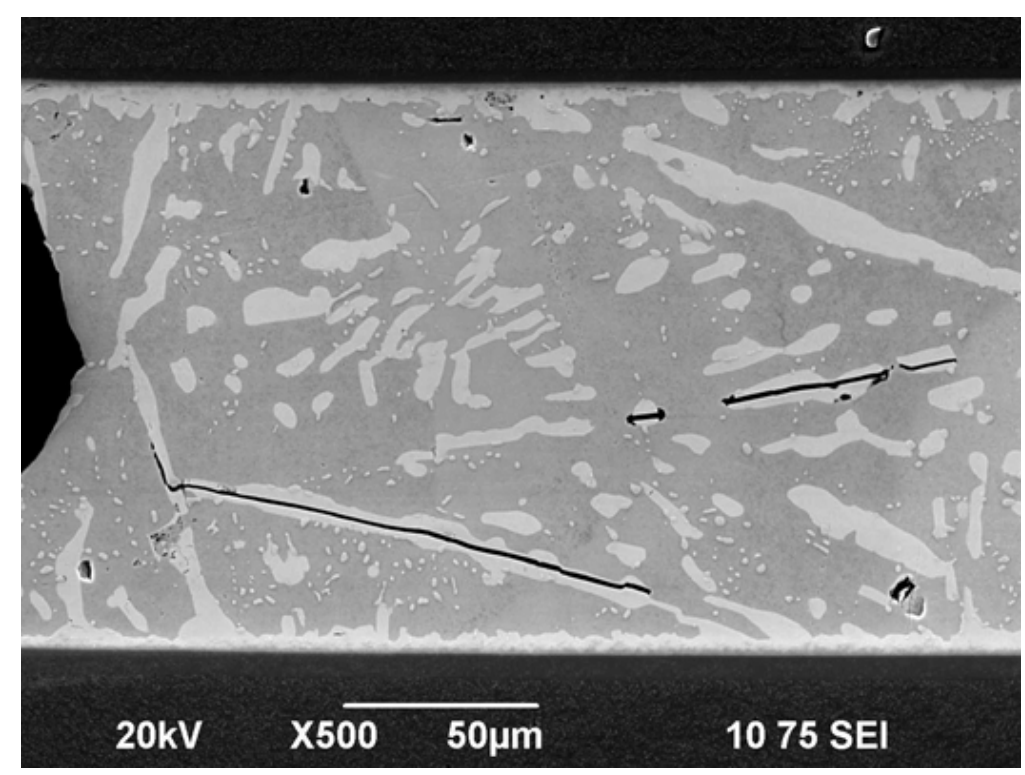

Figure 38 - Cracks along IMCs in a joint from a 30 days aged TOPS package on a thick Au board 


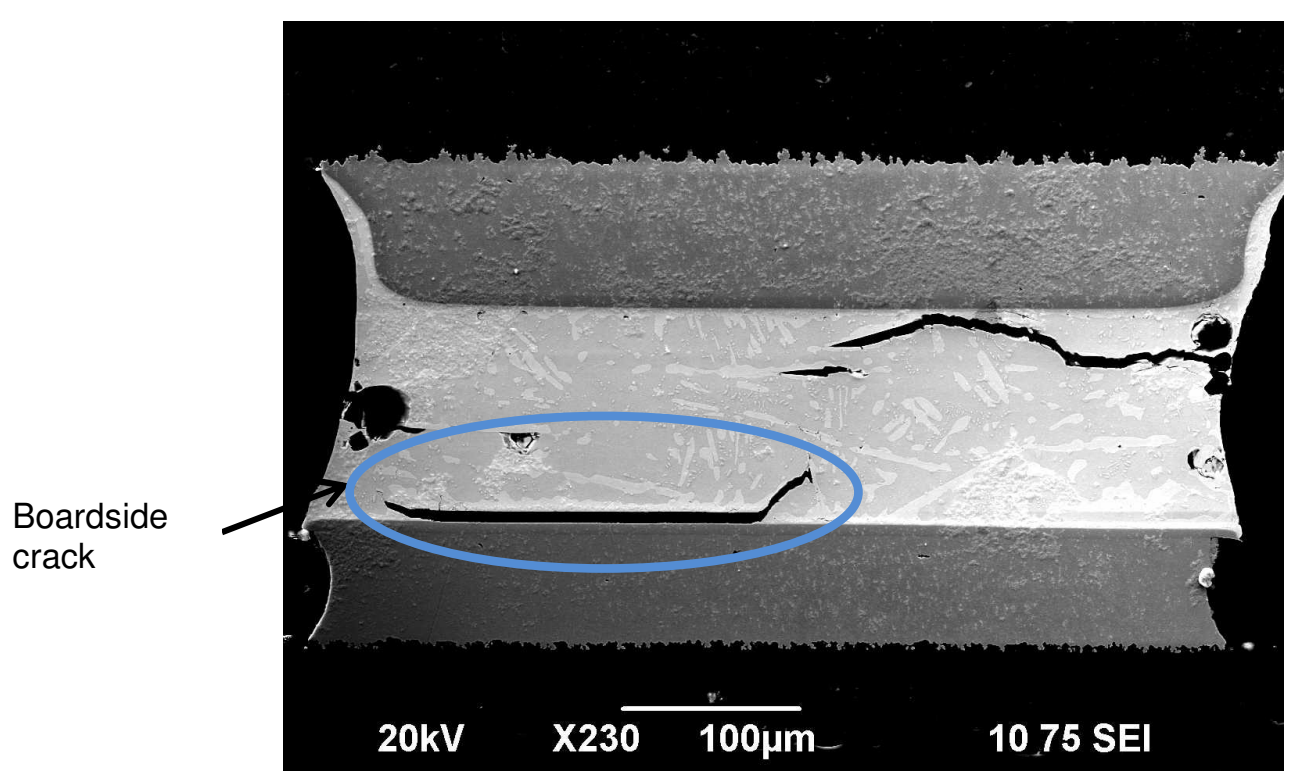

Figure 39 - Crack traveling along the board side interfacial IMC and bulk IMC particles in this 30 day aged TOPS joint

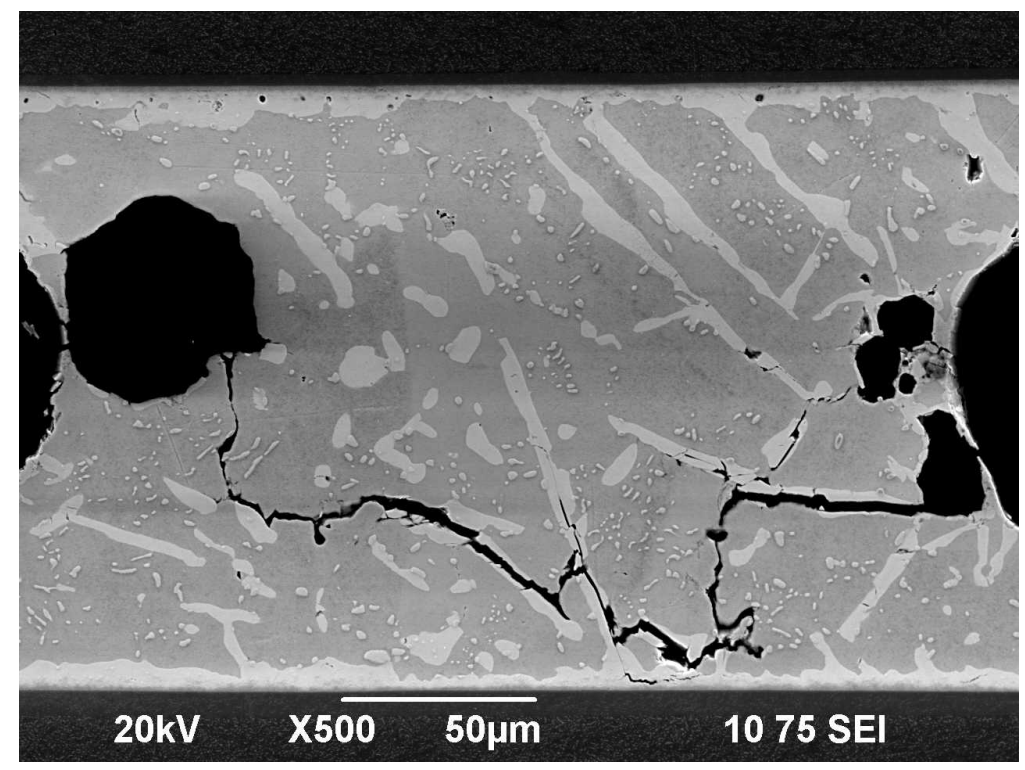

Figure 40 - Cracks travel from IMCs across the bulk to voids in this joint from a 30 day aged TOPS on a thick Au board 

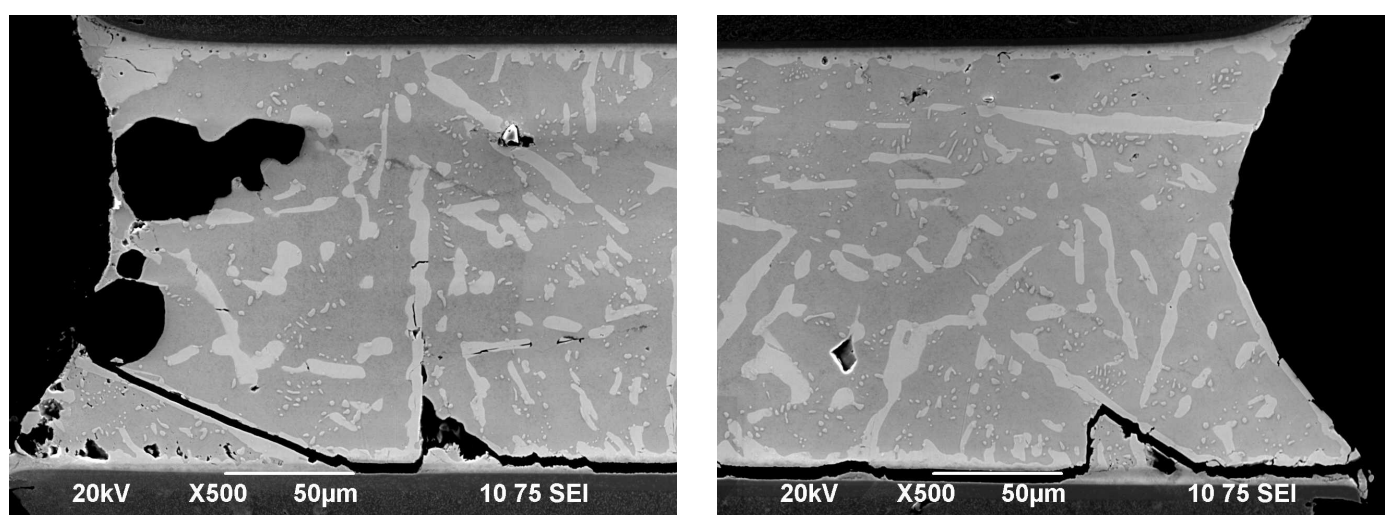

Figure 41 - Images of a joint that had a crack propagate along most of the length of the board side interface in a 30 days aged TOPS sample

\subsubsection{FP}

There are no images of FP samples that underwent reliability tests because such a vast majority of the packages fractured and completely separated from the flash and thick boards, indicating that their microstructure, as seen in the samples that only underwent isothermal aging, has serious reliability problems. 


\subsection{Microstructure Summary}

Table IV summarizes the IMC phases detected in the various treatment groups. Our results indicate that cracks can form both along the interfaces of $\mathrm{AuSn}_{4}$ with other intermetallics and within, along, and near $\mathrm{AuSn}_{4}$ pillar shaped IMCs that form in bulk solder. $\mathrm{AuSn}_{4}$ tends to form in 'pillar' shaped IMCs which are usually $\sim 5 \mu \mathrm{m}$ wide by $20 \sim 50 \mu \mathrm{m}$ long.

Table IV - Summary of IMC microstructure and reliability data

\begin{tabular}{|c|c|c|c|c|c|c|}
\hline \multirow{2}{*}{\multicolumn{3}{|c|}{ Component/Package }} & \multicolumn{3}{|c|}{ Length of Isothermal Aging at $125^{\circ} \mathrm{C}$} & \multirow[b]{2}{*}{ Failure Rate } \\
\hline & & & 0 days & 30 days & 56 days & \\
\hline \multirow{6}{*}{ QFN } & \multirow{3}{*}{$\begin{array}{l}\text { Flash } \\
\mathrm{Au}\end{array}$} & $\begin{array}{l}\text { Comp } \\
\text { side }\end{array}$ & $\begin{array}{c}\left(\mathrm{Cu}_{\mathrm{x}} \mathrm{Au}_{1-\mathrm{x}}\right)_{6} \mathrm{Sn}_{5} \\
\text { thin }\end{array}$ & $\left(\mathrm{Cu}_{\mathrm{x}} \mathrm{Au}_{1-\mathrm{x}}\right)_{6} \mathrm{Sn}_{5}$ & $\begin{array}{c}\left(\mathrm{Cu}_{\mathrm{x}} \mathrm{Au}_{1-\mathrm{x}}\right)_{6} \mathrm{Sn}_{5} \\
\text { thick }\end{array}$ & \multirow{3}{*}{$\begin{array}{c}\text { great } \\
17 / 162 \\
\text { (overstress } \\
\text { failures) }\end{array}$} \\
\hline & & Bulk & AgSn & AgSn & AgSn & \\
\hline & & $\begin{array}{l}\text { Board } \\
\text { side }\end{array}$ & $\left(\mathrm{Cu}_{1-p-q} \mathrm{Au}_{p} \mathrm{Ni}_{\mathrm{q}}\right)_{6} \mathrm{Sn}_{5}$ & $\left(\mathrm{Cu}_{1-p-q} \mathrm{Au}_{p} \mathrm{Ni}_{\mathrm{q}}\right)_{6} \mathrm{Sn}_{5}$ & $\left(\mathrm{Cu}_{1-p-q} \mathrm{Au}_{p} \mathrm{Ni}_{\mathrm{q}}\right)_{6} \mathrm{Sn}_{5}$ & \\
\hline & \multirow{3}{*}{$\begin{array}{c}\text { Thick } \\
\mathrm{Au}\end{array}$} & $\begin{array}{l}\text { Comp } \\
\text { side }\end{array}$ & $\left(\mathrm{Cu}_{\mathrm{x}} \mathrm{Au}_{1-\mathrm{x}}\right)_{6} \mathrm{Sn}_{5}$ & $\left(\mathrm{Cu}_{x} \mathrm{Au}_{1-x}\right)_{6} \mathrm{Sn}_{5}$ & $\begin{array}{c}\left(\mathrm{Cu}_{1-p-q} \mathrm{Au}_{\mathrm{p}} \mathrm{Ni}_{q}\right)_{6} \mathrm{Sn}_{5} \\
\mathrm{Cu} \text { rich, thick } \\
\end{array}$ & \multirow{3}{*}{$\begin{array}{c}\text { great } \\
17 / 162 \\
\text { (overstress) }\end{array}$} \\
\hline & & Bulk & $\mathrm{AuSn}_{4}, \mathrm{AgSn}$ & $\mathrm{AuSn}_{4}, \mathrm{AgSn}$ & $\mathrm{AuSn}_{4}, \mathrm{AgSn}$ & \\
\hline & & $\begin{array}{c}\text { Board } \\
\text { side }\end{array}$ & $\left(\mathrm{Cu}_{1-p-q} \mathrm{Au}_{\mathrm{p}} \mathrm{Ni}_{\mathrm{q}}\right)_{6} \mathrm{Sn}_{5}$ & $\left(\mathrm{Cu}_{1-p-q} \mathrm{Au}_{\mathrm{p}} \mathrm{Ni}_{\mathrm{q}}\right)_{6} \mathrm{Sn}_{5}$ & $\begin{array}{c}\left(\mathrm{Cu}_{1-p-q} \mathrm{Au}_{\mathrm{p}} \mathrm{Ni}_{\mathrm{q}}\right)_{6} \mathrm{Sn}_{5} \\
\text { Ni rich, thick }\end{array}$ & \\
\hline \multirow{6}{*}{ TOPS } & \multirow{3}{*}{$\begin{array}{l}\text { Flash } \\
\mathrm{Au}\end{array}$} & $\begin{array}{l}\text { Comp } \\
\text { side }\end{array}$ & $\left(\mathrm{Cu}_{1-p-q} \mathrm{Au}_{\mathrm{p}} \mathrm{Ni}_{\mathrm{q}}\right)_{6} \mathrm{Sn}_{5}$ & $\begin{array}{l}\left(\mathrm{Ni}_{1-x} \mathrm{Cu}_{x}\right)_{3} \mathrm{Sn}_{4} \\
\left(\mathrm{Au}_{\mathrm{x}} \mathrm{Ni}_{1-\mathrm{x}}\right) \mathrm{Sn}_{4}\end{array}$ & $\begin{array}{l}\left(\mathrm{Ni}_{1-x} \mathrm{Cu}_{\mathrm{x}}\right)_{3} \mathrm{Sn}_{4} \\
\left(\mathrm{Au}_{\mathrm{x}} \mathrm{Ni}_{1-\mathrm{x}}\right) \mathrm{Sn}_{4}\end{array}$ & \multirow{3}{*}{$\begin{array}{l}\text { great } \\
2 / 144\end{array}$} \\
\hline & & Bulk & $\mathrm{AuSn}_{4}$ & $\left(\mathrm{Au}_{\mathrm{x}} \mathrm{Ni}_{1-\mathrm{x}}\right) \mathrm{Sn}_{4}$ & $\left(\mathrm{Au}_{\mathrm{x}} \mathrm{Ni}_{1-\mathrm{x}}\right) \mathrm{Sn}_{4}$ & \\
\hline & & $\begin{array}{l}\text { Board } \\
\text { side }\end{array}$ & $\left(\mathrm{Cu}_{1-p-q} \mathrm{Au}_{\mathrm{p}} \mathrm{Ni}_{\mathrm{q}}\right)_{6} \mathrm{Sn}_{5}$ & $\begin{array}{l}\left(\mathrm{Au}_{\mathrm{x}} \mathrm{Ni}_{1-\mathrm{x}}\right) \mathrm{Sn}_{4} \\
\left(\mathrm{Ni}_{1-\mathrm{x}} \mathrm{Cu}_{\mathrm{x}}\right)_{3} \mathrm{Sn}_{4}\end{array}$ & $\begin{array}{l}\left(\mathrm{Au}_{\mathrm{x}} \mathrm{Ni}_{1-\mathrm{x}}\right) \mathrm{Sn}_{4} \\
\left(\mathrm{Ni}_{1-\mathrm{x}} \mathrm{Cu}_{\mathrm{x}}\right)_{3} \mathrm{Sn}_{4}\end{array}$ & \\
\hline & \multirow{3}{*}{$\begin{array}{l}\text { Thick } \\
\text { Au }\end{array}$} & $\begin{array}{l}\text { Comp } \\
\text { side }\end{array}$ & $\left(\mathrm{Cu}_{1-\mathrm{p}-\mathrm{q}} \mathrm{Au}_{\mathrm{p}} \mathrm{Ni}_{\mathrm{q}}\right)_{6} \mathrm{Sn}_{5}$ & $\begin{array}{l}\left(\mathrm{Ni}_{1-\mathrm{x}} \mathrm{Cu}_{\mathrm{x}}\right)_{3} \mathrm{Sn}_{4} \\
\left(\mathrm{Au}_{\mathrm{x}} \mathrm{Ni}_{1-\mathrm{x}}\right) \mathrm{Sn}_{4}\end{array}$ & $\begin{array}{l}\left(\mathrm{Ni}_{1-\mathrm{x}} \mathrm{Cu}_{\mathrm{x}}\right)_{3} \mathrm{Sn}_{4} \\
\left(\mathrm{Au}_{\mathrm{x}} \mathrm{Ni}_{1-\mathrm{x}}\right) \mathrm{Sn}_{4}\end{array}$ & \multirow{3}{*}{$\begin{array}{l}\text { good } \\
9 / 162\end{array}$} \\
\hline & & Bulk & $\mathrm{AuSn}_{4}$ thin & $\left(\mathrm{Au}_{x} \mathrm{Ni}_{1-\mathrm{x}}\right) \mathrm{Sn}_{4}$ thick & $\left(\mathrm{Au}_{\mathrm{x}} \mathrm{Ni}_{1-\mathrm{x}}\right) \mathrm{Sn}_{4}$ thick & \\
\hline & & $\begin{array}{l}\text { Board } \\
\text { side }\end{array}$ & $\left(\mathrm{Cu}_{1-p-q} \mathrm{Au}_{p} \mathrm{Ni}_{\mathrm{q}}\right)_{6} \mathrm{Sn}_{5}$ & $\begin{array}{l}\left(\mathrm{Au}_{\mathrm{x}} \mathrm{Ni}_{1-\mathrm{x}}\right) \mathrm{Sn}_{4} \\
\left(\mathrm{Ni}_{1-\mathrm{x}} \mathrm{Cu}_{\mathrm{x}}\right)_{3} \mathrm{Sn}_{4}\end{array}$ & $\begin{array}{l}\left(\mathrm{Au}_{\mathrm{x}} \mathrm{Ni}_{1-\mathrm{x}}\right) \mathrm{Sn}_{4} \\
\left(\mathrm{Ni}_{1-\mathrm{x}} \mathrm{Cu}_{\mathrm{x}}\right)_{3} \mathrm{Sn}_{4}\end{array}$ & \\
\hline \multirow{6}{*}{ FP } & \multirow{3}{*}{$\begin{array}{c}\text { Flash } \\
\mathrm{Au}\end{array}$} & $\begin{array}{l}\text { Comp } \\
\text { side }\end{array}$ & $\left(\mathrm{Au}_{1-\mathrm{x}} \mathrm{Ni}_{\mathrm{x}}\right) \mathrm{Sn}_{4}$ & $\left(\mathrm{Au}_{\mathrm{x}} \mathrm{Ni}_{1-\mathrm{x}}\right) \mathrm{Sn}_{4}$ & $\left(\mathrm{Au}_{1-\mathrm{x}} \mathrm{Ni}_{\mathrm{x}}\right) \mathrm{Sn}_{4}$ & \multirow{3}{*}{$\begin{array}{c}\text { unacceptable } \\
141 / 192\end{array}$} \\
\hline & & Bulk & $\left(\mathrm{Au}_{1-x} \mathrm{Ni}_{\mathrm{x}}\right) \mathrm{Sn}_{4}$ & $\left(\mathrm{Au}_{1-\mathrm{x}} \mathrm{Ni}_{\mathrm{x}}\right) \mathrm{Sn}_{4}, \mathrm{AgSn}$ & $\left(\mathrm{Au}_{1-\mathrm{x}} \mathrm{Ni}_{\mathrm{x}}\right) \mathrm{Sn}_{4}$ & \\
\hline & & $\begin{array}{l}\text { Board } \\
\text { side }\end{array}$ & $\left(\mathrm{Au}_{1-x} \mathrm{Ni}_{\mathrm{x}}\right) \mathrm{Sn}_{4}$ & $\left(\mathrm{Au}_{1-\mathrm{x}} \mathrm{Ni}_{\mathrm{x}}\right) \mathrm{Sn}_{4}$ & $\left(\mathrm{Au}_{1-\mathrm{x}} \mathrm{Ni}_{\mathrm{x}}\right) \mathrm{Sn}_{4}$ & \\
\hline & \multirow{3}{*}{$\begin{array}{c}\text { Thick } \\
\mathrm{Au}\end{array}$} & $\begin{array}{l}\text { Comp } \\
\text { side }\end{array}$ & $\left(\mathrm{Au}_{1-x} \mathrm{Ni}_{\mathrm{x}}\right) \mathrm{Sn}_{4}$ & $\left(\mathrm{Au}_{1-\mathrm{x}} \mathrm{Ni}_{\mathrm{x}}\right) \mathrm{Sn}_{4}$ & $\left(\mathrm{Au}_{1-\mathrm{x}} \mathrm{Ni}_{\mathrm{x}}\right) \mathrm{Sn}_{4}$ & \multirow{3}{*}{$\begin{array}{c}\text { unacceptable } \\
108 / 108\end{array}$} \\
\hline & & Bulk & $\left(\mathrm{Au}_{1-x} \mathrm{Ni}_{\mathrm{x}}\right) \mathrm{Sn}_{4}$ & $\left(\mathrm{Au}_{1-x} \mathrm{Ni}_{\mathrm{x}}\right) \mathrm{Sn}_{4}$ & $\left(\mathrm{Au}_{1-\mathrm{x}} \mathrm{Ni}_{\mathrm{x}}\right) \mathrm{Sn}_{4}$ & \\
\hline & & $\begin{array}{l}\text { Board } \\
\text { side }\end{array}$ & $\left(\mathrm{Au}_{1-\mathrm{x}} \mathrm{Ni}_{\mathrm{x}}\right) \mathrm{Sn}_{4}$ & $\left(\mathrm{Au}_{1-\mathrm{x}} \mathrm{Ni}_{\mathrm{x}}\right) \mathrm{Sn}_{4}$ & $\left(\mathrm{Au}_{1-\mathrm{x}} \mathrm{Ni}_{\mathrm{x}}\right) \mathrm{Sn}_{4}$ & \\
\hline
\end{tabular}




\subsection{IMC Thickness Measurements}

It is commonly understood by electronic packaging experts that intermetallic layers in solder joints grow thicker over time. Mechanically, it is best to minimize the thickness of any phase that is in some way mechanically detrimental, therefore thinner IMC layers should be more mechanically reliable. It is important to characterize the rate of growth to determine intervals that will maximize the differences in microstructure and determine how long of a treatment is necessary as these aging treatments are time consuming (upwards of 56 days) and expensive. There is large variation in layer thickness along the length of individual joints. It is important, therefore, to use as large a sample size and measurement region as possible to reduce variation in thickness measurements.

The measurements from the QFN packages are separated into component side (Figure 42) and board side (Figure 43) IMC layers because of the lead and board pads had different metallurgies. The QFN component leads were copper coated with matte Sn whereas the board had copper coated with the gold over nickel layers, resulting in different interfacial compounds and growth rates. The data from the TOPS packages (Figure 44), however, was combined because both the component leads and the board interfaces had copper leads coated with gold over nickel.

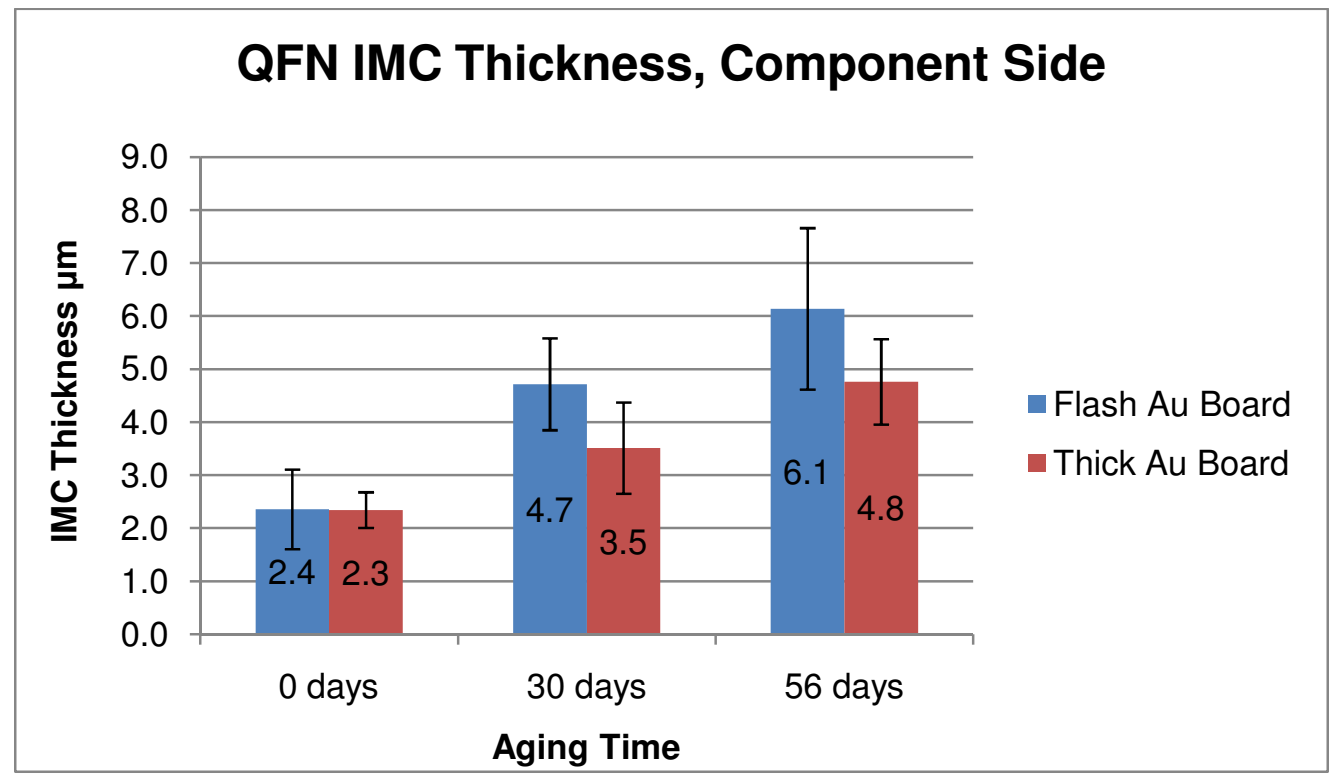

Figure 42 - IMC thickness measurements from the component/solder interface on QFN components (error bars are $\pm 1 \sigma$ ) 


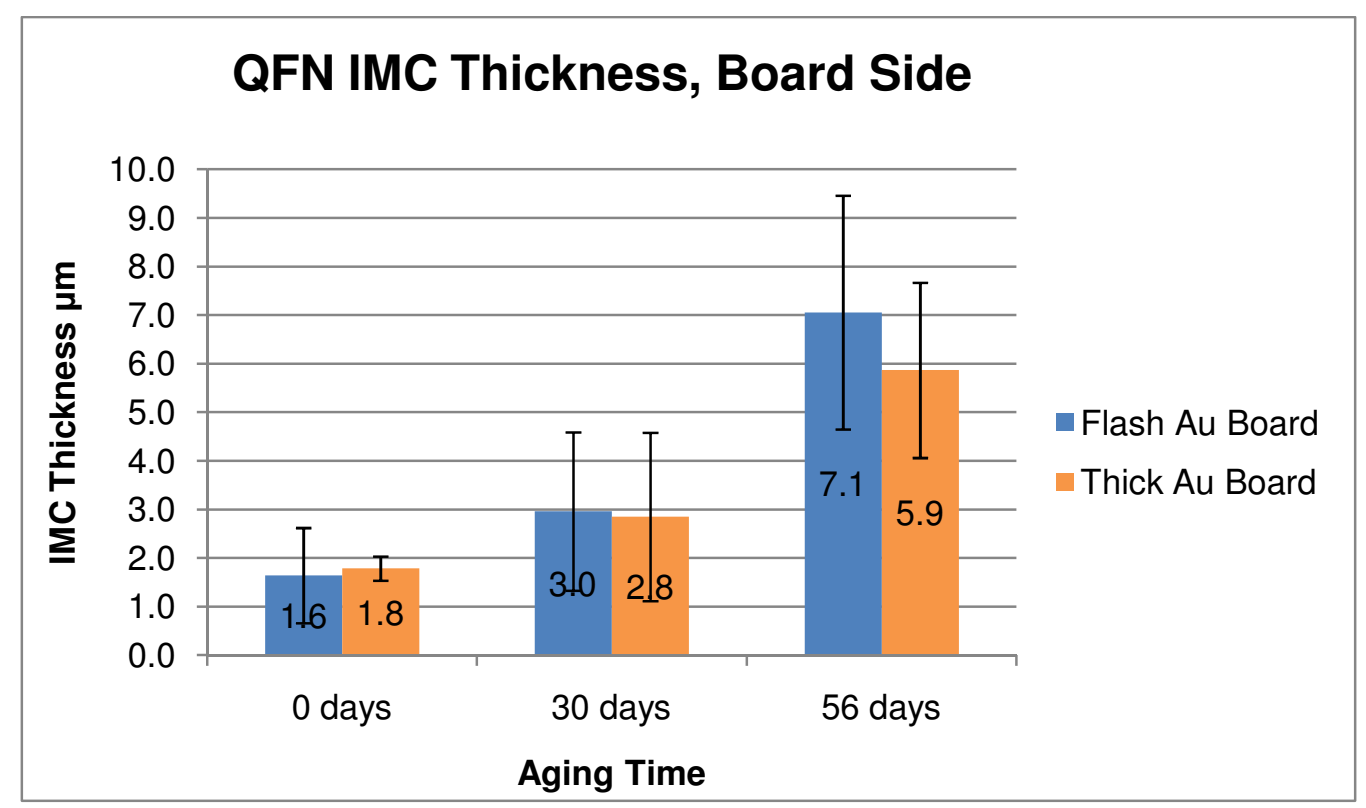

Figure 43 - IMC thickness measurements from the board pad/solder interface on QFN components (error bars are $\pm 1 \sigma$ )

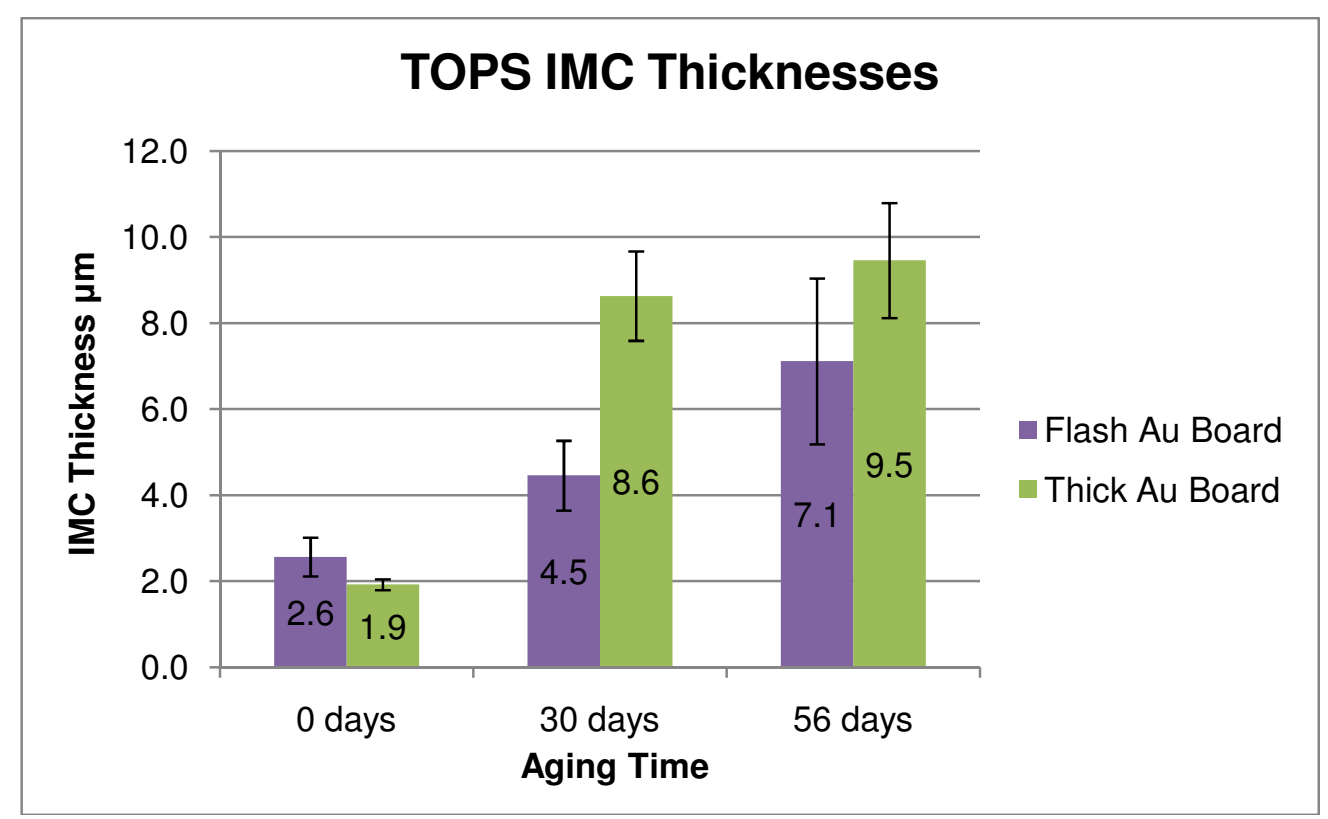

Figure 44 - IMC thickness measurements from the component/solder and board pad/solder interface on TOPS components (error bars are $\pm 1 \sigma$ )

The two most striking aspects of this data are the large variation within each group and the fact that the IMC growth rate appears to follow a square root function as has been reported by most 
researchers (Lee, et al. 2001, Daquan, et al. 2003, Qi, et al. 2009). Figure 45 demonstrates the square root behavior.

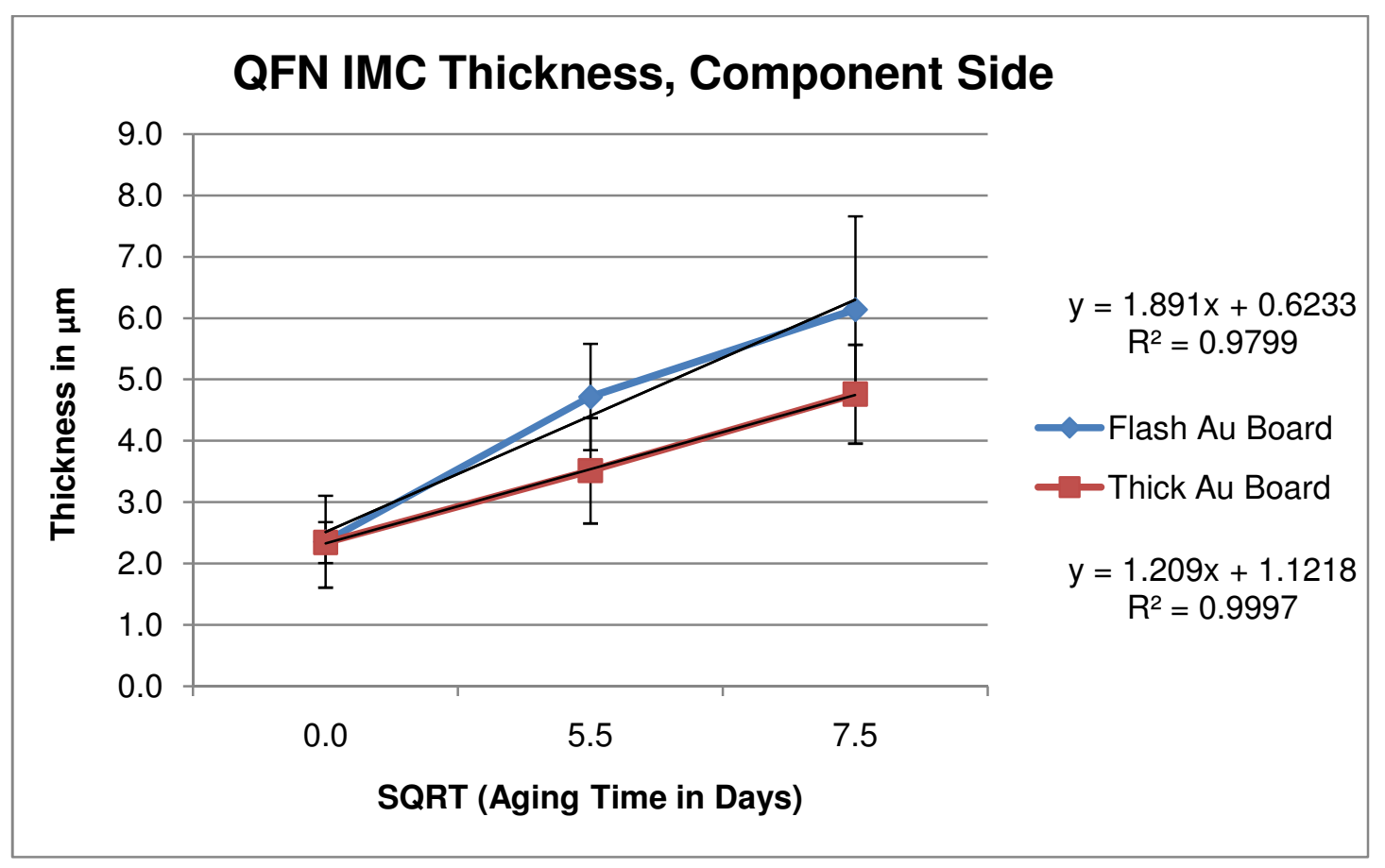

Figure 45 - Graph demonstrates that IMC growth data follows a time $e^{0.5}$ function 


\section{Chapter 5. Discussion}

The behavior of gold in the formation and evolution of intermetallic compounds in leadfree solder joints was studied using isothermal aging, mechanical reliability testing, and crosssectioning. Five different components with tin or with gold over nickel coatings on the leads were soldered to boards that had gold over nickel coatings that had either a thick gold or thin (flash) gold layer. The boards were isothermally aged to accelerate the growth of the intermetallic compounds so that their evolution could be studied. The goal was to determine how much gold could be in the lead-free solder joints and produce "safe" microstructures that would not negatively affect the mechanical reliability of the joints and compare that to what is well understood about gold in lead-tin solder joints. "Safe" microstructures would have few or no $\mathrm{AuSn}_{4}$ or $\left(\mathrm{Au}_{\mathrm{x}} \mathrm{Ni}_{1-\mathrm{x}}\right) \mathrm{Sn}_{4}$ intermetallics present as pillars in the bulk solder or interfacial layers in the joint. Mechanical reliability testing, cross sections, and resistance measurements were used to determine how safe the microstructure of each component type was with a particular solder joint gold content.

The solubility limits of gold, copper, and nickel in tin are extremely low, so intermetallic compounds form when the gold content is far less than $10 \mathrm{wt} \%$. The Au-Sn binary phase diagram in Figure 46 shows the solubility limit for gold in a tin matrix of about 0.3 wt\%.

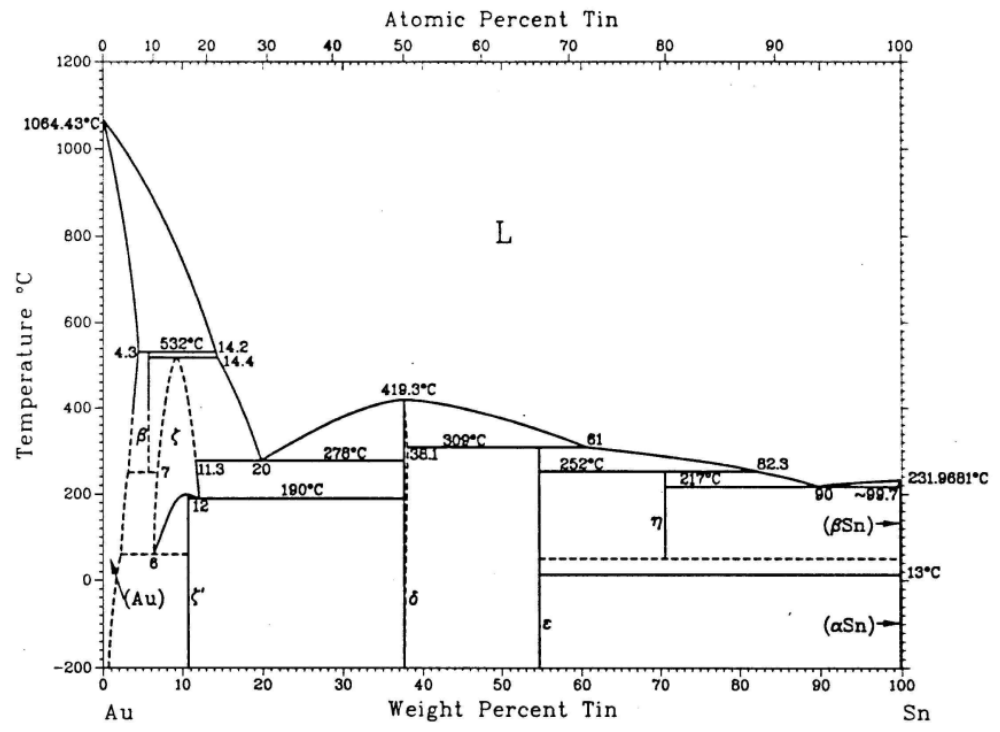

Figure 46 - Au-Sn Binary phase diagram (Selvaduray n.d.) 
Au has a $0.3 \mathrm{wt} \%$ solubility limit in $\mathrm{Sn}$ at $217^{\circ} \mathrm{C}$, which is below $250^{\circ} \mathrm{C}$, the temperature at which reflow soldering is performed for the SAC305 alloy. The composition of solder joints is more complicated than a binary phase diagram, but it serves to demonstrate that gold has a low solubility limit in tin and will form $\mathrm{Au}_{1-\mathrm{x}} \mathrm{Sn}_{\mathrm{x}}$ intermetallic compounds. $\left(\mathrm{Cu}_{1-\mathrm{x}} \mathrm{Au} \mathrm{u}_{\mathrm{x}}\right)_{6} \mathrm{Sn}_{5} \mathrm{IMCs}_{\mathrm{M}}$ were observed in the 0 days aged flash QFN samples which had less than $1.0 \mathrm{wt} \%$ Au, but they comprised a minor amount of the joint and the reliability testing indicated that this group of samples exhibited good reliability.

The intermetallic compounds form interfacial layers because of the similarity between $\mathrm{Au}$, $\mathrm{Ni}, \mathrm{Cu}$, and Ag. All four have FCC crystal structures, are near each other on the periodic table (which implies that they have similar electronegativities, bond lengths, and atomic radii), and are less similar to tin. It is energetically favorable for the $\mathrm{Au}, \mathrm{Ni}, \mathrm{Cu}$, and $\mathrm{Ag}$ to combine at the interfaces, where there is a lot of $\mathrm{Ni}$ or $\mathrm{Cu}$ available. $\mathrm{Ni}$, in particular, seems to have traveled across the joint from the Ni layers to combine with $\mathrm{Au}$ and $\mathrm{Sn}$ to form the $\left(\mathrm{Au}_{1-\mathrm{x}} \mathrm{Ni}_{\mathrm{x}}\right) \mathrm{Sn}_{4}$ compound. Using Equation (2) for diffusion length to calculate how far Ni could diffuse through $\mathrm{Sn}$, a simple calculation shows that $\mathrm{Ni}$ could travel $800 \mu \mathrm{m}$ through $\mathrm{Sn}$ at $125^{\circ} \mathrm{C}$ in 30 days, as in the intermediate aging treatment used in this experiment.

$$
x=\sqrt{2 D t}
$$

That $800 \mu \mathrm{m}$ is a conservative value as it uses the slower Ni diffusion perpendicular to the c-axis of Sn. The same calculation for diffusion parallel to the c-axis shows that $\mathrm{Ni}$ could have diffused $20.5 \mathrm{~cm}$ at $125^{\circ} \mathrm{C}$ in 30 days. This answers the question of whether Ni could diffuse across the joint to form intermetallic compounds in the bulk or at the Cu lead interface in the QFNs where no Ni layer was immediately available. This also answers the question of $\mathrm{Au}, \mathrm{Cu}$, and $\mathrm{Ag}$ being able to diffuse in the same manner as $\mathrm{Ni}$, since $\mathrm{Ni}$ has the lowest diffusion coefficient of these elements, meaning the other three would have even longer diffusion paths, meaning they could also diffuse across the entire length of the joint.

A thin film solution to the Fick's law diffusion equations, Equation (3), can be used to model the diffusion of $\mathrm{Ni}$ or $\mathrm{Cu}$ into the solder joint which can show that the Ni content would be $99.9 \% 2 \mu \mathrm{m}$ into the joint from the Ni layer after 30 days of aging at $125^{\circ} \mathrm{C}$. 


$$
C=C_{0} e^{\left(\frac{-x^{2}}{4 D t}\right)}
$$

They also show that the $\mathrm{Ni}$ content would be $99.3 \% 10 \mu \mathrm{m}$ in from the Ni layer after 56 days of aging. The $2 \mu \mathrm{m}$ and $10 \mu \mathrm{m}$ depths match roughly with the thickness of the intermetallics measured in this study. Although this model does not account for the change in diffusion coefficient as $\mathrm{Ni}$ or $\mathrm{Cu}$ atoms pass through the various intermetallic layers and compounds, it does illustrate that a high concentration of $\mathrm{Ni}$ or $\mathrm{Cu}$ from the board metallization or lead coatings could penetrate the joint and cause the intermetallic compounds to grow as these atoms combine with continually more Sn.

In the flash Au samples of QFN and TOPS, small amounts of Au IMCs were formed and the joint contents were $0.5 \sim 1.0 \mathrm{wt} \% \mathrm{Au}$ on the QFN and $2.5 \sim 3.0 \mathrm{wt} \% \mathrm{Au}$ on the TOPS. In the thick Au samples though, the QFN had $5.0 \sim 6.0$ wt\% Au and more Au containing IMCs in the joints as did the TOPS which had joint contents of $6.0 \sim 8.0 \mathrm{wt} \% \mathrm{Au}$. In the FP samples on flash and thick $\mathrm{Au}$ boards the joints were consumed with $\left(\mathrm{Au}_{1-\mathrm{x}} \mathrm{Ni}_{\mathrm{x}}\right) \mathrm{Sn}_{4}$ and had joint gold contents of double to triple the solubility limit $(8 \sim 16 \mathrm{wt} \% \mathrm{Au})$.

There are a few IMCs that were repeatedly observed in this experiment. They are listed in 
Table $\mathrm{V}$ along with the major metallic components of the joint, typical solder IMCs and respective crystal systems. 
Table V - Metals and IMCs found in this experiment with crystal structure information (Bangert n.d., Zou, et al. 2009, Ho, Shiau and Kao 2002, Baker 2002)

\begin{tabular}{|c|c|c|c|c|c|}
\hline Phase & Crystal Systems & $\begin{array}{l}\text { Bravais } \\
\text { Lattices }\end{array}$ & $\begin{array}{c}\text { Lattice } \\
\text { Parameter }(\AA)\end{array}$ & $\begin{array}{l}\text { Brittle / } \\
\text { Ductile } \\
\end{array}$ & Morphology \\
\hline $\mathrm{Ni}_{3} \mathrm{Sn}_{4}$ & triclinic & $\begin{array}{c}a \neq b \neq c \text { and } \\
a \neq \beta \neq \gamma\end{array}$ & $12.37,4.06,5.21$ & brittle & not seen \\
\hline $\mathrm{Ag}_{3} \mathrm{Sn}$ & orthorhombic & $a \neq b \neq c$ & - & brittle & pebbles \\
\hline $\mathrm{AuSn}_{4}$ & tetragonal & $a=b \neq c$ & $\begin{array}{c}6.512,6.516 \\
11.71 \\
\end{array}$ & brittle & $\begin{array}{l}\text { pillars, } \\
\text { boulders }\end{array}$ \\
\hline$\left(\mathrm{Au}_{1-x} \mathrm{Ni}_{\mathrm{x}}\right) \mathrm{Sn}_{4}$ & orthorhombic & $a \neq b \neq c$ & $6.32,6.32,11.44$ & brittle & $\begin{array}{l}\text { pillars, } \\
\text { boulders }\end{array}$ \\
\hline $\mathrm{Cu}_{6} \mathrm{Sn}_{5}$ & $\begin{array}{c}\text { monoclinic }(<186 \\
\left.{ }^{\circ} \mathrm{C}\right)\end{array}$ & $\begin{array}{c}\alpha \neq 90^{\circ} \\
\beta=\gamma=90^{\circ}\end{array}$ & $4.19,5.03$ & brittle & $\begin{array}{l}\text { interfacial } \\
\text { layers }\end{array}$ \\
\hline$\left(\mathrm{Cu}_{1-\mathrm{p}-\mathrm{q}} \mathrm{Au}_{\mathrm{p}} \mathrm{Ni}_{\mathrm{q}}\right)_{6} \mathrm{Sn}_{5}$ & monoclinic & $\begin{array}{c}\alpha \neq 90^{\circ} \\
\beta=\gamma=90^{\circ}\end{array}$ & $4.23,5.07$ & brittle & $\begin{array}{c}\text { interfacial } \\
\text { layers }\end{array}$ \\
\hline Sn & tetragonal $(\beta-S n)$ & $a=b \neq c$ & 5.83 & ductile & - \\
\hline $\mathrm{Cu}$ & FCC & - & 3.62 & ductile & - \\
\hline $\mathrm{Ni}$ & FCC & - & 4.46 & ductile & - \\
\hline $\mathrm{Au}$ & FCC & - & 4.09 & ductile & - \\
\hline
\end{tabular}

$\mathrm{AuSn}_{4}$ and $\left(\mathrm{Au}_{1-x} \mathrm{Ni}_{\mathrm{x}}\right) \mathrm{Sn}_{4}$ phases have an orthorhombic crystal structure (Ho, Shiau and Kao 2002) and are more anisotropic than the solder matrix, which is nominally $96.5 \mathrm{wt} \% \mathrm{Sn}$ and $\mathrm{Sn}$ is normally tetragonal. The $\left(\mathrm{Cu}_{1-\mathrm{p}-q} \mathrm{Au}_{\mathrm{p}} \mathrm{Ni}_{q}\right)_{6} \mathrm{Sn}_{5}$ which appeared in many samples, especially in the 30 days and 56 days aged groups, has a monoclinic structure. The $\left(\mathrm{Cu}_{1-\mathrm{p}-q} \mathrm{Au}_{\mathrm{p}} \mathrm{Ni}_{\mathrm{q}}\right)_{6} \mathrm{Sn}_{5}$ phase is based on the $\mathrm{Cu}_{6} \mathrm{Sn}_{5}$ crystal structure. The reliability data indicates that this phase is less problematic than the $\left(\mathrm{Au}_{1} \times \mathrm{XNi}_{\mathrm{x}}\right) \mathrm{Sn}_{4} \mathrm{IMC}$ phases. The tetragonal crystal system is a square cuboid, meaning two of its lattice parameters are equal, forming the square base, and the third has a different value, making it a rectangular prism. The tetragonal structure is anisotropic along the $c$ axis, which has the different value. Its properties are identical in the other two directions. The orthorhombic crystal system is also a cuboid; however, it has three different lattice parameters, making it anisotropic in three directions instead of two, as the tetragonal system is. The $\mathrm{Ni}_{3} \mathrm{Sn}_{4}$ IMC is triclinic, the most anisotropic crystal structure listed, and has been claimed as a source of reliability issues, but was not observed in any of the samples in this experiment.

The AuSn ${ }_{4}$ and $\left(\mathrm{Au}_{1-x} \mathrm{Ni}_{x}\right) \mathrm{Sn}_{4}$ pillars probably form because growth is energetically favorable along whatever crystal plane is perpendicular to the long axis of the pillars. The images from the TOPS samples (Figure 38 - Figure 41) that underwent reliability tests illustrate that the cracks tend to propagate along the center of the length of the pillars and interfacial layers. 
The structure of the IMCs means that their coefficients of thermal expansion (CTE) are anisotropic (Abtew and Selvaduray 2000) which would generate higher stresses in one direction than another when they were heated while bonded to a Sn solder matrix with a mismatched CTE that is less anisotropic. The cracks seen in the joints of TOPS packages always traveled along the length of the pillar shaped IMCs, the interfacial layer IMCs, or in a few cases, spanned from IMCs across bulk solder toward large voids. This supports the possibility that the cracks were created by local stresses generated by the anisotropic properties of the IMCs. However, because isothermal aging was used in this experiment, there is no mechanism for a CTE-mismatch to cause fatigue to occur, as would be the case if thermal cycling aging had been used. The cracks were propagated by the overstress and fatigue from the drop and vibration tests, respectively. It is likely that the delamination observed at the interfaces between the board pads and bulk solder occurred because of lattice mismatch between the Ni layer and the intermetallic. Ni has a lattice parameter of $4.462 \AA$ while $\mathrm{AuSn}_{4}$ has $6.51,6.52$, and $11.7 \AA$ as its lattice parameters, which equates to a $46 \%$ and $162 \%$ lattice mismatch (Baker 2002).

The anisotropic CTE mismatches may have generated sufficient local stresses to initiate microscopic. Those cracks only propagated enough to cause joint failure in the FP samples that were only isothermally aged and the FP, QFN, and TOPS packages that were isothermally aged and put through reliability tests. The high failure rate of the FP packages are not of particular interest as the reason for the failure, the high joint gold content of $10 \sim 15 \mathrm{wt} \%$ leading to a majority of the joint being $\mathrm{AuSn}_{4}$ and $\left(\mathrm{Au}_{1-\mathrm{x}} \mathrm{Ni}_{\mathrm{x}}\right) \mathrm{Sn}_{4}$, is clear. In the TOPS and QFN packages, however, the failure mechanism is more uncertain. The microscopic cracks that were observed in the reliability samples had propagated up to $10-1,000 \mu \mathrm{m}$ in length. That propagation most likely occurred during the vibration and drop tests through fatigue and overloading, but the initiation appears to be either at high stress points (i.e. the corners of the solder joint) or at intermetallic phases as pillars in the bulk or as interfacial layers.

Some researchers have noted that although $\left(\mathrm{Au}_{1-\mathrm{x}} \mathrm{Ni}_{\mathrm{x}}\right) \mathrm{Sn}_{4}$ compounds have a clearly detrimental effect on the reliability of solder joints, it is likely that the main cause for this is not just the CTE mismatch between IMC and matrix (Pitely, et al. 2004). This is because comparable 
solder systems with different IMCs that have similar CTE mismatches do not have the same reliability troubles. Therefore something else about $\left(\mathrm{Au}_{1-\mathrm{x}} \mathrm{Ni}_{\mathrm{x}}\right) \mathrm{Sn}_{4}$ compounds, such as their interface to surrounding compounds or their inherent ductility, could be contributing factors. Further work, such as nanoindentation or crystal phase orientation mapping might be needed to discern this.

QFN components failed at a $1 \%$ overall rate on flash Au boards and a $5 \%$ overall rate on the thick Au boards. The failures, however, are thought to be cause by the high strain experienced by the two QFNs packages that were placed adjacent to the mounting holes experienced as their microstructure did not match that of the FP and TOPS samples that failed or showed crack propagation along IMCs. The low gold content of these joints and the larger availability of copper, which some researchers found to inhibit the growth of $A u_{1-x} S n_{x}$ compounds is believed to be the reason for the higher reliability of these packages (Tian, et al. 2007, Ho, Shiau and Kao 2002).

TOPS components failed at a $1 \%$ overall rate on flash Au boards and a $6 \%$ overall rate on thick Au boards. One group of the failures on thick Au boards, however, came from one board which was later confirmed from x-ray scans performed during the manufacture of the boards as having numerous voids in the joints, lowering their mechanical strength and making it easier for propagating cracks to completely separate the joint. A vast majority of the cracks in these samples were observed in and along $\left(\mathrm{Au}_{1-x} \mathrm{Ni}_{x}\right) \mathrm{Sn}_{4} \mathrm{IMCs}$ in the bulk solder and interfacial layers.

FP components failed at a $74 \%$ overall rate on flash Au boards and at a $100 \%$ overall rate on thick Au boards. The large volume fraction of $\mathrm{AuSn}_{4}$ or $(\mathrm{Au}, \mathrm{Ni}) \mathrm{Sn}_{4}$ in these joints provided lower energy paths for crack propagation throughout the joint and created stress that could derive from the volume change associated with forming the IMC from tin. Clearly solder joints with a gold content above $10 \mathrm{wt} \%$ as most FP joints had, are unacceptably unreliable (Pan, Silk, et al. 2011).

In components with nickel layers, FP and TOPS, diffusion of copper from the Cu pad to $\mathrm{AuSn}_{4}$ intermetallics was greatly hindered. However, in components with bare copper leads 
QFN, copper was observed diffusing across the solder joint to the $\left(\mathrm{Au}_{\mathrm{x}} \mathrm{Ni}_{1-\mathrm{x}}\right) \mathrm{Sn}_{4}$ layers, forming $\left(\mathrm{Au}_{1-p-q} \mathrm{Cu}_{\mathrm{p}} \mathrm{Ni}_{\mathrm{q}}\right)_{6} \mathrm{Sn}_{5}$, which is thought to be less likely to crack (Pan, Silk, et al. 2011).

Some researchers found that the poor mechanical properties of IMC phases combined with the presence of voids in joints, made for easy crack paths during fast fractures. The paths of cracks observed in the micrographs from the reliability samples illustrate that $\left(\mathrm{Au}_{1-\mathrm{x}} \mathrm{Ni}_{\mathrm{x}}\right) \mathrm{Sn}_{4}$ and its precursor, $\mathrm{AuSn}_{4}$, are in fact easy paths for crack propagation. It was also observed that cracks will travel toward voids across bulk solder, confirming their effect in reducing the reliability of joints. 


\section{Chapter 6. Conclusions}

SAC305 solder joints with a gold content above $10 \mathrm{wt} \%$ exhibit unacceptably poor mechanical reliability as evidenced by components in the FP group, which failed at high rates ( $73.4 \%$ failure rate on flash au board; $100 \%$ failure rate on thick Au board) in the 0 days, 30 days, and 56 days condition on both the flash and thick Au boards. The joints that had copper available (QFN components had copper leads coated with tin), contained $\left(\mathrm{Au}_{1-\mathrm{p}-q} \mathrm{Cu}_{\mathrm{p}} \mathrm{Ni}_{\mathrm{q}}\right)_{6} \mathrm{Sn}_{5}$ rather than $\mathrm{AuSn}_{4}$ or $\left(\mathrm{Au}_{\mathrm{x}} \mathrm{Ni}_{1-\mathrm{x}}\right) \mathrm{Sn}_{4}$ IMCs. It seems that the copper-containing IMCs do not cause the same reliability problems that the $\mathrm{AuSn}_{4}$ and $\left(\mathrm{Au}_{\mathrm{x}} \mathrm{Ni}_{1-\mathrm{x}}\right) \mathrm{Sn}_{4}$ compounds do.

The conclusion of this work is that gold content of SAC305 solder joints on boards with Au over Ni over Cu should be kept below 3 wt\% to conservatively minimize the risk of creating a microstructure that has poor reliability. This can be achieved through the design of factors such as joint solder volume, lead and board coating thickness or through additional processing steps such as solder wicking. When $\mathrm{Cu}$ is available to diffuse into the joint, as in the QFN components, less than $5 \mathrm{wt} \%$ Au in the joint may be safe. 


\section{Chapter 7. Future Work}

Finite element analysis (FEA) could be used to model solder joints under vibration, impact (drop test), or thermal cycling and explore how cracks propagate along IMCs. This might clarify the cause of crack initiation (Alam, Lu and Bailey 2008). To be valuable this would require accurate material property values, especially anisotropic CTEs, strengths, moduli, and such as the values researchers report vary so much (Limaye, et al. 2008). Nanoindentation could be used to better characterize the mechanical properties of individual intermetallic joints. X-ray diffraction could be used to verify the crystal structure of the IMCs found in these particular joints. This would be especially useful in conjunction with the use of TEM to determine the orientation of the IMC crystals to see if the orientation of pillars or interfacial layers could influence the reliability of joints.

Further samples could be assembled using a method such as pretinning to replace the Au coating on components or boards with a Sn finish. They could then be aged and crosssectioned for study. Their microstructure could be predicted, however, by examining joints that have already been studied that already have the joint gold content that pretinning would reduce some components to. 


\section{References}

Abtew, M, and G Selvaduray. "Lead-free Solders in Microelectronics." Materials Science and Engineering, 2000: 95-141.

Alam, M, H Lu, and C, Chan, Y Bailey. "Fracture Mechanics Analysis of Cracks in Solder Joint Intermetallic Compounds." 2nd Electronics Systemintegration Technology Conference, 2008: 757-762.

Allied High Tech. grinding / polishing consumables. 2011.

http://www.alliedhightech.com/polishing/waterprfabr/ (accessed June 2010).

Allied High Tech: Mounting - Cold Mounting.

http://www.alliedhightech.com/mounting/coldmounting/ (accessed April 2010).

Asrar, N. "Detrimental Effects of Excessive Gold Plating on Lead-Free Solder Joints." Journal of Failure Analysis and Prevention. ASM International, April 23, 2009.

Baker, H. "Crystallographic Terms and Basic Concepts." In ASM Desk Editions: Metals Handbook. ASM International, 2002.

Banerji, D. "'Effect of Aging on the Strength and Ductility of Controlled Collapse Solder Joints"." 1st International Conference on Microstructures and Mechanical Properties of Aging Materials; Proceedings of a symposium sponsored by the Minerals, Metals,, 1993: 431-442.

Bangert, Andrea. Crystal Structure and Crystal System.

http://dave.ucsc.edu/myrtreia/crystal.html (accessed July 28, 2011).

Braithwaite, N. "Forward." In Lead-free Solder Interconnect Reliability, by D. Shangguan, vii. Materials Park, Ohio: ASM International, 2005.

Bunis, C. "Characterization of Gold Embrittlement in Solder Joints." Proceeding from the 25" International Symposium for Testing and Failure Analysis, 1999: 305-308.

CES. "'CES EduPack 2010 software, Granta Design Limited, Cambridge, UK, 2010."."

Chiang, MJ, SY Chang, and TH Chuang. "Reflow and Burn-in of a Sn-20In-0.8Cu Ball Grid Array Package with a Au/Ni/Cu Pad." Journal of Electronic Materials, 2004: 34-39.

Chiu, T, K Zeng, R Stierman, D Edwards, and K Ano. "Effect of Thermal Aging on Board Level Drop Reliability for Pb-free BGA Packages." Electronic Components and Technology Conference, 2004: 1256-1262.

Coombs, C. Printed Circuits Handbook. New York: McGraw Hill Companies, 2008.

Cullity, BD, and SR Stock. "Elements of X-Ray Diffraction." 11-19. Prentice Hall, 2001.

Daquan, Y, D Lilei, Z Jie, and W Lai. "The Formation And Growth Of Intermetallic Compounds Between Sn-." International Conference on Electronic Packaging Technology. IEEE, 2003. 327-329.

"Directive 2002/95/EC of the European Parliament and of the Council of 27 January 2003 on the restriction of the use of certain hazardous substances in electrical and electronic equipment." Official Journal of the European Union, 2003: 19-23. 
Federation of European Producers of Abrasives. fepa-abrasives.org (accessed April 14, 2011).

Fields, R, and S Low. "Physical and Mechanical Properties of Intermetallic Compounds Commonly Found in Solder Joints." Submission of NIST.

Gibbs, David. (June 2010).

Ho, CE, LC Shiau, and CR Kao. "Inhibiting the formation of (Au1-xNix)Sn4 and reducing the consumption of Ni metallization in solder joints." Journal of Electronic Materials, 2002: 12641269.

Lee, J, J Park, D Shin, Y Lee, and Y Kim. "Kinetics of Au-containing Ternary Intermetallic Redeposition at Solder/UBM Interface." Journal of Electronic Materials, 2001: 1138-1144.

Limaye, P, B Vandevelde, R Labie, D Vandepitte, and B Verlinden. "Influence of Intermetallic Properties on Reliability of Lead-Free Flip-Chip Solder Joints." IEEE Transactions on Advanced Packaging (IEEE Transactions on Advanced Packaging), 2008: 51-57.

Mallick, PK. "Epoxy." In Fiber-Reinforced Composites, 71-76. Boca Raton: CRC Press, 2008.

NASA Electronic Parts and Packaging. Intermetallic Creation and Growth. http://nepp.nasa.gov/wirebond/intermetallic_creation_and_growt.htm (accessed August 29, 2011).

National Institute of Standards and Technology. Cu-Sn System.

http://www.metallurgy.nist.gov/phase/solder/cusn.html (accessed July 2011).

Occupational Safety \& Health Administration. Lead.

http://www.osha.gov/SLTC/lead/index.html (accessed July 20, 2011).

Pan, J, J Silk, M Powers, and P Hyland. "Effect of Gold Content on the Reliability of SnAgCu Solder Joints." IEEE Transactions on Components, Packaging and Manufacturing

Technology, 2011.

- "Effect of Gold Content on the Reliability of SnAgCu Solder Joints." Proceeding of IPC Printed Circuits Expo, APEX and the Designers Summit 2011. Las Vegas, NV, 2011. 12-14.

Pitely, S, E Cotts, L Zavalij, and S Zarembo. "Linear coefficients of thermal expansion of Au0.5Ni0.5Sn4, Au0.75Ni0.25Sn4, and AuSn4." Scripta Materialia, 2004: 745-749.

Powers, M, J Pan, J Silk, and P Hyland. "Effect of Gold Content on the Microstructural Evolution of SAC305 Solder Joints under Isothermal Aging." Journal of Electronic Materials, 2011.

Prasad, Ray B. "Metallurgy of Soldering and Solderability: Solder Alloys and Their Properties." In Surface Mount Technology: Principles and Practice, by Ray B. Prasad, 455461. Kluwer Academic Publishers, 1997.

Pun, K, P Eu, M Islam, and C Cui. "Effect of Ni Layer THickness on Intermetallic Formation and Mechanical Strength of Sn-Ag-Cu Solder Joint." 10th Electronics Packaging Technology Conference, 2008: 487-493. 
Qi, L, et al. "Microstructure Changes and Compound Growth Dynamic at Lead-free/Cu Interface under Different Conditions." International Conference on Electronic Packaging Technology \& High Density Packaging (ICEPT-HDP) . IEEE, 2009. 1083-1087.

Railkar, Tarak A, and Robert W Warren. "Electronic Package Assembly." In Advanced Electronic Packaging, by Richard K Ulrich and William D Brown, 5, 98, 409-413. Piscataway: Wiley Interscience, 2006.

Salam, B, N Ekere, and R Durairaj. "A Study of Inter-Metallic Compounds (IMC) Formation and Growth in Ultra-Fine Pitch Sn-Ag-Cu Lead-Free Slder Joints." Electronics Systemintegration Technnology Conference. Dresden, Germany: IEEE, 2006. 988-994.

Salam, BNN, Ekere, and R Durairaj. "A Study of Inter-Metallic Compounds (IMC) Formation and Growth in Ultra-Fine Pitch Sn-Ag-Cu Lead-Free Solder Joints." 2006 Electronics System Integration Technology Conference, 2006: 988-994.

Santos, Michael, interview by Patrick Hyland. Engineering Intern (March 12, 2010).

Schluep, M, et al. Recycling - From E-waste to Resources. United Nations Environment Programme, 2009.

Selvaduray, G. Materials Engineering 115: Phase Diagram Module.

http://www.sjsu.edu/faculty/selvaduray/page/mate115/PhaseDiagramModule/index.html (accessed June 9, 2011).

Smith, GD. "Corrosion of Precious Metals and Alloys." Corrosion: Materials Handbook Desk Edition. ASM International, 2005.

Sun, F, P Hochstenbach, WD Van Driel, and GQ Zhang. "Aging Effects on IMC Formation and Joint Strength of Low-Ag SAC Solder/UBM (Ni (P)-Au) for WLCSP." 9th. Int. Conf. on Thermal, Mechanical and Multiphysics Simulation and Experiments in Micro-Electronics and Micro-Systems. 2008.

Tian, Y, C Wang, W Liu, and Y Chen. "Effects of Cu Addition on Growth of Au-Sn Intermetallics at Sn-xCu/Au Interface during Aging Process." IEEE Proceedings of High Density packaging and Microsystem Integration International Symposium, 2007: 1-4.

van der Lingen, E, L Cornish, S Taylor, R Süss, and S Grice. "Microstructure of Gold and Gold Alloys." In Metallography and Microstructures Handbook Desk Edition. Materials Park: ASM International, 2005.

Vianco. "An Overview of Surface finishes and Their Role in Printed Circuit Board Solderability and Solder Joint Performance." Circuit World 25, no. 1 (1998): 6-24.

Vianco, P, and A Kilgo. "The impact of process parameters on gold elimination from soldered connector assemblies." Soldering \& Surface Mount Technologies, 2000: 24-30.

Voort, George F. Vander. "Metallographic Specimen Preparation." In Failure Analysis and Prevention Handbook Desk Edition. ASM International, 2002.

Zhang, R, R Zhao, F Guo, and Z Xia. "Interfacial reaction between the electroless nickel immersion gold substrate and Sn-based solders." Microelectronics Reliability, 2009: 303-309.

Zheng, P. "Solder joint reliability of TFBGA assemblies with." Microelectronics Reliability, 2003: 925-934. 
Zou, H, H Yang, J Tan, and Z Zhang. "Preferential growth and orientation relationship of Ag3Sn grains formed between molten Sn and (001) Ag single crystal." Journal of Materials Research. Materials Research Society, June 2009. 